\title{
Experimental design and statistical evaluation of limiting dilution assays
}

Citation for published version (APA):

Strijbosch, L. W. G. (1989). Experimental design and statistical evaluation of limiting dilution assays.

[Doctoral Thesis, Maastricht University]. Rijksuniversiteit Limburg. https://doi.org/10.26481/dis.19890421ls

Document status and date:

Published: 01/01/1989

DOI:

10.26481/dis.19890421ls

Document Version:

Publisher's PDF, also known as Version of record

\section{Please check the document version of this publication:}

- A submitted manuscript is the version of the article upon submission and before peer-review. There can be important differences between the submitted version and the official published version of record.

People interested in the research are advised to contact the author for the final version of the publication, or visit the DOI to the publisher's website.

- The final author version and the galley proof are versions of the publication after peer review.

- The final published version features the final layout of the paper including the volume, issue and page numbers.

Link to publication

\footnotetext{
General rights rights.

- You may freely distribute the URL identifying the publication in the public portal. please follow below link for the End User Agreement:

www.umlib.nl/taverne-license

Take down policy

If you believe that this document breaches copyright please contact us at:

repository@maastrichtuniversity.nl

providing details and we will investigate your claim.
}

Copyright and moral rights for the publications made accessible in the public portal are retained by the authors and/or other copyright owners and it is a condition of accessing publications that users recognise and abide by the legal requirements associated with these

- Users may download and print one copy of any publication from the public portal for the purpose of private study or research.

- You may not further distribute the material or use it for any profit-making activity or commercial gain

If the publication is distributed under the terms of Article $25 \mathrm{fa}$ of the Dutch Copyright Act, indicated by the "Taverne" license above, 


\section{EXPERIMENTAL DESIGN AND STATISTICAL EVALUATION OF LIMITING DILUTION ASSAYS}

\section{PROEFSCHRIFT}

ter verkrijging van de graad van

doctor aan de Rijksuniversiteit Limburg te Maastricht, op gezag van

de Rector Magnificus, Prof.Dr. F.I.M. Bonke, volgens het besluit van het College van Dekanen, in het openbaar te verdedigen op vrijdag, 21 april 1989 om 16.00 uur

door

LEONARDUS WILHELMUS GERARDUS STRIJBOSCH

geboren te Helmond 
Promotor : Prof.Dr. W. Albers (UT)

Co-promotor: Dr. R.J.M.M. Does (RL)

Beoordelingscommissie :

Prof.Dr. G. Kootstra, voorzitter (RL)

Prof.Dr. B.B. van der Genugten (KUB)

Prof.Dr. F.F.H. Rutten (RL)

Prof. R. van Strik (EUR)

Prof.Dr.Ir. O.J. Vrieze (RL)

Financial support by the Dutch Kidney Foundation ("Nier Stichting Nederland") for the publication of this thesis is gratefully acknowledged. 
aan Liesbeth, Willern, Manus en Eefje aan mijn moeder

in dankbare herinnering aan mijn vader 

Chapter 1 INTRODUCTION

1.1 The theory of limiting dilution assays.

1.2 Main issues of limiting dilution assays exanined in this dissertation

Chapter 2 EXPERIMENTAL DESIGN

2.1 Introduction

2.2 The basis of the experimental design

2.3 A new procedure for devising an experimental design

2.3.1 Introduction

2.3.2 Graphical explanation and derivation of the design formulae 19

2.3.3 Froof of the correctness of the design formulae 21

2.4 Practical applications

\section{Chapter 3 DESIGN REFINEMENTS}

\subsection{Introduction}

3.2 The Fisher information

3.3 The choice of the sufficiently informative range

3.4 The cholce of the numbers of replicates.

3.5 A program for the design of dilution assays

\section{Chapter 4 DESIGN GENERHLIZATIONS}

\subsection{Introduction}

4.2 The one-parameter biological model $y=\beta x$

4.3 The two-parameter biological model $y=\alpha+\beta x$

4.3.1 Introduction 
4.3.2 The wase $\alpha=\alpha_{0}$ and $\beta \in\left[\beta_{1}, \beta_{2}\right]$

4.3.3 The case $\alpha \in\left[\alpha_{1}, \alpha_{2}\right]$ and $\beta=\beta_{0}$

4.3 .4 The case $\alpha \in\left[\alpha_{1}, \alpha_{2}\right]$ and $\beta \in\left[\beta_{1}, \beta_{2}\right]$

4.3.5 Applications of the proposed designs

Chapter 5 CONVENTIONAL ESTIMATION METHODS

5.1 Introduction

5.2 Notgtion

5.3 The maximum likel ihood (ML) method

5.3.1 Introduction 54

5.3.2 The ML estimation procedure 55

5.3.3 Reducing the bias of the ML estimator from infinity to the desired order

5.4. The minimun chi-square (MC) method

5.4 .1 Introduction 57

5.4.2 The MC estimation procedure 58

5.5 Confidence intervals $\quad 59$

Chapter 6 BIAS-REDUCING ESTIMATION METHODS

6.1 Introduction

6.2 The Jackkntfe (three versions)

6.2.1 Introduction

6.2 .2 The ild case

6.2 .3 Two non-1.d cases

6.2.4 Reducing the bilas with Jackknifing in the non-iid cases

6.3 The bootstrap (four versions)

6.3 .1 Introduction

6.3.2 The 11a case

6.3.3 Three non-ild cases

6.4 Other bias-reaucing methods 
Chapter 7 A MONTE CARLO STUDY FOR THE COMPARISON OF THE ESTIMATORS

7.1 Introduction

7.2 The simulation program

7.3 Results

7.3.1 Introduction

7.3.2 Comparison of the ML estimator with the Jackknife versions

7.3.3 Comparison of the ML estimator with the bootstrap versions

7.3.4 Comparison of the ML estimator with other bias-reducing estimators

7.3.5. Final comparison

APPENDIX A PASCAL program for the simulation of limiting dilution experiments and the comparison of estimation methods

SUMMARY 



\section{INTRODUCTION}

\subsection{The theory of limiting dilution assays}

Limiting and Serial Dilution Assays (LDA's, SDA's) are applicable in many areas of bioresearch, such as public hygiene, cell biology, inmunology, bacteriology and virology (see Taswe11 (1987) for a review). In general "the aim of such an analysis is to estimate either the frequency of a particular cell type among other but similar cells (LDA), on the density of particular cells or microorganisms per unit volume of solution, such as bacteria and viruses capable of (un)limited proliferation or having infective properties for certain cells (SDA). LDA's, SDA's and other related assays known as fermentation tube tests, coliform density tests, etc., can all be treated by the same statistical theory, though the underlying biological processes and laboratorium techniques differ. In both LDA and SDA the unknown parameter is comonly estimated by using the "single-hit Poisson model" with binary (positive or negative) data produced by samples taken from different dilutions. The assumptions underlying this model are well-known (see Finney (1978, p. 425), Taswell (1981), Miller (1982), Lefkovits and Waldmann (1984)) and will be described briefly using the terminology of LDA first. Fig. 1.1 illustrates the setup of a limiting dilution experiment. A test preparation contains numerous cells of which an unknown proportion has a certain property, for example, inmunocompetency. From this test prepartion, m different dilutions are prepared. Then, from dilution $1, n_{1}$ replicate cultures are taken such that the numbers of cells in the replicate cultures of dilution $i$ are independent Poisson distributed varlables with the same mean number $x_{i}$ of cells tested. A fraction of those cells has the intended property. The use of the Poisson distribution for the number of cells in a sample is justified by the assumptions that the total number of cells in the test preparation is sufficiently large, the suspension has been stirred well. before taking any sample or dilution and the sample volume of the celis is extremely small. when compared to the total volume of the sample. A further assumption is that a positive respanse is obtalned for a replicate culture 
1. and only if at least one cell of the specific type is present ("single$h\left(t^{4 t}\right)$.

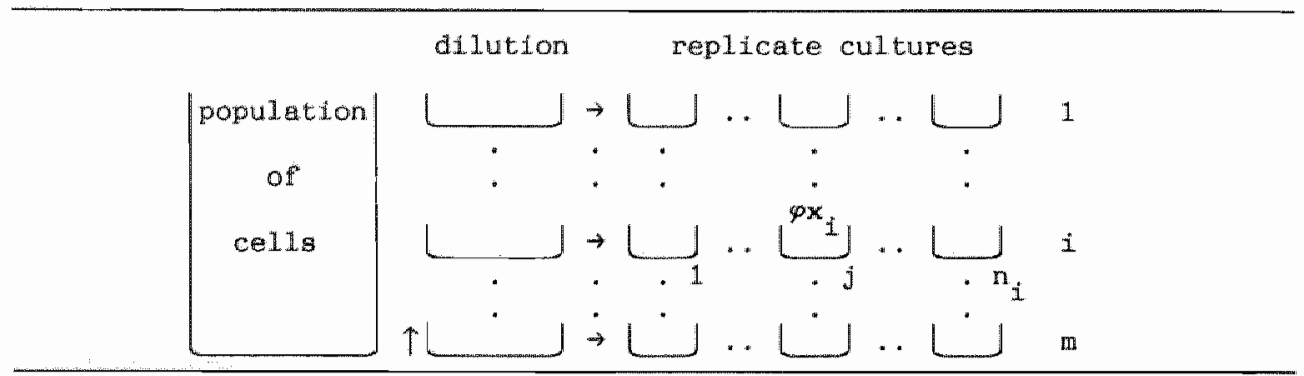

Fig. 1.1. The setup of a limiting ditution experiment. The number of ditutions is denoted by $m_{;} x_{i}$ is the (mean) rumber of cells tested in a replicate culture of ditution $i$; $\varphi_{i}$ is the (mean) number of cells of the spectflc type contatned in that culture; $p$ is the parameter to be est tmated.

For SDA, $\varphi$ is the density of a specific cell or microorganism per unit volume and the $x_{i}$ 's, $i=1, \ldots, m$, are dilution factors. For both LDA and SDA, $\left(\varphi \mathrm{x}_{i}\right)$ is the expected number of relevant cells for a culture in group $i$ while exp $\left(-p x_{i}\right)$, representing the zero term of the Poisson distribution that quantifies the number of relevent cells in the cultures, is the probability of a negative response. Hereinafter the terminology of LDA will prevail. LDA's are especially useful in the field of cellular imnunology. The assay is often used for the estimation of $T$ lymphocytes with specific properties such as cytotoxic properties or cytokine producing properties. It has been found to be a useful technique for studying (among others) the kinetics of specific $\mathrm{T}$ cell responses during an ongoing immune response. The culture techniques used must be adapted to the high demands of the assay system since accurate frequency analysis demands cell culture conditions that permit the growth of 'every' cell with the defined properties. In most experimental studies it is, of course, not possible to establish whether the culture conditions really allow the growth of every cell. Usually a constant fraction of such cells responds under the conditions used.

Expenimentally, the simplest approach is to distinguish between those cultures which respond and those which fail to respond, corresponding to cultures which contain either at least one relevant cell or no relevant 
cells. Thus the dose-response model $\mathrm{P}=\exp \left(-\mathrm{xx}_{\mathrm{x}}\right)$ (single-hit poisson model) is used to describe the relation between the mean number of cells tested per replicate culture and the number of negatively responding cultures per group. Culture groups for which px $\gg 1$ will most surely respond positively (value of $\mathrm{P}$ is near 0 ), culture groups for which $\varphi \mathrm{x}<1$ are likely to respond negatively (value of $\mathrm{P}$ is near 1 ). It is clear that a useful determination of the unknown parameter in dilution analysis requires setup whereby $\varphi x \sim 1$ for at least some culture groups (value of $\mathrm{P}$ is intermediate). At least some culture groups should be informative for values of $\varphi$ in a certain range. This means that advance information about $\varphi$ must be included in the design. No simple and widely accepted methods providing design characteristics on the basis of the researcher's criteria and a priori information about the unknown parameter can be found in existing 1 terature.

Many different statistical methods are reported and used for the analysis of date from LDA"s and SDA"s (see Loyer (1981). Taswel1 (1981)). Some of these (e.g. the least squares method, which fits a straight Iine $y=a+b x$ where $y$ is minus the natural logarithm of the fraction of negatively responding cultures in a group and $x$ is the corresponding (mean) number of cells tested in those cultures), are statistically far from ideal but easily executed, while others (1ike the maximum likelihood and minimum chi-square methods) are statistically more appropriate but much less easy to apply. However, with the present widespread availability of (micro-) computers and software, ease of computation is no longer a valid enough argument for preferring the simpler statistical methods. Since Mcarady (1915) described an estimation method that determines an estimator $\hat{\varphi}$ " the most probalble number") maximizing the probability of obtaining the specific arrangenent of positive and negative replicate cultures observed, the maximum likelihood method has been used by many authors. However, after the simulation study of Taswell (1981), who compared the meximum likelihood method and the minimum chi-square method and found that the last method should be preferred, controversy arose with respect to the use of those methods in dilution analysis (see Fazekas de St. Groth (1982)).

LDA and SDA belong to the general area of qualitative response (QR) models. Mast available textbooks on QR models are written for disciplines such as biology, psychology, sociology or engineering. For example, see Cox (1970). Finney (1971), Placket (1974). Haberman (1974, 1978, and 1979), 
Bishop, Fienberg and Holland (1975), and Daganzo (1979). Basic facts about applying oR models in general and, in particular to economics, can be found in a survey by Anemiya (1981).

\subsection{Main issues of limiting dilution assays examined in this dissertation}

Statisticians can contribute to the execution of a LDA or a SDA in at least three wys. In the first place they can prowide validity tests that detect deviations from the single-hit poisson model for parameter-estimation assays with known culture system where this model is assumed to apply most of the time. Taswell (1984) discusses principles of bioassay validity tests. However, walidity tests will not be discussed in this dissertation. Secondly, they can help the researcher construct an experimental design which will take advantage of existing a priori information. This hopefully precludes experimentation producing useless data and enables the adjustment of the prectsion of an estimator. And thirdly, they can advise on the statistical techniques to be used. The latter two topics form the subject of this study.

In many applications of dilution analysis the assays are very expensive and time-consuming, and, in some circumstances, also unrepeatable. In these cases it is of" vital interest to carefully choose an experimental design and an estimation method minimizing bias and/or mean square error. Recent research has been performed on design problems (Loyer (1981). Taswell (1987), Str1fbosch, Buurman, Does et al. (1987). Str1jbosch, Does and Burman (1988) and Strijbosch, Does and Albers (1988)). And, Monte Carlo studies heve been made on the choice of the statistical procedure to be used (Salama, Kocty and Tolley (1978), Loyer" (1981), Taswell (1981), Strijbosch, Buurman, Does et a1. (1987), Does, Strijbosch and Albers (1988) and Strijbosch and Does (1988)). Note that there is a difficulty in comparing the results of these Monte Carlo experiments because of the absence of generally accepted design methods: most authors used different experinental deslgns when generating simulation results. The controversy between Taswell (1981) and fazekas de St. Groth (1982) emerged partly as a consequence of this klnd of difficulty. It is obvious that the statistical properties of the possible estimators are dependent on the designs used. If these properties do not hold with other possible designs, it could easily occur 
that one author finds that estimator 1 is better than estimator 2 while another author finds the contrary.

The results on experimental design described by Strijbosch, Buurnan, Does et al. (1987) are presented in Chapter 2. Refinenents upon this design method and a program to perform these techniques are described by Strijbosch, Does and Buurman (1988) and presented in Chapter 3. The methods of Chapter 2 and 3 pertain to the experimental design for LDA's and SDA'S. As is described by Stmijbosch, Does and Albers (1988), the basic design method of Section 2.3 can be generalized for some other related and widely used biological models, such as the logistic regression model which is most common in bioassay. These generalizations are presented in Chapter 4. Chapter 2 to 4 provide formulae for the number of culture on doge groups and for the (mean) number of cells, dilution factors or doses to be used. These formulae incorporate lower and an upper bound for the unknown parameter(s), as well as some meaningrul design parameters chosen by the researcher. The second main subject to be dealt with will be connonly used estimation methods (Chapter 5) and some bias-reducing methods (Chapter 6) when applied to dilution analyses as described by Strijbosch. Bunman, Does et al. (1987). Does, Strijbosch and Albers (1988) and Stri.jbosch and Does (1988). In these studies Monte Carlo experiments have been performed in order to compare maximum likelihood and minimum chi-square methods on the one hand and bias-reducing methods on the other hand. These simulation results are presented and discussed in Chapter 7 . Finally, the relevant part of the PASCAL program used for the simulations is given in the Appendix. 



\section{EXPERIMENTAL DESIGN}

\subsection{Introduction}

An important issue in dilution analysis is the experimental design, i.e., the choice of the number of dilutions, the number of replicates in each dilution and the (mean) number of cells/organisms to be used per replicate. Assay designs are generally set up starting from a particular a priori estimate of the unknown parameter. However, depending on the type of experiment, a priori knowledge of the unknown parameter varies significantly. Taking into account the often limited availability of celis/organisms to be tested and the very labourious and costly experimental. procedures, it is obviously mandatory that an experimental design make optimal use of available means. In spite of the fact that dilution assays have been used since the beginning of this century, the development of design methods has been somewhat limited. Some of the recent suggestions for the experimental design of a dilution assay will be discussed. The design suggestions made by Finney (1978, p. 435) for dilution series can be used in practice although ready-to-use formulae are not given (see Subsection 2.3.1). Loyer (1981, p. 53) proposes a complicated procedure for the determination of an experimental design which is not suitable for general use. A design determined according to his method has the property that the probability of obtaining all fertile samples (1.e. only positive responses) is not larger than a user-supplied risk for all welues of the unknown parameter which are smaller than a user-supplied maximal value. There are several objections to this procedure which will be discussed in Section 2.4 . Next, without giving any design formulae, Taswell (1987) suggests that "the goal of optimization methods should be to minimize the error of the estimates subject to the constraint of a chosen level of the nondinformative assay probability" which is defined as the probability of obtaining either all responses negative or all responses positive.

In practice, both symetrical and asymmetrical designs have been used for LDA's (see e.g. Maryanski, Cerottini and Brunner (1980), Maryanski. MacDonald and Cerottini (1980). Vose and Bonnard (1983)) without explicit 
knowledge of the properties of the designs. In this chapter a useful and simple method for setting up a desigm, an the basis of the researcher's criteria and priori information regarding the unknown parameter $\varphi$, will be presented. Section 2.2 describes which basic considerations suggested and derived in Section 2.3 underlle the design method for dilution series. Finally, Section 2.4 discusses the practical application of the proposed method. An exemple of a design mentioned in the iterature is compared with the design which would have been obtained by the proposed design method.

\subsection{The basis of the experimental design}

This dissertation will describe a frequency determination of so-called single-hit phenomena. Culture conditions must be chosen carefully to fulfil. all the demands of single-hit responses, $1 . e .$, the relevant cells must be the only limiting cells in the system, and all relevant cells must grow out to be colonies the properties of which must be detectable in a yes/no way. Such celis can be $B$ cells producing antibodies, or $T$ cells with cytotoxic or lymphokine-producing properties. The numbers of negative replicates, the total numbers of replicates per dilution and the (mean) numbers of cells per culture are used to deterine the frequency of the limiting cell in the population. The statistical procedure used for the estimation of the unknown frequency is based on the assumption that the numbers of cells per culture have a Polsson distribution. It can simply be deduced that in the case of a frequency $\rho$ of a certain cell, the probability $P$ of a culture with $x$ cells responding negatively is $\exp \left(-p_{\mathrm{X}}\right)$. This dose-response relationship $\mathrm{P}=\exp \left(-\varphi_{\mathrm{X}}\right)$ is the starting point in the development of the experimental. destgn presented in Section 2.3 .

The need for such a development lies in the fact that in practice it turns out to be difficult to design experiments of limited size (e.g. 7 dilutions and 20 replicates) in which the design parateters are chosen to incorporate information available in advance about the unknown parameter and such that the design is optimal in some sense. Experiments for the determination of the unknown frequency of a certain wel1-defined cell in a population of cells by limiting dilution techniques can only be performed if a reasonable a priori estimate of that frequency is available. The design of the experiment is thus dependent on such point estimate $\tilde{\varphi}$ or (more general) 
an interval estimate $\left[\varphi_{1}, \varphi_{2}\right]$ representing the researcher's boundaries for possible values of $\varphi$. Another aspect which should play a substantial role in the construction of a design is the fact that each result of the experiment (depending on the true and unknown walue of $p$ ) wust contain a sufficient number of groups producing fractions of negative responders not too close to zero or one.

\subsection{A new procedure for devising an experimental design}

\subsubsection{Introduction}

The design problem is split into two parts. In the first part the number of dilutions and the corresponding (mean) numbers of cells tested are determined, whereas in the second part the number of replicate cultures are chosen. The design method propased in Subsection 2.3 .2 concerns only part one. Part two is dealt with in Chapter 3. The approach of Chapter 3 is more heuristic than that of Chapter 2.

Single-dose designs, $1 . e$. designs containing one set of experiments with a fixed mean number of cells per culture, are discussed by many authors, including Fisher (1922). Finney (1978, p. 435) and Fazekas de St. Groth (1982). Fisher (1922) calculated that the optimal dose $x=1.59 / p$ where $\varphi$ is the unknown frequency, which corresponds to a fraction of 0.203 negative responders. For this value the Fisher information is maximized (see Section 3.2$)$. This suggests that selecting $x=1.59 / \widetilde{\varphi}$, where $\tilde{\varphi}$ represents the researcher's best a priori guess for $\varphi$, would provide the most efficient. single-dose design. According to Fazekas de St. Groth (1982) the Praction of negative cultures must meet certain criteria. He stated that the experiment is efficient when the negative fraction is between 0.10 and 0.37 ; this range comprises levels of information (in the sense of the Fisher information) above $90 \%$ of the maximun. This corresponds to a suggestion of Finney (1978. p. 428) which is interpreted as follows : if sufficient a prioni information is avallable and if more than one dilution is used, select the values $\mathrm{x}_{1} \ldots \ldots \mathrm{x}_{\mathrm{m}}$ such that $0.9<\tilde{p} \mathrm{x}_{1}<2.5,1=1, \ldots, \mathrm{m}$, corresponding to negative

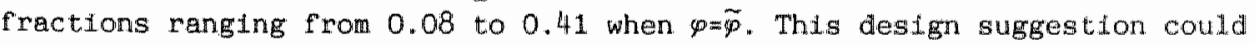
easily produce a setup which fails in providing useful data for the estimation of $\varphi$. If the a priori value $\tilde{\varphi}$ deviates too much from $\varphi$, all the 
replicates ight be either negative or positive. In such cases the experiment obviously does not yield any relevant information; nevertheless, one-stided confidence intervals for the unknown parameter can be determined (see Section 5.5). Table 2.1 provides the numerical information which is used in the discussion above. For example the second row has been obtained by solving $I(\varphi \mid m=1) / I$ opt $(\varphi \mid m=1)=(p x)^{2}(\exp (1.594)-1) /\left\{(\exp (p x)-1)(1.594)^{2}\right\}=$ 0.95 for $p x$, where $I(p / m=1)$ denotes the Flsher information for the singledose design and $I_{\text {opt }}(\varphi \mid m=1)$ denotes the maximal value of $I(\varphi \mid m=1)$.

\begin{tabular}{lllll}
\hline $\begin{array}{l}\text { Efficiency } \\
\text { relative to } \\
\text { optimal } p \mathrm{x}\end{array}$ & $\begin{array}{l}\text { Number of } \\
\text { relevant celis } \\
\text { in a culture } \\
(\varphi \mathrm{x})\end{array}$ & $\begin{array}{l}\text { Probability } \\
\text { of negative } \\
\text { response } \\
(\exp (-\varphi \mathrm{x}))\end{array}$ & $\begin{array}{l}\text { Number of } \\
\text { relevant cells } \\
\text { in a culture } \\
(\varphi \mathrm{x})\end{array}$ & $\begin{array}{l}\text { Probability } \\
\text { of negative } \\
\text { response } \\
\left(\exp \left(-\varphi_{\mathrm{x}}\right)\right)\end{array}$ \\
1.00 & 1.594 & 0.203 & 1.594 & 0.203 \\
0.95 & 1.165 & 0.312 & 2.101 & 0.122 \\
0.90 & 1.004 & 0.367 & 2.346 & 0.096 \\
0.85 & 0.885 & 0.413 & 2.552 & 0.078 \\
0.80 & 0.789 & 0.455 & 2.741 & 0.065 \\
0.75 & 0.706 & 0.494 & 2.922 & 0.054 \\
0.70 & 0.632 & 0.532 & 3.100 & 0.045 \\
0.65 & 0.566 & 0.568 & 3.278 & 0.038 \\
0.60 & 0.506 & 0.603 & 3.459 & 0.031 \\
0.55 & 0.450 & 0.638 & 3.646 & 0.026 \\
0.50 & 0.398 & 0.672 & 3.841 & 0.021 \\
0.40 & 0.302 & 0.739 & 4.266 & 0.014 \\
0.30 & 0.217 & 0.805 & 4.773 & 0.008 \\
0.20 & 0.139 & 0.870 & 5.433 & 0.004 \\
0.10 & 0.067 & 0.935 & 6.474 & 0.002 \\
\hline
\end{tabular}

Table 2.1. Eff tciency relative to optimal px $(=1.594)$ and corresponding watises for the (mean) number px in a replicate culture and the probabitity of obtatning a negative response exp $(-\varphi x)$ when using a single-dose design.

When a useful a priori guess is not available. Finney (1978, p. 437) states that the experimenter must decide between which lower $\left(\varphi_{L}\right)$ and upper $\left(\varphi_{U}\right)$ bound $\varphi$ (almost) certainly lies. Then he must plan an assay with values for the mean numbers of cells per culture ranging from $2 / \varphi_{\mathrm{L}}$ through $1 /\left(2 \varphi_{\mathrm{U}}\right)$. Furthernore, Finney (1978) suggests that the dilution factor ("2 and 4 are preferable to 10") should be as small as is practicable. These design proposalis, however, lack an indication of the number of dilutions which should be used. Since a geometrical series is (rightly) recomended for $x_{1}, \ldots, x_{\text {m }}$, m should obviously be dependent on $\varphi_{U} / \varphi_{L}$. In Subsection 2.3 .2 a 
simple and efficient design method for the one-parameter model is developed which is based on the researcher"s criteria. Compared with the suggestions of Finney (1978) mentioned above, it can be seen as more elaboratced concept which produces a setup with known and suitable properties. According to this design method, certain criteria have to be chosen by the researcher: a lower bound $\varphi_{1}$ and an upper bound $\varphi_{2}$ for the unknown parameter $\varphi$ lower bound $\mathrm{P}_{1}$ and an upper bound $\mathrm{P}_{2}$ for a fraction of negative responders to be considered sufficiently informative; and $d$, a number of dilutions which should lead to sufficiently informative fractions within the fixed bounds $P_{1}$ and $\mathrm{P}_{2}$.

\subsubsection{Graphical explanation and derivation of the design formulae}

The researcher must specify an interval estimate $\left[\varphi_{1}, \varphi_{2}\right]$ for $p$ based on existing a priori information. There must be strong reasons supporting the notion that the true value $\varphi$ is between these bounds "Only fractions of negative responders between certain values $P_{1}$ and $P_{2}\left(P_{1}\left(P_{2}\right)\right.$ are considered sufficiently informative by the researcher. The aim is to have, per experiment (on the average), d dilutions that yield sufficiently informative fractions. Then, using the formulae $(2.1)-(2.4)$, the number of dilutions $m$, the mean number of celis $x_{1}$ in the replicate cultures of the first dilution, and finally the dilution factor $c$ can be determined :

$$
m=d+\operatorname{ENTIER}\left(\log \left(\varphi_{2} / \varphi_{1}\right) / \log (c)\right)
$$

$$
x_{1}=\left\{\left(\log P_{1}\right)\left(\log P_{2}\right) c^{1-m / 1} /\left(\omega_{1} \varphi_{2}\right)\right\}^{1 / 2} .
$$

$$
c=\left\{\left(\log _{1}\right) /\left(\log _{2}\right)\right\}^{1 / d}
$$

('ENTIER' means 'the integer part of' and $\log$ is the natural logarithm function).

These design formulae can be explained in a heuristic way assisted by the graphical illustration in Fig. 2.1 (see Strijbosch, Does and Burmen (1987)). 


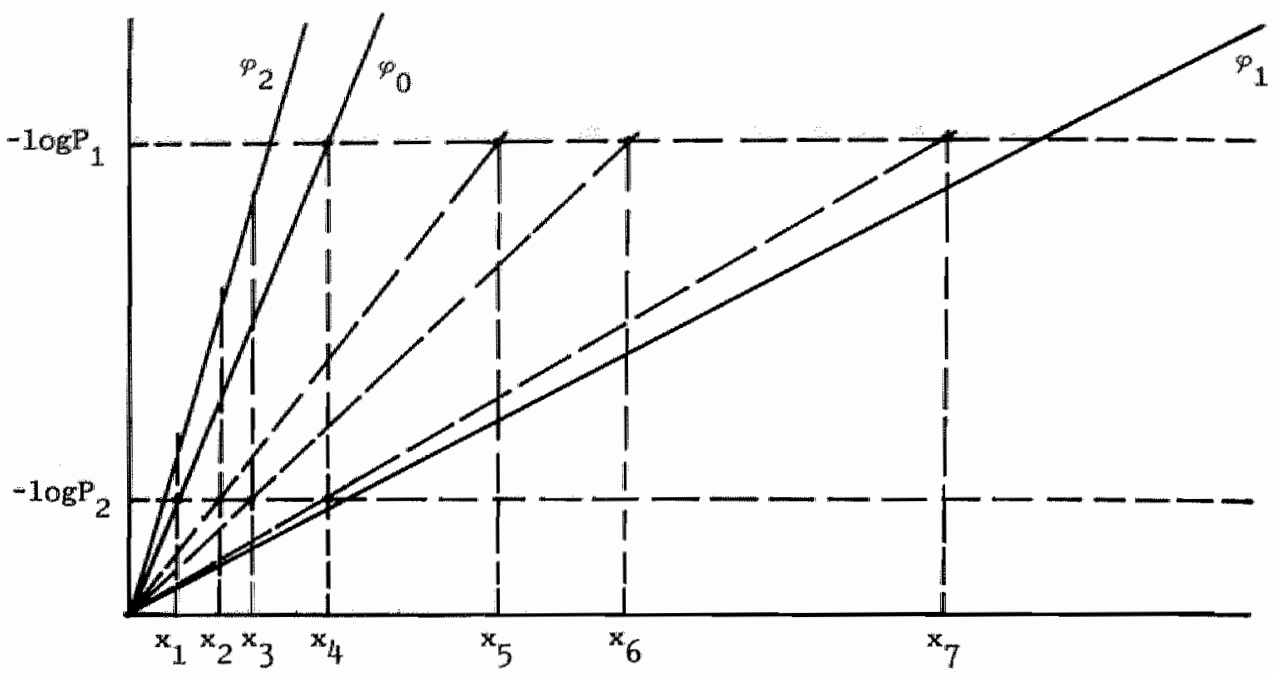

Fig. 2.1. The construction of a destgn method based on a lower boundary $\varphi_{1}$ and a upper boundary $p_{2}$ for the unknown parameter $\varphi$, and on a sufficientiy informative range $\left[P_{1}, P_{2}\right]$ for the proportion of negative responders in indtvidual culture groups. It ts assumed here that, for each value of $\varphi E$ $\left[\varphi_{1},{ }^{\prime}{ }_{2}\right]$, three culture groups produce sufftctently informative data.

In this Figure the dose-response relationship $P=\exp (-\phi x)$ is presented as a straight line through the origin with slope $\varphi$. Suppose that $d=3$, and $x_{1} \cdot x_{2} \cdot x_{3}$ are given values satisfying the condition $-\log \left(P_{2}\right)<\varphi_{2} x_{1}<\varphi_{2} x_{2}<$ $\varphi_{2} x_{3} \leq-\log \left(\mathrm{P}_{1}\right)$. The value of $x_{4}$ can then be found by letting $\varphi$ decrease from $\varphi_{2}$ to $\varphi_{0}$ which is determined by the point $\left(x_{1},-\log \left(\mathbb{P}_{2}\right)\right)$. For $p \in\left(p_{0}, p_{2}\right]$, 1t follows that $-\log \left(P_{2}\right)<\varphi x_{1}<\varphi x_{2}<\varphi x_{3} \leq-\log \left(P_{1}\right)$. while $\varphi x_{1} \leq-\log \left(P_{2}\right)$ for $p \leq \varphi_{0}$. Thus a new value $x_{4}$ has to be added to the series in order to satisfy the design requirements mentloned at the end of subsection 2.3.1. It follows that $x_{4}=-\log \left(P_{1}\right) / \varphi_{0}$. Since $p_{0}=-\log \left(P_{2}\right) / x_{1}$, it is clear that $x_{4}$ is neither dependent on $x_{2}$ nor $x_{3}$. Rather $x_{4}$ is a function of $x_{1}: x_{4}=$ $x_{1} \log \left(P_{1}\right) / \log \left(P_{2}\right)$. In general it follows that $x_{i+d}=x_{i} \log \left(P_{1}\right) / \log \left(P_{2}\right)$. so that the choice of a geometrical series $x_{i}=x_{1} c^{i-1}$ with $c=$ $\left[\log \left(P_{1}\right) / \log \left(P_{2}\right)\right]^{1 / d}$ is obvious. Note that in Fig. $2.1 x_{1} \ldots, x_{7}$ satisfy 
$x_{i}=x_{i-d} c^{d}, i=4, \ldots, 7$, but do not satisfy $(2.4)$. The geometrical series $(2.4)$ is chosen for convenience.

The remaining unknown design characteristics $x_{1}$ and can be found by demanding two conditions. The first one is a condition of symetry, i.e. on a logarithmic scale the interval $\left[x_{1}, x_{m}\right]$ must lie symetrically within the interval $\left[-\log \left(\mathrm{P}_{2}\right) / \varphi_{2},-\log \left(\mathrm{P}_{1}\right) / \varphi_{1}\right]$. The lower bound of the last interval is the least possible value for $x_{1}$, and "analogously, the upper bound is the largest value for $x_{m}$. Thus : $x_{1} x_{m}=\log \left(P_{1}\right) \log \left(P_{2}\right) /\left(\varphi_{1} \varphi_{2}\right)$. As $x_{1} x_{m}=x_{1}^{2} c^{m-1}$. $(2.2)$ is obtained. Finally, (2.1) is explained by observing that typically $x_{1} \equiv-\log \left(P_{2}\right) / \varphi_{2}$, while $x_{m-d+1} \cong-\log \left(P_{2}\right) / \varphi_{1}$, and hence $c^{m-d}=x_{m-d+1} / x_{1} \cong$ $\varphi_{2} / \varphi_{1}$. This satisfles the second condition being that m be sufficiently large.

In the next Subsection (2.3.3) this procedure is proven to be mathematically correct.

\subsubsection{Proof of the correctness of the design formulae}

The following proposition will be proved.

For each $\varphi \in\left[\varphi_{1}, p_{2}\right]$, exactly a values of $x_{1}, \ldots, x_{m}$ as defined by (2.1) (2.4) satisfy the condition $P_{1} \leq \exp \left(-\varphi x_{i}\right)<p_{2}$.

Let $x_{0}=x_{1} / c$ and $x_{m+1}=x_{m} c$. It suffices to prove that for each $\varphi \in\left[\varphi_{1}, \varphi_{2}\right]$ exactly one integer $i_{\varphi}$ exists which satisfies the following conditions :

$$
1 \leq \dot{i}_{p} \leq \mathrm{n}-\mathrm{d}+1
$$

$$
x_{1}>-\log \left(\mathbb{P}_{2}\right) / \varphi
$$

$$
x_{i_{\varphi}+d-1} \leq-\log \left(P_{1}\right) / \varphi \text {. }
$$

$$
x_{i_{\varphi}-1} \leq-\log \left(\mathbb{P}_{2}\right) / \varphi .
$$

$$
\mathrm{x}_{\mathrm{i}_{\varphi}+\mathrm{d}}>-\log \left(\mathrm{P}_{1}\right) / \varphi .
$$


From $(2.1)$ and $(2.3)$ it can be shown that $(2.6)$ and $(2.7)$ as well as $(2.8)$ and (2.9) are equivalent to

$$
1<x_{1} p /\left(-\log \left(P_{2}\right)\right) \leq c .
$$

Fon (2.1) it follows that

$$
m=d+\log \left(\varphi_{2} / \varphi_{1}\right) / \log (c)-\varepsilon, \text { for some } \varepsilon, 0 \leq \varepsilon<1
$$

Thus, from (2.2)

$$
x_{1}=-\log \left(P_{2}\right) c^{(1+\varepsilon) / 2 / \varphi_{2}}
$$

From $(2.3),(2.10)$ and $(2.12)$ it follows

$$
(1-\varepsilon) / 2+\log \left(\varphi_{2} / \varphi\right) / \log (c)<i_{\varphi} \leq(3-\varepsilon) / 2+\log \left(\varphi_{2} / \varphi\right) / \log (c)
$$

Hence exactly one integer $1_{\varphi}$ satisfies (2.13). Furthermore, it is obvious from $(2.11)$ that

$$
0 \leq \log \left(\varphi_{2} / \varphi\right) / \log (c) \leq m-d+\varepsilon
$$

Fron (2.13) and (2.14) can be concluded that (2.5) is valid.

\subsection{Practical applications}

\section{An application of $(2.1)-(2.4)$}

Suppose that an experiment has to be set up to estimate the frequency of a certain well-defined cell in a population of cells. The frequency of that cell is a priori estimated to be smaller than $1 / 2000\left(=p_{1}\right)$ and larger than $1 / 200\left(=\varphi_{2}\right)$, and for each value of the unknown parameter $\varphi$ within these bounds 3 (=d) groups of replicate cultures are required yielding fractions of negative cultures larger than $0.15\left(=P_{1}\right)$ and smaller than $0.70 \quad\left(=P_{2}\right)$. Applying the design formulae (2.1)-(2.4) leads to the following experimental design : $m=7$ groups of replicate cultures with respectively $98,171,298$, 
520, 908,1585 and $2767\left(x_{1}, \ldots, x_{7}\right)$ cells tested per culture. In onder to clarify the procedure Table 2.2 and Fig. 2.2 are presented. Table 2.2 gives the probabilities of a negative response for all combinations of the seven $x_{i}$ 's used and five different values of the unknown frequency $p$. As a result of the procedure, exactly three probabilities in the range 0.15 through 0.70 are abtained for each frequency $p$ between $\varphi_{1}$ and $\varphi_{2}$.

\begin{tabular}{lccccccc}
\hline$\varphi$ & $x_{1}$ & $x_{2}$ & $x_{3}$ & $x_{4}$ & $x_{5}$ & $x_{6}$ & $x_{7}$ \\
& 98 & 171 & 298 & 520 & 908 & 1585 & 2767 \\
\hline $1 / 200$ & $(0.61)$ & $(0.43)$ & $(0.23)$ & 0.07 & 0.01 & 0.00 & 0.00 \\
$1 / 300$ & 0.72 & $(0.57)$ & $(0.37)$ & $(0.18)$ & 0.05 & 0.01 & 0.00 \\
$1 / 500$ & 0.82 & 0.71 & $(0.55)$ & $(0.35)$ & $(0.16)$ & 0.04 & 0.00 \\
$1 / 1000$ & 0.91 & 0.84 & 0.74 & $(0.59)$ & $(0.40)$ & $(0.20)$ & 0.06 \\
$1 / 2000$ & 0.95 & 0.92 & 0.86 & 0.77 & $(0.64)$ & $(0.45)$ & $(0.25)$ \\
\hline
\end{tabular}

Table 2.2. Some function values of $f_{i}(\varphi)=\exp \left(-\varphi_{x},\right), i=1, \ldots, m$, representing the probabiltties of a negative response. The following design parameters are used : $\varphi_{1}=1 / 2000, \varphi_{2}=1 / 200, d=3, p_{1}=0.15$ and $p_{2}=0.70$, resulting in $m=7$. The values between $P_{1}$ and $P_{2}$ appear between parentheses.

In Fig. 2.2 the functions $\exp \left(-\varphi x_{i}\right), i=1, \ldots, m_{*}$ for $\varphi \in\left[\varphi_{1}, \varphi_{2}\right]$, as well as the horizontal lines at $\mathrm{P}_{1}$ and $\mathrm{P}_{2}$, are presented. Fig. 2.2 illustrates the property of the design, i.e. a vertical line for each $\varphi \in\left[\varphi_{1}, \varphi_{2}\right]$ each intersecting exactly d functions at points between $\mathrm{P}_{1}$ and $\mathrm{P}_{2}$.

\section{A comparison with Loyer"s design}

From the design procedure proposed by Loyer (1981) the first dilution $\left(x_{1}\right)$ of a geometricall series of dilutions is determined as a function of five parameters : the number of replicates $(n)$, the number of culture groups $(m)$, the dilution factor (c), an upper bound for the unknown parameter $\left(\varphi_{2}\right)$ and the meximum acceptable probabllity of obtaining only positive responses (p). The formula used is :

$(2.15) \quad \prod_{i=1}^{m}\left(1-\exp \left(-\varphi_{2} x_{1} c^{i-1}\right)\right)^{n}=p$. 


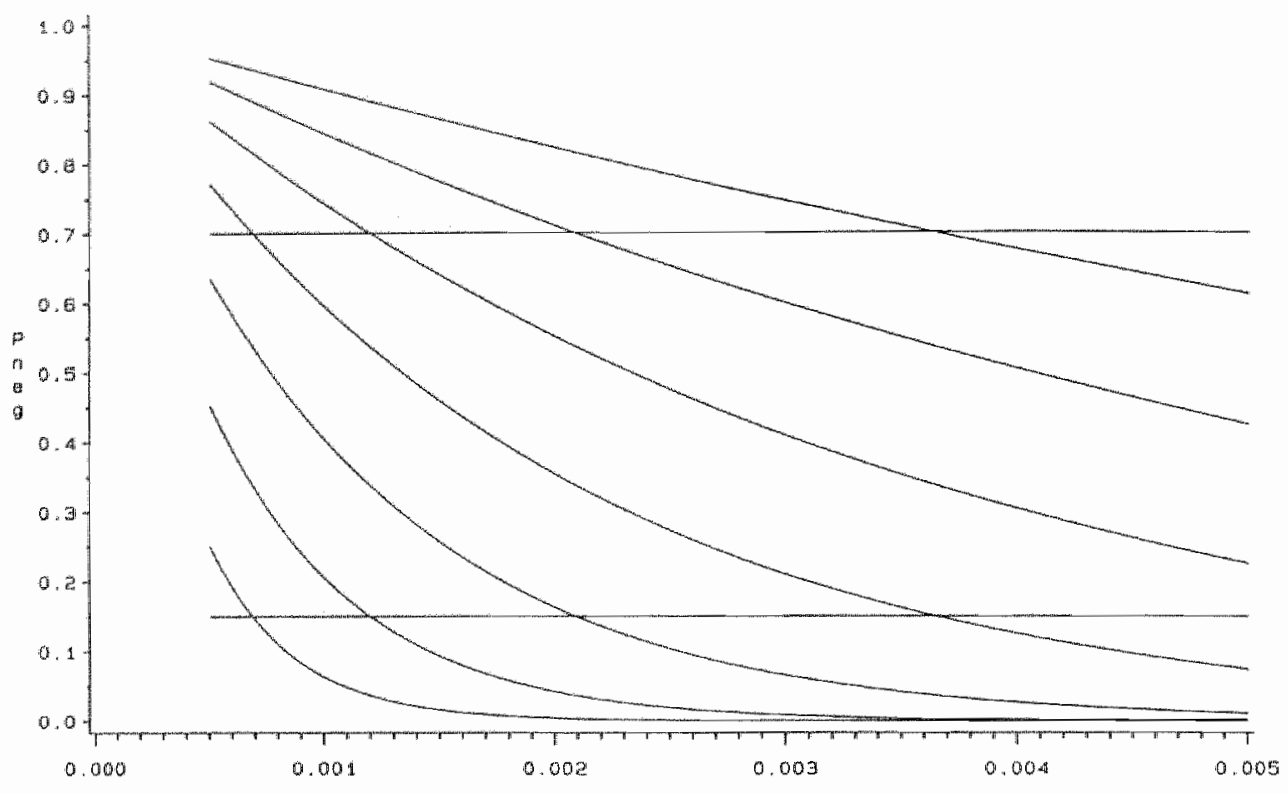

$\varphi$

Fig. 2.2. Graph of the functions $f_{i}(\varphi)=\exp \left(-\varphi x_{i}\right), i=1, \ldots, m_{*}$ representing the probabilities of a negative response, and $g_{i}(\varphi)=P_{i}, i=1,2$. The following destgn parameters are used : $\varphi_{1}=1 / 2000, \varphi_{2}=1 / 200, d=3, P_{1}=0.15$ and $P_{2}=0.70$, yielaing $m=$ ?.

The value of $x_{1}$ is determined from iterative computation. Apart from being complicated, there are several objections to this procedure. In the first place, the proposed design method denands that the number of dilutions as well as the number of replicates per dilution be chosen in advance.

Secondly, the walues of the (mean) number of cells tested per replicate are dependent on the number of replicates while this is generally not desirable. Furthermore, only an upper bound for the unknown parameter is included in the procedure. It is not consistent to use a design method which prohibits the occurrence of ondy positive responses but does not prohibit the event of only negative responses. The maximum probability of this event is given by $\pi_{i=1}^{\mathrm{tal}} \exp \left(-n \varphi_{1} x_{i}\right)=\exp \left(-n p_{1} x_{1} \sum_{i=1}^{m} c^{i-1}\right)$, where $\varphi_{1}$ is the lower bound for the unknown parameter. Table 2.3 11lustrates the properties of Loyer's design procedure through a comparison with parameter values for the procedure (2.1) $-(2.4)$ producing approximately equal values for $c, m$, and $x_{1}$. Note that 
in some cases other choices for $\mathbb{P}_{1}$ and $P_{2}$ would be desirable (see also Section 3.3). In Table 2.3 the lower bound $\varphi_{1}$ is calculated according to $p_{1}=\varphi_{2} c^{d-m}+\varepsilon,(\varepsilon>0)$. When $\varepsilon$ is sufficiently small, $p_{1}$ and $P_{2}$ can be determined from $\left(\log P_{1}\right)^{2} \cong x_{1}^{2} c^{2 d-1} \varphi_{2}^{2}$ and $\left(\log P_{2}\right)^{2}=x_{1}^{2} c^{-1} \varphi_{2}^{2}$. respectively. Thus $P_{2}$ is dependent on $d$ only through $\varepsilon$. In the Table $\varepsilon=0.01$ is chosen.

\begin{tabular}{|c|c|c|c|c|c|c|c|c|c|}
\hline \multicolumn{6}{|c|}{ LOYER' S-----DESIGN----PROCEDURE } & \multicolumn{4}{|c|}{ PARAMETER VALUES FOR $(2,1)-$} \\
\hline & & "VPT" & & & OUTPUT & & PROD & NG EQUA & $c, m, x_{1}$ \\
\hline$n$ & 四 & $p$ & $c$ & $\varphi_{2}$ & $x_{1}$ & $d$ & $\varphi_{1}$ & $P_{1}$ & $P_{2}$ \\
\hline 6 & 3 & 0.01 & 2 & 8 & 0.109 & $\begin{array}{l}1 \\
2 \\
3\end{array}$ & $\begin{array}{l}1.01 \\
2.01 \\
4.01\end{array}$ & $\begin{array}{l}0.417 \\
0.175 \\
0.031\end{array}$ & $\begin{array}{l}0.646 \\
0.647 \\
0.647\end{array}$ \\
\hline 12 & 3 & 0.01 & 2 & 8 & 0.166 & $\begin{array}{l}1 \\
2 \\
3\end{array}$ & $\begin{array}{l}1.01 \\
2.01 \\
4.01\end{array}$ & $\begin{array}{l}0.262 \\
0.069 \\
0.005\end{array}$ & $\begin{array}{l}0.512 \\
0.513 \\
0.514\end{array}$ \\
\hline 24 & 3 & 0.01 & 2 & 8 & 0.234 & $\begin{array}{l}1 \\
2 \\
3\end{array}$ & $\begin{array}{l}1.01 \\
2.01 \\
4.01\end{array}$ & $\begin{array}{l}0.153 \\
0.024 \\
0.0005\end{array}$ & $\begin{array}{l}0.391 \\
0.392 \\
0.392\end{array}$ \\
\hline
\end{tabular}

Table 2.3. Comparitson of some destgns obtained from Loyer's design procedure with possible combinations of parameter values for the procedure $(2.1)-(2.4)$ producing approximately equal $c, m$ and $x_{1}$.

\section{Estimating the density of rope spores in potato flour}

The design parameters in the next example are chosen such that a design results which is described in the literature. Finney (1978), Section 20.6. presents a design, referring to Fisher and Yates (1963), for the estimation of the density of rope spores ( $B$. mesentericus) in potato flour. "Whe experiment used 5 replicates, each of 1 c.c., for each of 10 dilutions obtained in a geometrical fashion with $x_{1}=1 / 128 \mathrm{~g}$. per $100 \mathrm{c} . \mathrm{c} .=0.0078125$ g. per $100 \mathrm{c.c}$. and $x_{1}=x_{1} 2^{i-1}$. The corresponding numbers of negative responders were $5,5,3,3,2,1,0,0,0,0$, respectively. Leading to the estinete $p$ $=7.66$ rope spores per $1 / 100$ gram. Approximately the same (serial) dilution serles could be obtained using $(2.1)-(2.4)$ with, for example, $\varphi_{1}=0.40$, $\varphi_{2}=52.9, \mathrm{~d}=3, \mathrm{P}_{1}=0.10$ and $\mathrm{P}_{2}=0.75$, leading to $\mathrm{c}=2.0003, \mathrm{~m}=10$ and 
$x_{1}=0.007814$. This exercige arakes clear under which assuntions the described design was valda.

\section{Tho relation between in and $\mathrm{P}_{1} \mathrm{P}_{2} \mathrm{~d}$}

The design procedure forces one to choose values for $\mathrm{P}_{1}$ and $\mathrm{P}_{2}$. According to Fazekas de St. Groth (1982), it is considered better not to choose $P_{1}$ and $P_{2}$ symetrically around 0.203 which is the optimal value for when $P_{1}=P_{2}$ and $\varphi_{1}=\varphi_{2}$ and there are large numbers of replicates. Suggestions for the deternination of $P_{1}$ and $P_{2}$ in the general case can be found in Section 3.3. However, it seems sensible to choose $P_{1}$ always smaller than 0.203 and $\mathrm{P}_{2}$ always larger. Furthermore, making $\mathrm{P}_{1}$ larger and/or $\mathrm{P}_{2}$ smaller will usually increase m (but never decrease $\mathrm{m}$ ). The same is true for making $\varphi_{1}$ smaller and/or $\varphi_{2}$ larger. Increasing d will always increase $m$. From practical experience in limiting dilution assays it appears that $d=3$, $\mathrm{P}_{1}=0.15, \mathrm{P}_{2}=0.70$, are reasonable choices, whereas the a priori boundaries on $p$ can often be chosen so that $\varphi_{2} / \varphi_{1}=10$. The influence of $d$ and the choices for $\mathrm{P}_{1}$ and $\mathrm{P}_{2}$ on the number of culture groups is illustrated in Table 2.4 .

\begin{tabular}{llllllll}
\hline $\mathrm{P}_{1}$ & $\mathrm{P}_{2}$ & $\mathrm{~d}$ & $\mathrm{~m}$ & $\mathrm{P}_{1}$ & $\mathrm{P}_{2}$ & $\mathrm{~d}$ & $\mathrm{~m}$ \\
0.05 & 0.80 & 1 & 1 & 0.10 & 0.75 & 1 & 2 \\
0.05 & 0.80 & 2 & 3 & 0.10 & 0.75 & 2 & 4 \\
0.05 & 0.80 & 3 & 5 & 0.10 & 0.75 & 3 & 6 \\
0.05 & 0.80 & 4 & 7 & 0.10 & 0.75 & 4 & 8 \\
& & & & & & & \\
$\mathrm{P}_{1}$ & $\mathrm{P}_{2}$ & $\mathrm{~d}$ & $\mathrm{~m}$ & $\mathrm{P}_{1}$ & $\mathrm{P}_{2}$ & $\mathrm{~d}$ & $\mathrm{~m}$ \\
0.15 & 0.70 & 1 & 2 & & & & \\
0.15 & 0.70 & 2 & 4 & 0.17 & 0.50 & 1 & 3 \\
0.15 & 0.70 & 3 & 7 & 0.17 & 0.50 & 2 & 6 \\
0.15 & 0.70 & 4 & 9 & 0.17 & 0.50 & 3 & 10 \\
\hline
\end{tabular}

Table 2.4. The dependence of the number $m$ of cutture groups on the vatues of the destgn parameters $p_{1}, P_{2}$ and $d$. The quotient $\varphi_{2} / p_{1}$ is taken as 10 . 


\section{$(2.1)-(2.4)$ applied in practice}

The design method presented here has been applied (see for example Doveren, Buurman, van der Linden et al. (1986)) and has been found useful. especially when low numbers of celis were avallable for LDA's such as in experiments with cells obtained from fine needie biopsies of rejecting kidney allografts. A typical experiment from the study of Doveren, Bumman. van der Linden et al. (1986) is presented in Table 2.5.

\begin{tabular}{lllll}
\hline $\begin{array}{l}\text { Culture } \\
\text { group }\end{array}$ & $\begin{array}{l}\text { Cells tested } \\
\text { per replicate }\end{array}$ & $\begin{array}{l}\text { Number of } \\
\text { replicates }\end{array}$ & $\begin{array}{l}\text { Number of } \\
\text { negative } \\
\text { cultures }\end{array}$ & $\begin{array}{l}\text { Fraction of } \\
\text { negative } \\
\text { cultures }\end{array}$ \\
1 & 176 & 24 & 24 & 1.00 \\
2 & 289 & 24 & 24 & 1.00 \\
3 & 473 & 24 & 23 & 0.96 \\
4 & 775 & 24 & 18 & 0.75 \\
5 & 1271 & 24 & 21 & 0.87 \\
6 & 2084 & 24 & 15 & 0.63 \\
7 & 3416 & 24 & 11 & 0.46 \\
8 & 5600 & 24 & 6 & 0.25 \\
\hline
\end{tabular}

Table 2.5. Experimental data from a LDA. Responder celts from a kidney allograft were obtained by fine-needle asptration blopsy 8 days after carine kidney transplantation. The responder cells from the recipient were cultured with stimulator cells from the donor for 10 days and assayed for spectic cytolysis against PHA blasts of the donor dog. The destgn parameters chosen were $\varphi_{1}=1 / 4000, \varphi_{2}=1 / 300, P_{1}=0.15, P_{2}=0.65$, and $d=3$. The pracedure to calculate the number of culture groups and numbers of cells tested per. replicate produced $m=8, x_{8}=5584$ and $c=1.6391$. For convemience $x_{8}$ and $c$ have been replaced by 5600 and $100 / 61$ respectively. Replicate cultures were scared as negative for CTL-P if the ${ }^{51} \mathrm{Cr}$ release value was smallew than three times the standard deviation above mean background level. 



\section{DESIGN REFINEMENTS}

\subsection{Introduction}

In this Chapter the design method for dilution series will be completed with some suggestions for tuning the design parameters $\mathbb{P}_{1}$ and $P_{2}$ when the number of dilutions has already been determined. Guidelines and formulae for choosing these parameters are given in Section 3.3. A method for determining the (equal) number of replicates $n=n_{i}, i=1, \ldots, m$, on the basis of a usersupplied coefficient of variation is given in Section 3.4. Section 3.2 describes the role the Fisher information plays in design considenations. The application of the proposed design methods is straightforward, although the conputer program described in Section 3.5 will expeditate the setup of a design in the laboratory.

There are several uncertainties in choosing the design parameters. Of course, it is difficult to fix values for $\varphi_{1}$ and $\varphi_{2}$. Perhaps a more natural approach is to base a design on a 'bell-shaped" a priori distribution rather then on a uniform distribution as was conceived in $(2.1)-(2.4)$. Furthernore, it is unclear how $\mathrm{P}_{1}$ and $\mathrm{P}_{2}$ should be chosen. In general. values like $P_{1}=0.15$ and $P_{2}=0.70$ will suffice (see Fazekas de St. Groth (1982)), but it would be more ideal, for example, to choose $P_{1}$ and $P_{2}$ as close as possible to some value $P_{0}$ which is the best cholce for a single-dose design with a certain number of replicates (see Subsection 2.3.1 and Section 3.2). Formula (2.1) admits two alternative refinements that could be dimportant in constructing a design for a specific experiment. Both refinements make use of the fact that either $\varphi_{2} / \varphi_{1}$ might be larger or $c$ might be smaller without altering m because in (2.1) ENTIER is used. With equal $m$ and $c$, every $\varphi_{1}$ and $\varphi_{2}^{*}$ satisfying $c^{\mathrm{m}-\mathrm{d}} \leq \varphi_{2}^{*} / \varphi_{1}^{*}<c^{\mathrm{m}-\mathrm{d}+1}$ could be chosen instead of $\varphi_{1}$ and $\varphi_{2}$ " This results in the same $x_{1}$ only when $\varphi_{1} \varphi_{2}^{*}=\varphi_{1} p_{2}$ which lis assumed from now on. Analogously, with equal $m$ and $\varphi_{2} / \varphi_{1}, P_{1}^{*}$ and $P_{2}^{*}$ could be chosen instead of $\mathrm{P}_{1}$ and $\mathrm{P}_{2}$ whenever $\left(\varphi_{2} / \varphi_{1}\right)^{1 /(\mathrm{m}-\mathrm{d}+1)}<\mathrm{c}^{*}=\left[\log \left(\mathrm{P}_{1}^{*}\right) / \log \left(\mathrm{P}_{2}^{*}\right)\right]^{1 / \mathrm{d}} \leq$ $\left(\varphi_{2} / \varphi_{1}\right)^{1 /(m-d)}$. These are important tools. It follows that, with an equal number of dilutions, the properties of a design are valid for a larger 
interval of $p$, and, alternatively " it is possible to choose other, maybe better, values for $\mathbb{P}_{\mathcal{L}}$ and $\mathbb{P}_{2}$.

\subsection{The Fisher information}

An important crlterdu in design considerations is the Fisher information defined by $I(\varphi)=\operatorname{var}_{\varphi}(\partial \log L(\varphi) / \partial(\varphi))$ where $\log L(\varphi)$ denotes the log 11kelthood function (see Bickel and Doksum (1977, p. 127), and Subsection 5.3 .2$)$. It follows that for an assay with mean numbers or cells $x_{1}, \ldots, *_{m}$, numbers of replicates $n_{1}, \ldots, n_{m}$ and $p$ as the true value of the parameter, the Fisher information is given by

$$
I(\varphi)=\sum_{i=1}^{m} n_{1} x_{1}^{2} /\left(e^{p x_{i}}-1\right)
$$

The asymptotic variance of the maximum likelihood estimator $\hat{\varphi}_{M L}$ (see Subsection 5.3.2) equals the recipracal of $I(\varphi)$ (cf. formula (3.2)). Since $\varphi$ is unknown. $I(\varphi)$ is unknown too. However, an approximation of $I(\varphi)$ is obtained as a by-product of the determination of the maximum likelihood estimate (see Subsection 5.3.2). For experiments with one single dose, maximizing $I(\varphi)$ (or minimizing $C V(\varphi)$ to be defined in (3.2)) produces $\varphi_{\mathrm{x}}=1.59$ as noted earlier. This suggests a choice for $\mathrm{x}$ when a good point estimate of $\varphi$ is available. It should be noted here that small sample research conducted by Halvorson and Ziegler (1933) shows that for small numbers of replicates the optimal number of cells should be determined according to $1.2<p \mathrm{x}<1.5$ rather than to $\varphi_{\mathrm{x}}=1.59$. This suggests that the optitial single-dose fraction $\mathrm{P}_{0}$ of negative responders should be dependent on the number of replicates and fis generally larger than 0.203 . However, this subject is not investigated any further in this study. If the a priori information is an interval estimate, it is clear that the assay must contain several different dilutions as determined, for example, by formulae (2.1)$(2.4)$. With these formulae, the design parameters $P_{1}$ and $P_{2}$ can be used in order to influence the function $C V(\varphi)$ on $\left[\varphi_{1}, \varphi_{2}\right]$ in a desirable way. 


\subsection{The choice of the sufficiently informative range}

Better values for $P_{1}$ and $P_{2}$ should be obtained when the maximum of the asymptotic value of the coefficient of variation on $\left[\varphi_{1}, \varphi_{2}\right]$ is smaller and hence the estimator varies less. The coefficient of variation is defined by the guotient of the standard error of the ML estimate and $p$. Accordingly. let $C V(\varphi)$ be defined by

$$
\operatorname{CV}(\varphi)=1 /(\varphi \sqrt{I(\varphi)})
$$

Both objectives, viz., a smaller $\mathrm{CV}(\phi)$ and less varying estimator $\hat{\varphi}_{\mathrm{ML}}$, can be achieved by defining

$$
p_{1}^{*}=p_{0}^{s q} \text { and } P_{2}^{*}=P_{0}^{s / q}
$$

where $P_{0}=0.203$ (or, depending on the number of replicates, a larger value), and $q=\left(c_{*}^{*}\right)^{d / 2}$ with $c_{+}^{*}=\left(\varphi_{2} / \varphi_{1}\right)^{1 /(m-d+1)}+\varepsilon(\varepsilon>0$, but small), and $s$ some suitable transformation of $q$. The addition of a small number $\varepsilon$ is mandatory" since with $c^{*}=\left(\varphi_{2} / \varphi_{1}\right)^{1 /(m-d+1)}$ one extra culture group becomes necessary. However, $\epsilon$ should be sufficiently small to attain maximal gain for the alternatives $\mathrm{P}_{1}^{*}$ and $\mathrm{P}_{2}^{*}$. Usually, $\varepsilon=0.01$ can be chosen. Trying several obvious transformations as proposed by Tukey $(1977, \mathrm{p} .91), s=1 / \sqrt{\mathrm{q}}$ seems to be suitable for the purpose of equalizing $C V(\varphi)$ as much as possible provided that $n_{i}=n, i=1, \ldots, m$. This result has been obtained from empirical observation rather than algebralc analysis. Table 3.1 illustrates this observational process with a few numerical results. In this Jable the transformation which is used in $(3.3)$ is indicated by $p$ where $s=q^{p}$. The number $E$ is substituted by the value 0.01 . The resulting values for $P_{1}^{*}$ and $\mathrm{P}_{2}$ are given. Moreover, based on the design obtained when substitutung $\mathrm{P}_{i}$ by $P_{1}^{*}, i=1,2,(3.2)$ is evaluated in $\varphi_{1},\left(\varphi_{1}+\varphi_{2}\right) / 2$ and $\varphi_{2}$. As table 3.1 shows, the maximum value of $\mathrm{CV}(\varphi)$ on $\left[\varphi_{1}, \varphi_{2}\right]$ is minimal when $p=-0.50$. 


\begin{tabular}{|c|c|c|c|c|c|c|}
\hline$d=2$ & $P_{1}$ & $P_{2}$ & $c$ & $\mathrm{Cr}(0.001)$ & $c v(0.0055)$ & $C V(0.01)$ \\
\hline & 0.150 & 0.700 & 2.306 & 0.274 & 0.223 & 0.239 \\
\hline$p$ & $\mathrm{P}_{1}^{*}$ & $\mathrm{P}_{2}^{*}$ & $c_{+}^{*}$ & $\operatorname{cv}(0.001)$ & $C V(0.0055)$ & $C V(0.01)$ \\
\hline $\begin{array}{l}-0.75 \\
-0.50 \\
-0.25\end{array}$ & $\begin{array}{l}0.145 \\
0.096 \\
0.058\end{array}$ & $\begin{array}{l}0.662 \\
0.606 \\
0.545\end{array}$ & $\begin{array}{l}2.164 \\
2.164 \\
2.164\end{array}$ & $\begin{array}{l}0.269 \\
0.253 \\
0.240\end{array}$ & $\begin{array}{l}0.219 \\
0.224 \\
0.230\end{array}$ & $\begin{array}{l}0.238 \\
0.248 \\
0.261\end{array}$ \\
\hline$d=3$ & $P_{1}$ & $\mathbb{P}_{2}$ & $c$ & $\operatorname{cv}(0.001)$ & $\operatorname{cv}(0.0055)$ & $C V(0.01)$ \\
\hline & 0.150 & 0.700 & 1.746 & 0.203 & 0.179 & D. 188 \\
\hline p & $\mathbb{P}_{1}^{*}$ & $P_{2}^{*}$ & $c_{*}^{*}$ & $C V(0.001)$ & $\mathrm{CV}(0.0055)$ & $\operatorname{cv}(0.01)$ \\
\hline $\begin{array}{l}-0.75 \\
-0.50 \\
-0.25\end{array}$ & $\begin{array}{l}0.150 \\
0.104 \\
0.067\end{array}$ & $\begin{array}{l}0.626 \\
0.572 \\
0.515\end{array}$ & $\begin{array}{l}1.595 \\
1.595 \\
1.595\end{array}$ & $\begin{array}{l}0.199 \\
0.189 \\
0.181\end{array}$ & $\begin{array}{l}0.170 \\
0.173 \\
0.177\end{array}$ & $\begin{array}{l}0.184 \\
0.191 \\
0.200\end{array}$ \\
\hline
\end{tabular}

Table 3.1. Motivation of the chatce for the transformation function $s$ in formula (3.3). The parameters of the designs used are $\varphi_{1}=0.001, p_{2}=0.01, \mathbb{P}_{1}$ $=0.15, P_{2}=0.70, n=12$, and $d=2$ or 3 , resulting $i n m=4$ or 7 , respectively.

\subsection{The choice of the numbers of replicates}

The second part of the design problem is the determination of the numbers of replicates for each dilution. Experiments in Fazekas de St. Groth (1982) and Strijbosch, Butrman, Does et al. (1987) indicate that, in practice, values of the order of 20 suffice. Nevertheless, more precise considerations can be given for the determination of the number of replicates in general. Assuming that $n_{1}=n, i=1, \ldots$ m, a value of $n$ can be derlved from the requilement that the coefficient of variation CV $(\varphi)$ is not larger than a predetermined vallue. Thus the maximum value of $\operatorname{CV}(\varphi)$ on $\left[\varphi{ }_{1}\right.$ . $\left.\varphi_{2}\right]$ is needed for the determination of $\mathrm{n}$. From graphical analysis using various designs according to $(2.1)-(2.4)$. It seems that as a natural consequence of the design method, for $\varphi_{1} \leq \varphi \leq \varphi_{2}$, the quantity $C V(\varphi)$ attalns 1 ts maximum at $\varphi_{1}$ or $\varphi_{2}$ provided that $n_{i}=n, i=1, \ldots$, m lexceptions to this situation only occur for very extreme designs like the one obtained for $\phi_{1}=0.001, p_{2}=0.500, d=2, P_{1}=0.01$ and $P_{2}=0.99$ (resulting in $m=4, c=21.406$ and 
$\left.\left.x_{1}=0.097\right)\right)$. Furthermone, $\mathrm{CV}\left(\varphi_{1}\right)$ and $\mathrm{CV}\left(\varphi_{2}\right)$ are approximately equal when using the $P_{1}^{*}$ and $P_{2}^{*}$ alternatives according to $(3.3)$. A simple method to determine the (equal) number of replicates is therefore given by formula

$$
n=1+\operatorname{ENTIER}\left[\left[\operatorname{cov}^{2} \Sigma_{i=1}^{m} \varphi_{0}^{2} x_{i}^{2} /\left(e^{\varphi_{0} x_{i}}-1\right)\right]-1\right]
$$

where $\mathrm{CoV}$ denotes the user-supplied value of the coefficient of variation, and $\varphi_{0}=\varphi_{1}$ when $C V\left(\varphi_{1}\right) \geq C V\left(\varphi_{2}\right)$, and $\varphi_{0}=\varphi_{2}$ otherwise.

\subsection{A program for the design of dilution assays}

The setup of a design according to the suggestions in Chapter 2 and this Chapter can be simplified by appropriate software. In Strijbosch, Does and Buurman (1988) two programs (DESIGN and EVALUATE) are described that can be used on a common microcomputer with operating system MS-DOS or PC-DOS. These programs are both applicable to LDA and SDA without restriction. The program DESIGN is useful in the laboratory prior to the pinal determination of the setup for a particular experiment and will be described in more detail. The program gives the researcher the opportunity to set up different designs "to improve a design according to several suggestlons, to make a graph of a design (see Fig. 2.2) and to evaluate the results of antificial data obtained from a random experiment corresponding with the chosen design, until he is convinced of having a suitable design for a particular experiment. The main options of this program are descibed next. DESIGN is completely menu-driven and has three different meru"s. In the Main Menu the user car choose from the options D (go to the Design Menu), I (make an illustration), S (go to the Simulation Menu), II (ask for help) and (Quit the prograny).

In the Design Menu, the five design parameters $\varphi_{1}, \varphi_{2}, P_{1}, P_{2}$, and $d$, which are initialized as in Fig. 3.1, may be altered. When the user is satisfied with the entered values, he can get the resulting design determined through $(2.1)-(2.4)$ by pressing the $\mathbb{R}$-key (Recalculate). When

$$
m>d+\log \left(\varphi_{2} / \varphi_{1}\right) / \log (c)-1
$$


DESIGN MENE

Options

$M:$ Main meru.

L : change Lower bound phil.

U : change Upper bound phi2.

d : change d.

1 : change $\mathbf{P 1}$.

CURRENT VALUES

phil $=0.000500$

phi2 $=0.005000$

$\mathrm{d}=3$

$P 1=0.150$

$\mathrm{P} 2=0.700$

Resulting Design

II $=7$

$x[1]=97.811856$

$c=1.745584$

2 : change $\mathrm{P} 2$.

$H$ : Help.

E: replace phi1 $1 \backslash 2$ by phi* $1 \backslash 2$.

phi $^{*} 1=0.000393$

phi*2 $=0.006365$

$\mathrm{p}^{* 1}=0.105$

$\mathrm{P}:$ replace $\mathrm{P} 1 \backslash 2$ by $\mathrm{P}^{*} 1 \backslash 2$.

$\mathbb{P}^{*} 2=0.568$

Choose :

F1g. 3.1. The Destgn Menu in the program DESIGN. Current values of the destgn parameters can be adjusted by choosing one or more options.

values $\varphi_{1}^{*}$ and $\varphi_{2}^{*}$ exist which satisfy $\varphi_{1}^{*}<\varphi_{1}\left\langle\varphi_{2}\left\langle\varphi_{2}^{*}\right.\right.$ and $\varphi_{1}^{*} \varphi_{2}^{*}=\varphi_{1} \varphi_{2}$ and result (with equal $d, P_{1}$ and $P_{2}$ ) in the same design (1.e. equal $m_{*} x_{1}$, and c). In that case the ultimate $p^{*}$-values are displayed in a special box with the heading "Alternatives". Another way to exploit the situation in (3.5) is a reduction of the P-range which can improve the design. In the event of (3.5). (this will generally be the case), in addition to the ${ }^{*}$-values, the $\mathrm{P}^{*}$-values as can be obtained from (3.3) are displayed as alternatives in the "Alternatives"-box. When (3.5) holds with an equality sign (for example as a result of choosing the ultimate $\varphi^{*}$-values by pressing the F-key when (3.5) is true)), it is still possible that the optimal $\mathrm{F}^{*}$-values as determined by (3.3) are not equal to the present P-values. In that case only these $\mathrm{F}^{*}$ values are displayed as altematives. In Fig. 3.1 a typical screen of the Design Menu is displayed.

Choosing the I-option in the Main Menu will cause the display of a screen in which the functions $f_{i}(\varphi)=\exp \left(-\varphi \mathrm{x}_{i}\right), i=1, \ldots$, m, representing the 
probabilities of a negative response and $g_{i}(\varphi)=P_{1}, i=1,2$, are drawn for $p E$ $\left[\varphi_{1}, \varphi_{2}\right]$. This graph is mainly illustrative. It shows various properties of the current design (see Fig. 2.2). Exactly a values of $f_{1}(\varphi), 1=1, \ldots$, are between $P_{1}$ and $P_{2}$ for each $\varphi$ whtch is the maln property of the design. Fis. 2.2 shows, for example, that a wider p-range could be chosen which maintains the same design.

In the Simulation Menu the main options are $T$ (change True $p$ ). $n$ (input $\left.n_{1}, i=1, \ldots, m\right)$. C (determine $n=n_{i}$ on the basis of a user-supplied coefficient of variation CoV according to (3.4)) and S (Start simulation). The true value of $p$ is initialized as $\left(\varphi_{1}+\varphi_{2}\right) / 2$ and can be adjusted by pressing the T-key. The numbers of replicate cultures are initialized as $n_{i}=12, i=1, \ldots, m$, and can be changed by pressing the $n-k e y$. The usersupplied coefficient of variation is altered by pressing the c-key. "The present values of $n_{i}, i=1, \ldots, m$, and $C o V$ always correspond to each other according to $(3.4)$. In other words, after Cov is changed, $n_{i}=n, i=1, \ldots, m$ holds, where $n$ is obtained from $(3.4)$; while after altering $n_{i}, i=1, \ldots, m_{\text {, }}$ $\operatorname{CoV}$ will be the maximum of $\operatorname{CV}\left(\dot{\varphi}_{1}\right)$ and $\operatorname{CV}\left(\varphi_{2}\right)$ which are obtained from (3.1) and $(3.2)$. After pressing $S$ the results of the simulation $\left(r_{1}, 1=1, \ldots, m\right.$, denoting the numbers of negatively responding cultures) are presented, as well as the values of three different estimators $\left(\hat{\varphi}_{M L}\right.$ " $\hat{\varphi}_{M C}$, and $\hat{\varphi}_{\mathrm{Je}}$, see Chapters 5 and 6) with the corresponding standard errors and $95 \%$ confidence bounds. In addition $x^{2}$ goodness-of-fit test statistics are calculated. If this statistic is significant at the $5 \%$ level, it is starred, indicating that the assumed single-hit Poisson model with the estimated value does not fit the data. When $r_{i}=n_{1}, i=1, \ldots$, or or $r_{i}=0, i=1, \ldots$, m, one-sided confidence intervals are presented (see Section 5.5). "The results of one sinulation with the design of Fig. 3.1 and with the (true) $p$ and $n=n_{1}$. $i=1, \ldots .$. , as stated in Fig. 3.2 are presented in Fig. 3.3 .

The described program is used to determine the number of dlutions, the number of cells tested per culture and the number of replicate cultures. The demanded accuracy of the assay and the a priorl information about the value of the frequency to be estimated determine the parameters mentioned above. The degree of difficulty in determining the frequency interval. in which the unknown frequency will range will depend on the type of experiment. 


\section{SIMULATION MENU}

Options

M : Main menu.

T : change True phi.

$\mathrm{n}$ : input $\mathrm{n}[\mathrm{i}], i=1, \ldots, \mathrm{m}$.

\section{CURRENT VALUES}

phi1 $=0.000500$

phi $=0.004000$

phi2 $=0.005000$

$\mathrm{CoV}=0.203404$

$\mathrm{n}[1]=12$

$\mathrm{n}\left[7^{\prime}\right]=12$

C : base $n=n[1]$ on Coefficient of variation (Cov).

S: Start simulation.

H : Help.

Choose :

F1g. 3.2. The stmulation Menu in the program DESIGN. Current values of $p$, $n_{t}, t \in 1, \ldots, m$, and CoV can be changed by choosing the appropriate option.

Changtng CoV witt change $n, t=1, \ldots, m$, and vice versa.

\begin{tabular}{|r|rrrr|}
\hline 1 & $x[i]$ & $n[i]$ & $r[i]$ & $r[i] / n[i]$ \\
\hline 1 & 97.81186 & 12 & 7 & 0.5833 \\
2 & 170.73880 & 12 & 6 & 0.5000 \\
3 & 298.03891 & 12 & 7 & 0.5833 \\
4 & 520.25193 & 12 & 0 & 0.0000 \\
5 & 908.14339 & 12 & 0 & 0.0000 \\
6 & 1585.24051 & 12 & 0 & 0.0000 \\
7 & 2767.17034 & 12 & 0 & 0.0000 \\
\hline
\end{tabular}

$\mathrm{CoV}=$

True phi $=$
0.203404

0.004000

\begin{tabular}{|c|cccccc|}
\hline \multirow{2}{*}{ Method } & Estimate & St.Error & Lower & Upper & Gof-X2 & DF \\
\hline Max.L1k & 0.004080 & 0.000764 & 0.002583 & 0.005578 & 7.108 & 6 \\
Jackkn1 & 0.003987 & 0.000704 & 0.002607 & 0.005368 & 6.957 & 6 \\
MAn.Chi & 0.003645 & 0.000658 & 0.002355 & 0.004935 & 6.702 & 6 \\
\hline
\end{tabular}

Press a key ... .

Fig. 3.3. The results of one stmulation with design parameters, true $\varphi$ and $n, t=1, \ldots$, , as stated in the Figures 3.1 and 3.2 . 
In specific situations where either only a higher or a lower frequency may be expected, it can be more economical to set up two designs : one for the higher and one for the lower potential range. Especially when the lower bound of the higher range is much larger than the upper bound of the lower range, the choice of two designs may lead to a more economical use of resources.

The program EVALUATE uses the same statistical procedures as DESICN. It reads files with experimental data on disc consisting of one or more data sets $\left\{\left(x_{i}, n_{i}, r_{i}\right)_{i=1}, \ldots, m\right)$ and calculates the three estinates with corresponding standard errors, $95 \%$ confidence bounds and goodness-of-fit statistics for each data set in the file. The results are written to disc file. 



\section{DESIGN GENERALIZATIONS}

\section{1 Introduction}

The quality of the experinental design is cructal for the accuracy of the results of the statistical anaysis. This chapter deals with the experimental design for quantal two-parameter biomedical models which describe the relation between a binary ("quantal") response and one independent variable (dose) in such a way that the dose-response relationship can be expressed as a linear regression model $y=\alpha+\beta x$ where $x$ is a function of the dose $z$ and $y$ is a function of the probubility $P(x)$ of a postitue response. A well-known example of such model is the logit regression model resulting from the logistic function $P(x)=1 / 1+1+\exp (-$ $(\cos +1))$ where $x=\log z$ and $y$ is the logt of $P(x)$ (see Ashton (1972) and Finney $(1978, p .3591)$. This model could be used to study the toxicity of a certain drug, or substance, e.g., the relationship between the dose of ar insecticide and the mortellty of a target insect species.

The one-parameter blomedical models $(\alpha=0)$ such as Limiting or Serlal Dulution Assays $[P(x)=1-\exp (-\not x)$ where $x=z$ and $y=-10$ g $(1-P(x))]$ forma special case. Design formula for this case have been proposed in chapter 2 (Subsection 2.3.2). In Section 4.2 this method will be presented in a sighty different mener in onder to fit within the context of this Chapter. An experimental design for the two-parameter model is more complicated, since the a priori. knowledge on two different parameters has to be incorporated. Suggestions for designs are given by Brown (1966). Hsi. (1969). Tsutakawa (1972, 1980) and Finney (1978, Chapter 19), Emong others. These methods do not provide formulae for design characteristics based on a priori estimates of both parameters. Here the design method for the oneparameter model as proposed in Subsection 2.3 .2 is generaljzed for the twoparameter case. Three special cases are dealt with (Subsections 4.3.2 4.3.4). A design corresponding to an example taken from the literature is compared with the design which would have been obtained when using the generalized design formulae in this case (Subsection 4.3 .5 ). 
4.2 The one-parameter blological model $y=\beta x$

In Subsection 2.3 .2 the design fortulae have been expressed in the parameters of the single-hit Poisson model using $p$ as the unknown parameter. and $\mathrm{P}_{1}$ and $\mathrm{P}_{2}$ as bounds for fraction of negative responders to be considered sufficiently informative. As in the context of this chapter the linearized models will be used, the design formulae of Subsection 2.3 .2 have to be reformulated. Furthermore, in the context of the two-parameter biological models, the sufficlently informative range can best be expressed as fractions of positive responders (cf. Section 4,1 ).

The following criterla have to be chosen by the experimenter :

(1) a lower $\left(\beta_{1}\right)$ and an upper $\left(\beta_{2}\right)$ boundary for the unknown frequency $\beta$ lo $\left.<\beta_{1} \leq \beta \leq \beta_{2}\right)$,

(ii) a lower $\left(\mathrm{P}_{1}\right)$ and an uppev $\left(\mathrm{P}_{2}\right)$ boundary for the fractions of positive replicates considered sufficiently informative $\left.10<P_{1}<P_{2}<1\right)$,

(11i) an integer number (d) of doses which will produce sufficientiy informative data as specified under (ii). (d 21$)$.

Let $y_{1}=-\operatorname{Iog}\left(1-p_{1}\right)$, and $y_{2}=-\log \left(1-P_{2}\right)$. so that $0<y_{1}<y_{2}$. Formulae (2.1)(2.4) are now transformed to

(4.1) $\mathrm{m}=\mathrm{d}+\operatorname{ENTIER}\left(\log \left(\beta_{2} / \beta_{1}\right) / \log (C)\right)$

$(4.2) \quad x_{1}=\left(y_{1} y_{2} c^{1-n 1} /\left(\beta_{1} \beta_{2}\right)\right\}^{1 / 2}$,

$(4.3) \quad c=\left\{y_{2} / y_{1}\right\}^{1 / d}$.

(4.4) $\quad x_{i}=x_{1} \mathrm{c}^{i-1}, i=2, \ldots$, n

As 1 s show in Subsection 2.3.3, the resulting assay design has the property that for each $\beta$ in the interwal $\left[\beta_{1}, \beta_{2}\right]$ exactly d values of $x_{1} \ldots \ldots x_{m}$ satisfy the following condition :

(4.5) $\quad y_{1}<\beta x_{i} \leq y_{2}, i=1, \ldots$, w. 
4.3 The two-parameter" biological model $y=\alpha+\beta x$

\subsubsection{Introduction}

After a linearizing transformation many dose-response relationships can be expressed as a linear regression model with two unknown parameters : $y=\alpha+\beta x$ where $x=\log z, z=$ dose, and $y=f(P(x)), P(x)=$ probability of $a$ positive response (see Ashton (1972) and Finney(1978)). For example the logistic model.

$$
P(x)=(1+\exp (-(\alpha+\beta x)))^{-1}
$$

can be written as

$$
y=\log (P(x) /(1-\mathbb{P}(x)))=\alpha+\beta x .
$$

As an example of the application of the logistic model, consider the study of the relationship between the dose of an insecticide and the mortality of a target insect species. A dose $x$ (actually the logarithm of the true dose) of an insecticide is given to each of in insects in a group. In order to formulate the model it is useful to assume that each insect possesses its own tolerance against a particular insecticide and dies when the dose level. exceeds the tolerance. Suppose that the tolerance $T_{j}$ of the $j$-th insect is an independent drawing from a logistic distribution identical for all insects. Then $P\left(T_{y}(x)=(1+\exp (-(\alpha+\beta x)))^{-1}\right.$.

In analogy to the design method for the one-parameter case (see section 4.2). design methods for the two-parameter case can be developed for the situations that a priori the following is available : elther a point estimate for $\alpha$ and an interval. estimate for $\beta$ (Subsection 4.3.2), or a point estimate for $\beta$ and an interval estimate for $\alpha$ (Subsection 4.3.3). $0^{\circ}$ interval estimates for both $\alpha$ and $\beta$ (Subsection 4.3 .4 ). 
4.3.2 The case $\alpha=\alpha_{0}$ and $\beta \in\left[\beta_{1}, \beta_{2}\right]$

Suppose that $\alpha_{0}$ is a point estimate for $\alpha$ and that $\left[\beta_{1} * \beta_{2}\right]$ is an

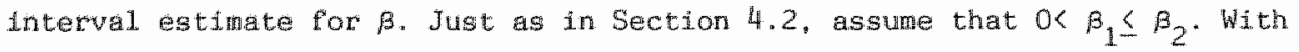
respect to $\alpha_{0}$, the more interesting, and at the same time more complicated, case where $\alpha_{0}<y_{1}<y_{2}$ will be investigated. The interval $\left[y_{1}, y_{2}\right]$ is based on the interval $\left[P_{1}, P_{2}\right]$. The $P_{1}$ and $P_{2}$ mark sufficiently informative range for fractions of positive responders. The design formulae $(4.1)-(4.4)$ can then be applied directly:

$$
m=d+\operatorname{ENTIER}\left(\log \left(\beta_{2} / \beta_{1}\right) / \log (c)\right)
$$

$$
x_{1}=\left[\left(y_{1}-\alpha_{0}\right)\left(y_{2}-\alpha_{0}\right) c^{1-m} /\left(\beta_{1} \beta_{2}\right)\right]^{1 / 2} .
$$

(4.10) $\quad c=\left[\frac{y_{2}-\alpha_{0}}{y_{1}-\alpha_{0}}\right]^{1 / d}$.

$$
x_{i}=x_{1} c^{i-1}, i=2, \ldots, m \text {. }
$$

The property of the resulting design is that for each $\beta \in\left[\beta_{1}, \beta_{2}\right]$ exactly $d$ values of $x_{1} \ldots, x_{m}$ satisfy the condition $y_{1}<\alpha_{0}+\beta x_{1} \leq y_{2}$. Note that for the doses determined by this design we may write:

(4.12) $z_{i}=z_{i-1}^{c}$,

which means that the original doses should be chosen equidistantly on a loglog-scale. This is remarkable, since in most literature (see Brown (1966). Tsutekawa $(1972,1980)$. Finney (1978), Hamilton $(1979,1980))$ doses, equidistant on the log-scale, are recommended or used in Monte Carlo experiments "Brown (1966) proposed a procedure for using available information to design a quantal assay of the potency of a test preparation relative to standard preparation. The probabilities of response to the two preparations for varying log-doses were considered well-approximated by cumulative normal distributions with common standard deviation $\sigma$ and means denoted by $\mu_{T}$ and $\mu_{S}$, respectively. For the potency $(\rho)$ of the test 
preparation relative to the standard preparation the relation $\log (p)=\mu_{S}-$ $\mu_{\mathrm{T}}$ holds. Brown (1966) assumed the prior information avallable to be represented as lower and upper bounds for the parameters o, $\mu_{S}$ and $\log (\rho)$. His design proposal was based on this prior information and included suggestions for the extreme log-doses of both standard and test preparation and for the spacing of the log-doses which he assumed to be equal. Finney (1978) advocated symmetric designs in general since they are usually easier to effectuate and analyze statistically. Tsutakawa (1980) presented experimental designs for estimating an extreme percentage point of a logistic distribution when the location and scale parameters are unknown. His method has been based on a prior distribution of the parameters and a predicted value of posterior variance. The numerical results in his paper are restricted primarily to designs with equally spaced levels. As (4.8)(4.12) show, doses equidistant on the log-scale are inappropriate if a good a priori estimate for $\alpha$ is available and if one requires a design which has the above-mentioned property, namely, for each $\beta \in\left[\beta_{1}, \beta_{2}\right]$ exact $] y$ d values of $x_{1}, \ldots, x_{m}$ satisfy the condition $y_{1}<\alpha_{0}+\beta x_{i} \leq y_{2}$.

Finally, in the remaining case $y_{1} \leq \alpha_{0} \leq y_{2}$, it is easy to see that $\mathrm{m}=d$, while the $x_{i}^{\prime} s, i=1, \ldots, d$, merely need to satisfy : $y_{1}<\alpha_{0}+\beta_{2} x_{1} \leq y_{2}$. $i=1, \ldots, d$.

\subsubsection{The case $\alpha \in\left[\alpha_{1}, \alpha_{2}\right]$ and $\beta=\beta_{0}$}

Suppose that $\left[\alpha_{1}, \alpha_{2}\right]$ is an interval estimate for $\alpha$ and that $\beta_{0}$ is a point estimate for $\beta$. As before, suppose that $\left[y_{1}, y_{2}\right]$ marks a sufficiently informative range. Then the following design formulae can be deduced fron $(4.1)-(4.4):$

$$
m=d+\operatorname{ENTIER}\left(\left(\alpha_{2}-\alpha_{1}\right) / e\right)
$$

$$
x_{1}=\left(y_{1}+y_{2}-\alpha_{1}-\alpha_{2}+e(1-m)\right) /\left(2 \beta_{0}\right) \text {. }
$$

(4.15) $e=\left(y_{2}-y_{1}\right) / d_{n}$

(4.16) $\quad x_{i}=x_{1}+(i-1) e / \beta_{0}, i=2, \ldots$, m. 
This follows from the trangformations $y^{*}=e^{y}, \beta^{*}=e^{\alpha}, x^{*}=e^{\beta_{0}}$ and applying $(4.1)-(4.4)$ to the model $y^{*}=\beta^{*} x^{*}$. The property of the resulting design is that for each of $\in\left[\alpha_{1}, \alpha_{2}\right]$ exactly $d$ values of $x_{1}, \ldots, x_{\text {m }}$ satisfy the condition $y_{1}<\alpha+\beta_{0} x_{1} \leq y_{2}$. Wate thet doses are equidistant on the logscale.

\subsubsection{The case $\alpha \in\left[\alpha_{1}, \alpha_{2}\right]$ and $\beta \in\left[\beta_{1}, \beta_{2}\right]$}

Fig. 4.1 illustrates the construction of the design formulae in this Subsection. Suppose that $\left[\alpha_{1}, \alpha_{2}\right]$ and $\left[\beta_{1}, \beta_{2}\right]$ are interval estimates for $\alpha$ and $\beta$ respectively such that $\alpha_{1}<\alpha_{2}<y_{1}, 0<\beta_{1}<\beta_{2}$ and $\beta_{1} / \beta_{2} \leq\left(y_{2}-\alpha_{2}\right) /\left(y_{2}-\alpha_{1}\right)$.

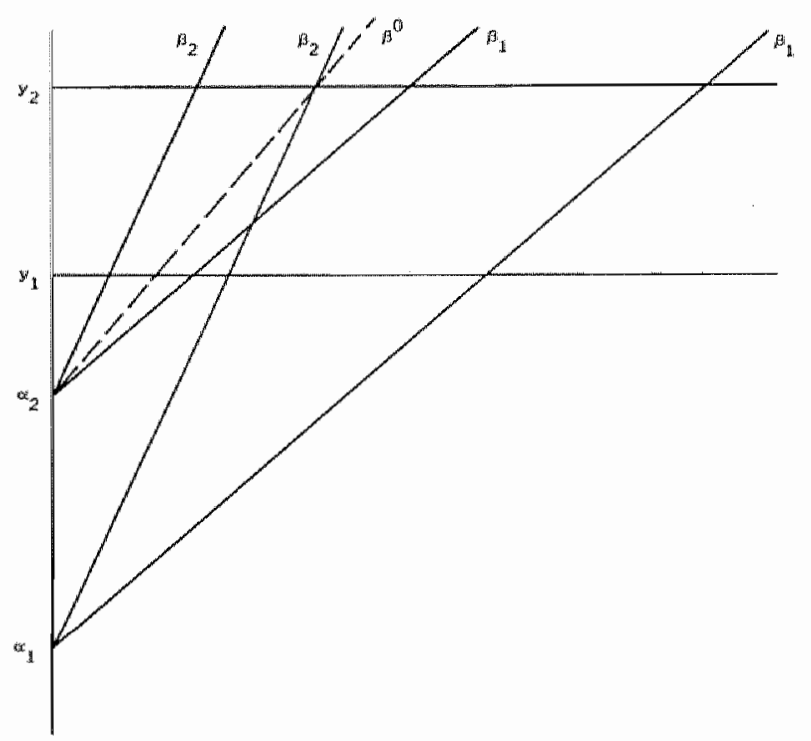

$\mathrm{Fig}$. 4.1. Illustration of the conditions for the construction of the design method in Subsection 4.3.4.

"This configuration corresponds to the situation which is of primary interest and will be investigated analogously to Subsection 4.3.2. The last condition means that the slope $\left(\beta^{a}\right)$ of the line through the points $\left(0, \alpha_{2}\right)$ and $\left(\left(y_{2}-\alpha_{1}\right) / \beta_{2}, y_{2}\right)$ is greater than or equal to $\beta_{1}$. Then, combining the results of the two preceding Subsections, a method can be devised. Firstly. the approximate number of doses is determined. Applying $(4.8)-(4.11)$ with 
$\alpha_{0}=\alpha_{1}$ yields $m_{1}$ and $c_{1}$. In order to cover all remaining combinations of $\alpha$ and $\beta$, it is sufficient to extend the desigm applying $(4.8)-(4.11)$ once more on $y=\alpha_{2}+\beta x$ with $\beta \in\left[\beta^{0}, \beta_{2}\right]$ where $\beta^{0}=\beta_{2}\left(y_{2}-\alpha_{2}\right) /\left(y_{2}-\alpha_{1}\right)$. This leads to values for $m_{2}$ and $c_{2}$. Since the $m_{1}$ and $m_{2}$ doses overlap an interval corresponding: with d doses, $m=m_{1}+m_{2}-d$ doses are needed for a design with the property that at least $d$ values satisfy $y_{1}<\alpha+\beta x_{i} \leq y_{2}$ (for any $\alpha \in\left[\alpha_{1}, \alpha_{2}\right]$ and $\beta E$ $\left.\left[\beta_{1}, \beta_{2}\right]\right)$. It is not possible to construct a design with the property that exactly d values satisfy this condition. Consider, for example, a configuration which satisfies $\left(y_{1}-\alpha_{2}\right) / \beta_{1}=\left(y_{1}-\alpha_{1}\right) / \beta_{2}$. Then, assuming that we have exactly d values which satisfy the condition for $(\alpha, \beta), \beta \in\left[\beta_{1}, \beta_{2}\right]$, it is, as is 1llustrated in Fig. 4.2, easy to see that the parameters can be chosen such that (many) more than d values satisfy the condition for $\left(\alpha_{2}, \beta_{1}\right)$.

It follows that

$$
\begin{aligned}
\mathrm{m}=\mathrm{d}+ & \operatorname{ENTIER}\left(\log \left(\beta_{2} / \beta_{1}\right) / \log \left(c_{1}\right)\right)+ \\
& \operatorname{ENTIER}\left(\log \left(\left(y_{2}-\alpha_{1}\right) /\left(y_{2}-\alpha_{2}\right)\right) / \log \left(c_{2}\right)\right) .
\end{aligned}
$$

where

$$
c_{1}=\left\{\left(y_{2}-\alpha_{1}\right) /\left(y_{1}-\alpha_{1}\right)\right\}^{1 / d}
$$

and

(4.19) $\quad c_{2}=\left\{\left(y_{2}-\alpha_{2}\right) /\left(y_{1}-\alpha_{2}\right)\right\}^{1 / d}$.

Obvious choices for $x_{1}$ and $x_{m}$ are

(4.20) $\quad x_{1}=\left(y_{2}-\alpha_{2}\right) c_{2}^{1-d / \beta_{2}}$.

and

$$
x_{m}=\left(y_{1}-\alpha_{1}\right) c_{1}^{d-1} / \beta_{1} .
$$

Now, it follows from the results of the Subsections 4.3 .2 and 4.3 .3 , that the cholce of $x_{i}, 1=2, \ldots, m-1$, should depend on the ratio of the lengths of the intervals $\left[\alpha_{1}, \alpha_{2}\right]$ and $\left[\beta_{1}, \beta_{2}\right]$. When the first is large and the second $1 \mathrm{~s}$ small, equidistant values for $x_{i}, i=1, \ldots, m$, are advisable, whereas in the 


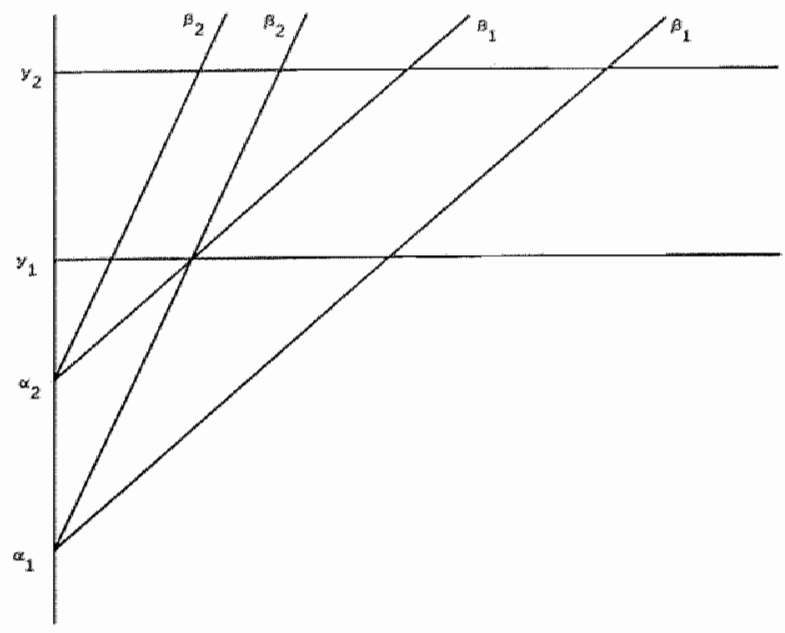

Fig. 4.2. A configuration which shows that tit is impossible to construct a desigm with the property that for each $\left(\alpha_{1}, \beta\right) \in\left[\alpha_{1}, \alpha_{2}\right] *\left[\beta_{1}, \beta_{2}\right]$ exactly $d$ values of $x_{1}, \ldots, x_{m}$ satisfy the condition $y_{1}<\alpha+\beta x_{i} \leq y_{2}$.

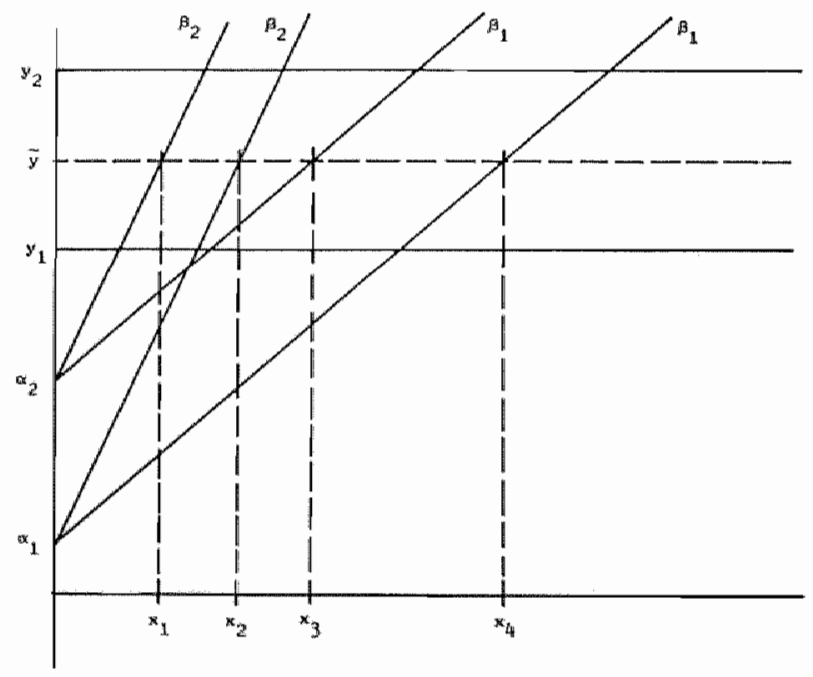

Fig. 4.3. The motivation of the chotce for the weights of translation and rotation in the construction of the design formulae (4.22)-(4.24). 
opposite case a geometrical series is preferabie. Combining these ideas, the following design formulae are proposed :

$$
\begin{aligned}
& x_{i}=\left[T\left[x_{1}+\left(x_{i m}-x_{1}\right)(i-1) /(m-1)\right]+\mathbb{R} x_{1}\left(x_{m} / x_{1}\right)(i-1) /(m-1)\right] /(T+\mathbb{R}) . \\
& 1=2, \ldots, \mathbb{m}-1,
\end{aligned}
$$

where

$$
T=\left(\alpha_{2}-\alpha_{1}\right) /\left(y_{1}+y_{2}-\alpha_{1}-\alpha_{2}\right)
$$

and

$$
R=\left(\beta_{2}-\beta_{1}\right) /\left(\beta_{1}+\beta_{2}\right)
$$

The choice of the weights $T$ (for translation) and $\mathbb{R}$ (for rotation) 1 s illustrated in Fig. 4.3 and can be motivated as follows. The design formulae of Subsection $4.3 .2\left(\alpha_{1}=\alpha_{2}=\alpha_{0}\right)$ could be found by studying the effect of rotation of the line $y=\alpha_{0}{ }^{* \beta x}$ around the point $\left(0, \alpha_{0}\right)$, on the log-doses. Accordingly, the design formulae of Subsection 4.3 .3 $\left(\beta_{1}=\beta_{2}=\beta_{0}\right)$ could be found by studying the effect of translation of the line $y=\alpha+\beta_{0} x$ from $y=\alpha_{1}+\beta_{0} x$ to $y=\alpha_{2}+\beta_{0} x$ on the log-doses. These effects must be quantified somehow in order to determine the weights $R$ and $T$. Since the effect of rotation is different for $y_{1}$ and $y_{2}$, all effects are considered for $\hat{y}=\left(y_{1}+y_{2}\right) / 2$ only. Furthermore, the effects of rotation for $\alpha=\alpha_{1}$ and $\alpha=\alpha_{2}$, respectively, are accumulated, as well as are the effects of translation for $\beta=\beta_{1}$ and $\beta=\beta_{2}$, respectively. Thus, the effect of rotation can be expressed as $\left(x_{3}-x_{1}\right)+\left(x_{4}-x_{2}\right)$. whereas the effect of transiation 15 $\left(x_{4}-x_{3}\right)+\left(x_{2}-x_{1}\right)$. Since $x_{1}=\left(\tilde{y}-\alpha_{2}\right) / \beta_{2}, x_{2}=\left(\tilde{y}-\alpha_{1}\right) / \beta_{2}, x_{3}=\left(\tilde{y}-\alpha_{2}\right) / \beta_{1}$ and $x_{4}=\left(\tilde{y}-\alpha_{1}\right) / \beta_{1}$, the quotient of $R$ and $T$ is :

$$
\frac{R}{T}=\frac{\left(\beta_{2}-\beta_{1}\right)\left(y_{1}+y_{2}-\alpha_{1}-\alpha_{2}\right)}{\left(\alpha_{2}-\alpha_{1}\right)\left(\beta_{1}+\beta_{2}\right)} .
$$

Hence, $(4.23)$ and $(4.24)$ represent possible choices for $R$ and $T$.

For this design we have found that for each $\left(\alpha_{*}, \beta\right) \in\left[\alpha_{1}, \alpha_{2}\right]^{*}\left[\beta_{1}, \beta_{2}\right]$ the number of values $x_{1} \ldots x_{m}$ which satisfy the condition $y_{1}<\alpha+\beta x_{1} \leq y_{2}$ is approximately $\alpha$. However, in the vicinity of $\left(\alpha_{1}, \beta_{1}\right)$ and $\left(\alpha_{2}, \beta_{2}\right)$ this number 

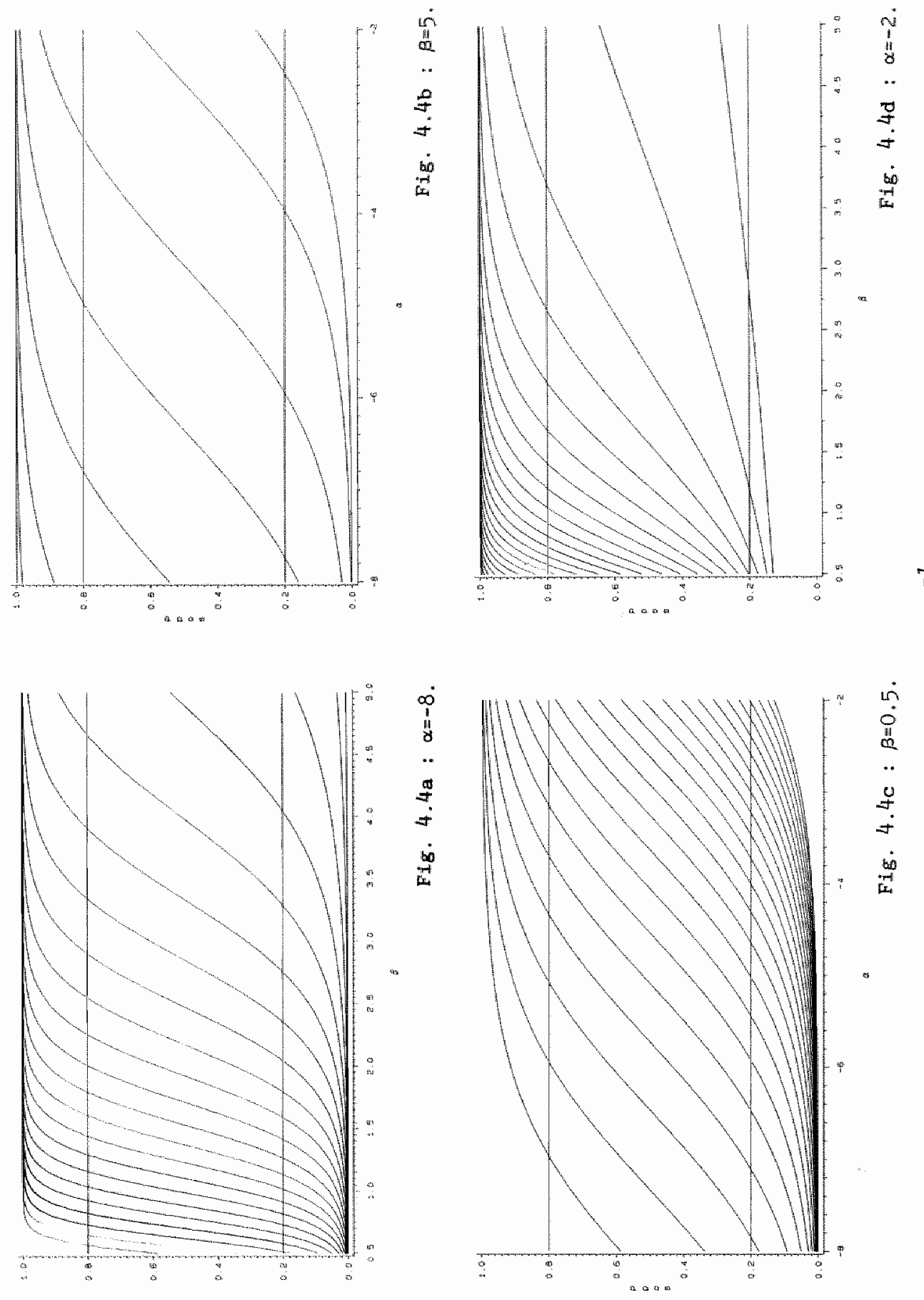

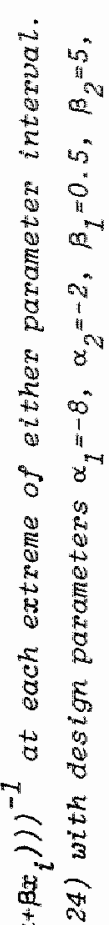

i.

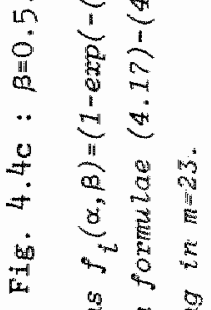

类

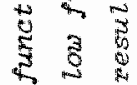

a 0

एक

S E

葛

$\dot{x} a^{N}$

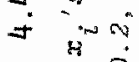

$a^{10} 0^{11}$ 
is often d-1. while near $\left(\alpha_{2}, \beta_{1}\right)$ it can be much larger than $d$. If not both conditions $\alpha_{1}<\alpha_{2}<y_{1}$ and $\beta_{1} / \beta_{2} \leq\left(y_{2}-\alpha_{2}\right) /\left(y_{2}-\alpha_{1}\right)$ are satisfied, altemetives for the formulae $(4.17)-(4.24)$ are possible applying the same concepts. In the next Subsection a design taken from the literature will be compared with the design obtained when applying one of the design methods proposed in Section 4.3.

Analogous to Fig. 2.2 for the one-parameter design. Figures $4.4 a-4.4 d$ illustrate the properties of the two-parameter design according to the formulae $(4.17)-(4.24)$. The design parameters used are $\alpha_{1}=-8, \alpha_{2}=-2, \beta_{1}=0.5$. $\beta_{2}=5, P_{1}=0.2, P_{2}=0.8$ and $d=3$ resulting in $m=23$. The functions $f_{1}(\alpha, \beta)=$ $\left.\left(1+\exp \left(-\alpha+\beta x_{i}\right)\right)\right)^{-1}, i=1, \ldots, m$, are drawn for $\alpha=-8$ and $\beta E[0.5 .5]$ (Fig. 4. 4a), $\alpha \in[-8,-2]$ and $\beta=5$ (Fig. 4.4b), $\alpha \in[-8,-2]$ and $\beta=0.5$ (Fig. 4.4c), $\alpha=-2$ and $\beta E[0.5 .5](F i g .4 .4 d)$.

\subsubsection{Applications of the proposed designs}

In this Subsection it will be investigated which parameter choices in the design methods will approximately reproduce the design used in an example taken from the literature, thus throwing some light on the circumstances under which such designs are suitable. The example illustrates the design method of Subsection 4.3 .4 .

\section{Berkson}

As an alternative to the ML method for the estimation of the parameters $\alpha$ and $\beta$, Berkson (1944) proposed the criterturn "Minimum Logit $x^{2}$ " "This modified definition of $x^{2}$ only applies to the logistic function end enables minimization to be accomplished in one stage without iteration. In order to 111ustrate his method Berkson (1944) presented in his Table I an experiment. with doses $40,60,80,100,120,140,160,180,200,250,300$. From the recorded experiment, essuming the logistic model (4.6). estimates $\hat{\alpha}=-10.33$ and $\hat{\beta}=5.66$ are obtained. Since he uses the transformation $x=\log _{10}(z)$. $\hat{\beta}=5.66 / \log (10)=2.46$ must be used here. Applying $(4.17)-(4.24)$ with $\alpha_{1}=-11$, $\alpha_{2}=-10, \beta_{1}=2, \beta_{2}=3, d=4, P_{1}=0.2$ and $P_{2}=0.8$, doses 22, 27, 34, 43, 55.72, 95. 126, $172,238,335$ result. Note that none of the design methods discussed in this Chapter could produce equidistant doses. 


\section{Altermative choices for $x$, and $x$}

When it is fmportant that for all considered parameter values $\alpha$ and $\beta$, the proportions of positive responders in an experiment vary from $P_{1}$ to $\mathbb{P}_{2}$. better choices for $x_{1}$ and $x_{m}$ (instead of $(4.20)$ and (4.21), respectively) are $x_{1}=\left(y_{1}-\alpha_{2}\right) / \beta_{2}$ and $x_{1}=\left(y_{2}-\alpha_{1}\right) / \beta_{1}$ (see Fig. 4.1). This is the case. for example when the Spearman-Karber method is applied to estimate the $E_{50}$ (median effective dose) which refers to the log-dose that on the average produces a response in 50\% of the subjects. The corresponding statistic (see Spearman (1908) and Karber (1931)) is given by

(4.26) $\quad \sum_{i=1}^{\text {III }}\left(p_{i+1}-p_{i}\right)\left(x_{i}+x_{i+1}\right) / 2$,

where $p_{1}$ denotes the proportion of positively responding subjects at $x_{1}$, and thus $\left(p_{1+1}-p_{1}\right)$ is an estimator of the proportion of subjects whose tolerances 1 ie between $x_{1}$ and $x_{i+1}$. Conditions for the application of the Spearman-Kurber method to estimate $E D_{50}$ are that $\mathrm{p}_{1}=0, \mathrm{p}_{\mathrm{m}}=1$, the intervals between the $x_{i}, i=1, \ldots, m$, are not too wide, and the underlying tolerance distribution is symetric. When for some $i$ the quantity $\left(p_{i+1}-p_{i}\right)$ is negative (due to sanpling variation), groups should be combined in order to clear the data from such irregularities prior to the application of the formula. However, not auch is known about the small sample properties of the Spearman-Karber statistic when applied to experimental data as obtained from a desfgrn with unequally spaced log-doses with respect to other commonly used statistics such as the ML statistic.

\section{Estimating the ED}

In estimating the $E D_{\gamma}$ where $\gamma$ is close to 0 of 1 , it is considered important (see Wetherild. (1963)) to locate the doses around the ED $\gamma$."This can easily be achieved by choosing $P_{1}$ and $P_{2}$ such that $P_{1}<\gamma<P_{2}$ and applying the most appropriate desigm method of this Chapter. 


\section{CONVENTIONAL ESTIMATION METHODS}

\subsection{Introduction}

In this Chapter two conventional statistical procedures, i.e. the Maximum Likel hood (ML) method and the Minimum Chi-square (MC) method, for the evaluation of the experimental data in dilution analysis will be described. Most of the literature published on dilution series has been devoted to methods for estimating the unknown parameter. Recent references to this literature are Finney (1978), Salama, Koch and Tolley (1978), Taswell (1981), Loyer (1981). Fazekas de St. Groth (1982), Loyer and Hamilton (1984) and Taswe11 (1987) among other's.

Finney (1947,1951 and 1978, p. 430) proposed a ML estimation procedure that solves the ML equation with iterative approximation based on a $10 \mathrm{~g}-\log$ transformation (Mather (1949)). From this method the same estimated value of the unknown parameter is obtained as from the straightforward ML method presented in Section 5.3. However, different confidence bounds are found, since Finney"s method produces an estimator of $\operatorname{var}(\log (\hat{\varphi}))$, while the straightforward ML method produces an estimator of $\operatorname{var}(\hat{\varphi})$.

Taswel1 (1981) compared four statistical procedures for the estimation of the unknown parameter in dilution series with Monte Carlo sinulation. These methods are the Least Squares (LS) method, the Weighted Mean (WM) method, the ML method and the MC method. A formula for the LS estimate of $p$ can be obtained by epplying the standard unwelghted least squares regression procedure on $\log (p)=-\infty x$ where $p=r / n$ and $r$ is the number of negative responders. As noted by Taswell (1981) and Fazekas de St. Groth (1982) there are several reasons why this formerly used method should not be applied in dilution analysis. In the first place, the usual assumptions of the linear regression model are not satisfied. Another reason is that the use of $p_{i}=r_{i} / n_{i}$ without incorporating $n_{i}$ in the statistical procedure results in a loss of information. Lefkovits and Waldmann (1984) did not see objections in. using the LS method instead of the ML or MC method arguing that "in most blological experiments we are not trying to find some physical constants whose definition has to be absolutely precise". However, in full agreement 
wth Taswell (1987), the fact that biological experiments are not physical experiments with accurate adjustments of instruments but rather represent roughly approximate assessments of biological activities does not justify Indiference with respect to the choice of the estimation method to be used. With an inaccurate statistical method as the LS method experimental results can generally only become worse. Some problems of the LS method are resolved by the WM method which ls obtained by weighting the individual estimates $\hat{\phi}_{\mathbb{1}}=-\log \left(\mathrm{p}_{1}\right) / \mathrm{x}_{\mathbb{1}}$ with terms related to their respective variances and taking: theil mean. However, this method is also statistically inappropriate.

Taswell (1981) found that the four estimators can be ranked in the following order by decreasing bias and mean square error : LS, WM, ML and MC. There is no doubt that the last two methods are preferable to the other two. However, regarding the comparison of the ML and MC method, the meaning of the conclustons of Taswel1 (1981) cannot be fully understood "since it is not entirely clear which experimental designs he used in the simulations (see Chapter 7). Obviously, the properties of statistical methods are dependent on the experimental design used.

Loyer (1981) compared the expected values and exact mean square errors of the ML estimator with those of some alternative estimators which will be discussed brlefly. An estimator $\left(\hat{\varphi}_{C}\right)$ described by Thamas (1955) simply adjusts the ML estimator with the correction factor exp $(-0.805 / \mathrm{n})$. Since the bias of the ML estimator is undoubtedly dependent on both $\mathrm{n}$ and the rest of the design parameters (see Chapter 2), use of this estimator in only special designs would be appropriate. Fisher (1922) described an estimator $\left(\hat{\varphi}_{F}\right)$ which is based on the total number of negative responders $\left(\Sigma r_{i}\right)$. Fisher showed hils estimator to be $87.7 \%$ efficient, consequently only computational corvenience could justify general use of this method. Thomas (1942) described an estimator $\left(\hat{\varphi}_{\mathrm{T}}\right)$ which is the geometric mean of the estimators obtained by using the approximations $\exp \left(-\varphi_{x}\right) \cong\left(1-\varphi_{x}\right)$ and $\exp \left(-\varphi_{x}\right) \cong$ $1 /\left(1+\varphi_{\mathrm{x}}\right)$ in the derivative of the log-likelihood function. Finally, Johnson and Brown (1961) described an estimator $\left(\hat{\varphi}_{\mathrm{J}}\right)$ which, like Fisher's estimator. uses only the total number of negative responders and is also $87.7 \%$ efficient. For similar reasons, as advanced before, the last two estimators should not generally be used when adequate computer facilities are available. Loyer (1981) used the following (small) designs for the comparison of the statistical methods described : $m=3, n=3,5$ and $10, c=2,4$ 
and 10, and $x_{2}=0.01$. As he stated, these nine experinental designs should cover vintually all $=3$ serial dilution setting found in the literature and should be apropriate for $\varphi \equiv 160$. The comparisons have been made for $p=10(10) 300$. The designs with $c=4$ and $c=10$ would have been obtained with $(2.1)-(2.4)$ using $\varphi_{1}=10, \phi_{2}=300, d=1, P_{1}=0.3344, P_{2}=0.7604$, and $\varphi_{1}=10$. $p_{2}=300, d=2, P_{1}=0.0042, P_{2}=0.9467$, respectively. The design with c=2 could not be obtained with $(2.1)-(2.4)$ since $d=3-\mathbb{E N T I E R}(\log (30) / \log (2))$ is $10 \mathrm{~s}$ than 1. Loyer (1981) finds that no single estimator performs best across all designs. He states that, in general, $\hat{\varphi}_{\mathrm{T}}$ performed best at "high" ailution factors $(c=10)$ " $\hat{\varphi}_{\mathrm{J}}$ performed best at "intermediate" dilution factors (cal) and $\hat{\varphi}_{\mathrm{C}}$ performed best at "low" dilution factors $(\mathrm{c}=2)$. As the considered estimators seem to be most useful for the very small designs mentioned just above, they are not considered in this chapter. The main interest here pertains to LDA where designs are usually larger.

Fazekas de St. Groth (1982) advanced several arguments for the use of ML methods instead of MC methods. He proposed the ML estimation procedure as set out in detail in Finney (1978).

Loyer and Hamilton (1984) payed attention to interval estimation procedures commonly applied to small (standard) serial dilution experiments and based on exact probabilities. Furthermore they of fer an alternative method for the calculation of two-sided confidence intervals.

Taswe11 (1987) repeats the conclusions of his 1981 paper. Criticism (see Fazekas de St, Groth (1982)) and other reactions (see Mi11er (1982) and Lefkovits and Waldmann (1984)) are discussed and suggestions are made for the Monte Carlo comparison of estimation methods in dilution andiysis (soe Chapter 7).

After intraducing in Section 5.2 the notetion to be used. Section 5.3 $1 \mathrm{~s}$ devoted to the ML method and Section 5.4. to the MC method. Finglhy, 1n Section 5.5. some remarks on (one-sided) confidence intervals are given. 


\subsection{Notation}

First some notation will be (re) introduced. The design parameters in dilution experinents are denoted by m (1,e. the number of groups of replicate cultures), $x_{1}$ (1.e. the (mean) number of cells tested in replicate culture group 1 ) and $n_{1}$ (1.e. the number of replicate cultures for group i). $1=1, \ldots . .$, Fur therwore let $p$ denote the unknown frequency. The blometrical model can be formulated as follow:

$$
\begin{array}{llll}
Y_{11} & Y_{12} & \cdots & Y_{1 n_{1}} \\
Y_{21} & Y_{22} & \cdots & Y_{2 n_{2}}
\end{array}
$$

$$
\begin{array}{cccc}
* & \cdot & & \cdot \\
Y_{m 1} & Y_{\mathrm{m} 2} & \ldots & Y_{\mathrm{mn}} \\
Y_{\mathrm{m}}
\end{array}
$$

where the $Y_{i j}$ are independent Bernoulli-distributed randon variables with $P\left(Y_{i j}=0\right)=1-P\left(Y_{i j}=1\right)=\exp \left(-y p x_{i}\right), i=1, \ldots, m, j=1, \ldots, n_{i}$ lcf. Does, Strijbosch and Buurman $(1988))$. A negative response for a replicate culture is thus denoted by zero. From grounds of sufficiency it follows that the relevant observations from a limiting dilution assay consist of the Independent binomial random variables $R_{i}$ which are defined by $\mathbb{R}_{1}=\sum_{j=1}^{n_{i}}$ (1$\left.Y_{i j}\right)$, i.e. $R_{i} \sim \operatorname{Bin}\left(n_{i}, \exp \left(-\operatorname{\varphi xx}_{i}\right)\right), i=1, \ldots, m$. The vector $\left(R_{1}, \ldots, R_{m}\right)$ will be denoted by $\underline{R}$. Furthermore let $n_{i}-R_{i}$ be denoted by $Q_{1}$ and $\left(Q_{1}, \ldots, Q_{m}\right)$ by $\underline{Q}$.

\subsection{The maximum 1ikel thood (ML) method}

\section{3 .1 Introduction}

One of the most important and most used methods in dllution analysis is the ML estination procedure. The corresponding estimator is often called the "most probable number" as introduced by McCrady (1915). The method of ML together with other principles of estimation, is presented with the required rigor in texts on statistical theory (e.g. Kendall and Stuart (1973)). Some of its main properties are asymptotic sufficiency, efficiency and 
consistency. It is clear that this method in dilution series is advocated by many authors such as Mather (1949). Peto (1953). Fazekas de St. Groth (1982) and Burman, Daemen, Groenewegen et al. (1983). One of the shortcomings of the ML method is that it leads to biased estimators. The positive bias of the ML estimator is well known by researchers in the field (see Eisenhart and Wilson (1943). Thomas and Woodward (1955). McCarthy. Thomas and Delaney (1958)). Special attention has been given in the literature to the bias of the ML estimator in small designs like the design with small $\mathrm{n}$ and $\mathrm{m}=3$ which is comonly used in serial dilution assays : Johnson and Brown (1961) gave mathematical approximations expressing the bias in the serial dilution problem as being related to the number of replicates: Salama, Koch and Tolley (1978) calculated exact biases of about $10 \%$ for $m=3$ decimal solutions $(\mathrm{c}=10)$ with $\mathrm{n}=10$ replicates per culture group.

\subsubsection{The ML estimation procedure}

The ML estimator $\hat{\varphi}_{M L}$ is determined as the value of $\varphi$ that maximizes

$$
\log L(\varphi)=\Sigma_{i=1}^{m} \sum_{j=1}^{n_{i}}\left\{-\left(1-Y_{i j}\right) \varphi x_{i}+Y_{1 j} \log \left(1-\exp \left(-\varphi x_{i}\right)\right)\right\}
$$

or

$$
\left.\log L(\varphi)=\Sigma_{i=1}^{m}\left\{-R_{i} \varphi_{x_{i}}+Q_{i}\right] \log \left(1-\exp \left(-\varphi x_{i}\right)\right)\right\}
$$

where $L(\varphi)$ denotes the relevant part of the likelihood function. The velue of $p$ that maximizes $\log L(\varphi)$ is usually calculated by Newton's method of iterative approximation (see e.g. Daellenbach, George and McNickle (1983). p. 576) :

$$
\text { (5.4) } \quad \hat{\varphi}_{k+1}=\hat{\varphi}_{k}-\left.\frac{\partial \log L(\varphi) / \partial \varphi}{\partial^{2} \log L(\varphi) / \partial \varphi^{2}}\right|_{\hat{\varphi}_{k}}
$$

where

$$
\partial \log L(\varphi) / \partial \varphi=\sum_{i=1}\left(-R_{i} x_{i}+Q_{i} x_{i} \exp \left(-\varphi x_{i}\right) /\left(1-\exp \left(-\varphi x_{1}\right)\right)\right\}
$$


and

$$
\partial^{2} \operatorname{logL}(\varphi) / \partial p^{2}=\Sigma_{i=1}^{n}\left\{-Q_{i} x_{i}^{2} \exp \left(-\varphi x_{i}\right) /\left(1-\exp \left(-\varphi x_{i}\right)\right)^{2}\right\}
$$

The formula for the Fisher information (3.1) is found as follows. Let $p_{i}=$ $\exp \left(-\omega_{1}\right), i=1, \ldots, m$, and $\log L(\varphi)=\tau(\varphi)=\sum_{1=1}^{m} t_{i}(\varphi)$. Moreover, Iet ' denote the partial derivation with respect to $\varphi$. Then $l_{i}(\varphi)=\mathrm{R}_{i} \log \left(\mathrm{p}_{i}\right)+$ $\left(n_{1}-R_{i}\right) \log \left(1-p_{1}\right)$ and $l_{i}^{n}(\varphi)=\left(R_{i}-n_{i} p_{i}\right) p_{i}^{i} /\left(p_{i}\left(1-p_{1}\right)\right)$. Thus $I(\varphi)=$

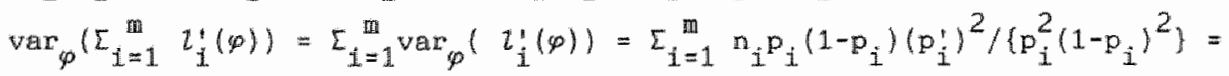
$\sum_{i=1}^{m} n_{1} x_{i}^{2} /\left(\exp \left(\varphi x_{1}\right)-1\right)$

A serious problem might seem to arise with the ML estimation pracedure. If ald $\mathbb{R}_{\mathcal{L}}$ are 0 , which event occurs with an (extremely) small but undeniably positive probability, then $\hat{p}_{M L}=\infty$, and hence $E_{\hat{p}_{M L}}=\infty$, thus leading to an infinite, rather than an asymtotically negligibie, bias. This undesirable phenomenon can be eliminated by the following simple modification which wiI be tachtly assumed hereafter : If all $R_{1}$ indeed happen to be 0 , then modify $\hat{\varphi}_{M L}$ by replactrig an arbitrary $Y_{i y}$, say one corresponding with the smallest $x_{1}$. by 0 . In Subsection 5.3 .3 It is demonstrated by wey of example for the case $n=1$ that this simple modification suffices to reduce the bias from infinity to the desired order $n_{\mathbb{1}}^{-1}$.

Evaluated at $\hat{\varphi}_{M L}$, formula $(5.6)$ provides an approximation of -I $(\varphi)$ where $I(\varphi)$ denotes the Fisher information (see section 3.2). An estimator of the varience of $\hat{\varphi}_{M L}$ is given by

$$
S^{2}\left(\hat{\varphi}_{M L}\right)=\left.\frac{-1}{\partial^{2} \operatorname{logL}(\varphi) / \partial \varphi^{2}}\right|_{\hat{\varphi}_{M L}} .
$$

\subsubsection{Reducing the bias of the ML estimator from infinity to the desired order}

In this Subsection it will be shown for the case nu=1 that the modified ML estimator (see Subsection 5.3 .2 ) has a finite bias. Let $R$ be a binomil distributed variable with parameters $n$ and $p$ where $p=\exp (-\varphi)$ with $0<p<1$. Clearly, for $\varphi$ the ML estimator $\hat{\varphi}=-\log \hat{p}=-\log (R / n)$ will have $E \hat{\varphi}$ $=\infty$. However, let $X=\max (1, \mathbb{R})$ and set $\tilde{\varphi}=-\log (X / n)$. Then $E(\tilde{\varphi}-\varphi)=0\left(n^{-1}\right)$ as desired. 
To prove this statement observe that

$$
\begin{aligned}
E(\widetilde{\varphi}-\varphi) & =-E[\log (X / n)-\operatorname{Iog} p\}=-E\{\log (1+Z)] \\
& \approx-E\left\{Z-Z^{2}(1+\Theta Z)^{-2} / 2\right\} .
\end{aligned}
$$

for some $\theta=\theta_{Z} \in[0,1]$, with $Z=(X-n p) / n p$. It is iamediate that $\mathrm{EZ}=$ $(n p)^{-1} P(R=0)=O\left(n^{-1}\right)$. To deal with the second term on the right-hand side of (5.8). Schwarz' inequality and the fact that $E(X-n p)^{4}=O\left(n^{2}\right)$ can be applied to show that this term is $O\left(n^{-1}\left\{E(1+\theta Z)^{-4} j^{1 / 2}\right)\right.$. According to a well-known inequality for binomial probabilities (see e.g. Okanoto (1958)), $\mathbb{P}(A) \leq \exp \left(-n p^{2} / 2\right)$ where $A$ is the event that $x \leq n p / 2$. Now the maximum of $(1+\Theta Z)^{-4}$ on $A$ is reached for $X=1$ and equals $(n p)^{4}$, uniformly in $\Theta=\theta_{Z}$. Hence $E(1+\theta Z)^{-4} I_{A}=\theta\left((n p)^{4} \exp \left(-n p^{2} / 2\right)\right)=o(1)$. On $A^{c}$. cleardy $(1+\Theta z)^{-4^{2}}$ is bound and hence $\mathrm{E}(1+\mathrm{OZ})^{-4}=O^{\prime}(1)$, which implies that the second term on the right-hand side of $(5.8)$ is $O\left(n^{-1}\right)$ as well.

\subsection{The minimum chi-square (MC) method}

\section{4 .1 Introduction}

Large sample theory shows that the difference between ML estimators and MC estimators tends to disappear when the number of observations is increased. Furthermore, ML and MC estimators have some important properties in common such as consistency, asymptotic normality of distribution and asymptotic efficiency (see Rao (1957)). The use of MC estimators as compared to ML estimators in bioassays has been a matter of discussion (see Berkson (1980). Fazekas de St. Groth (1982). Mantel (1985)). Berkson (1980) states that the use of MC estimators is preferable in cases where it is not certain that the ML estination procedure is best. However, in the discussion of that paper this point of view is criticized. A serious objection to the MC method when applied in dilution assays is that the number of expected frequencies is necessarily small for some culture groups, since the experimental design Is constructed in order to obtain sufficiently informative data for a range of parameter values (see Chapter 2). This can lead to unstable values of $x^{2}$ (cf. (5.9)). The amount of information about parameter values in dilution 
assays can increase in different ways. Designs with a large number of dilutions (m) and small numbers of replicates ( $n$ ) which are useful when a parmeter has to be estimated if not much a priori information is available and a provisional estimate is required, or designs with small m and large $\mathrm{n}$ which are useful when much a priorl information is avallable and an accurate estimate 1 sequlred, can and will be constructed in dilution analysis. As Mantel (1985) remarked, the ML estimator 1 s consistent no matter how information increases, whereas for the MC estimator to be consistent it is essential that the information increases by getting replicate numbers lncreasingly large. This property of MC estimators suggests that they are not generally applicable in dilution analysis like ML estimators are. However, 1ittle is known ebout bias and efficiency of ML and MC estimators when applied to data from dilution experiments with small or moderate size.

\subsubsection{The MC estimation procedure}

The MC estimator $\hat{\varphi}_{M C}$ is determined as the value of that minimizes

$$
x^{2}(\varphi)=\Sigma_{i=1}^{m} \frac{\left(\mathbb{R}_{i}-n_{i} \exp \left(-\varphi x_{i}\right)\right)^{2}}{n_{i} \exp \left(-\varphi x_{i}\right)\left(1-\exp \left(-\varphi x_{i}\right)\right)} .
$$

Since the expected value of the $M C$ estimator is infinite. $\hat{\varphi}_{M C}$ has been adapted in the same manner as $\hat{g}_{M L}$ has; see Subsection 5.3.2. Newton's method of iterative approximation can be enployed to determine $\hat{\varphi}_{M C}$ in the same way as $\hat{p}_{M L}$. Now

(5.10) $\quad \hat{\varphi}_{k+1}=\hat{\varphi}_{k}=\left.\frac{\partial x^{2}(\varphi) / \partial \varphi}{\partial^{2} x^{2}(p) / \partial \varphi \varphi^{2}}\right|_{\hat{\varphi}_{k}}$

where

$$
\partial x^{2}(\varphi) / \partial \varphi=\Sigma_{i=1}^{m} \frac{n_{i} x_{i} \exp \left(-\varphi x_{i}\right)\left(2 R_{i}-n_{i}\right)+R_{i}^{2} x_{i}\left(\exp \left(\varphi x_{i}\right)-2\right)}{n_{i}\left(1-\exp \left(-\varphi x_{i}\right)\right)^{2}}
$$

and 


$$
\begin{aligned}
\partial^{2} x^{2}(\varphi) / \partial \rho^{2}=\Sigma_{i=1} & {\left[\frac{-n_{i} x_{i}^{2}\left(\exp \left(-\varphi x_{i}\right)+\exp \left(-2 \varphi x_{i}\right)\right)\left(2 x_{i}-n_{i}\right)}{n_{i}\left(1-\exp \left(-\varphi x_{i}\right)\right)^{3}}\right.} \\
& \left.+\frac{R_{i}^{2} x_{i}^{2}\left(\exp \left(\varphi x_{i}\right)-3+4 \exp \left(-\varphi x_{i}\right)\right)}{n_{i}\left(1-\exp \left(-\varphi x_{i}\right)\right)^{3}}\right] .
\end{aligned}
$$

An estimator of the variance of $\hat{\varphi}_{M C}$ is given by

$$
S^{2}\left(\hat{\varphi}_{M C}\right)=\left.\frac{2}{\partial^{2} x^{2}(\varphi) / \partial \varphi^{2}}\right|_{\hat{\varphi}_{M C}}
$$

\subsection{Confidence intervals}

As the ML and MC estimators are asymptotically normally distributed, two-sided $95 \%$ confidence intervals can be approximated by $\hat{\varphi} \pm 1.96$ s where $\hat{\varphi}$ is the point estimate and $s$ the estimate of the standard deviation corresponding to the method used. The same procedure applies to the estimation methods described in Chapter 6 provided that $s$ is avallable. In the simulation study (Chapter 7) which compares the estimation methods described in both Chapter 5 and chapter 6, it will be investigated in which proportion the calculated confidence bounds contain the true value of the parameter.

When $r_{i}=n_{i}, i=1, \ldots, m$, the point estimates from all methods equal 0 and estimates of the standard deviation cannot be determined. In that case a one-sided confidence interval $\left[0, \varphi_{U}\right]$ is more appropriate. With a confidence level of $95 \%, \varphi_{U}$ can be determined from $\pi_{i=1}^{m} \exp \left(-\varphi_{U} x_{i} n_{i}\right)=0.05$, that is

$$
p_{u}=\log (20) / \sum_{i=1}^{m} n_{i} x_{i}
$$

When $r_{i}=0, y=1, \ldots, m$, a one-sided confidence interval $\left[\varphi_{L}, \infty\right]$ (for SDA) or $\left[\varphi_{L}, 1\right]$ (for LDA) 1 s more appropriate. With a confidence level of $95 \%, \varphi_{L}$ can be determined from

$$
\prod_{i=1}^{m}\left(1-\exp \left(-\varphi_{L} x_{1}\right)\right)^{n_{1}}=0.05
$$


The value of ${ }^{\prime}{ }_{L}$ canmot be expressed in closed form but must be determined prom 1tarative approximation. Both one-sided confidence intervals coincide with the intervals which would have been obtained with Woodward"s method based on exact probabilities (see Woodward (1957) and Loyer and Hamilton (1984)). 


\section{BIAS-REDUCING ESTIMATION METHODS}

\subsection{Introduction}

In this Chapter a number of bias-reducing estimation methods related to the ML method for the evaluation of the experimental data in dilution analysis will be described : jackknife versions of the ML method, bootstrap versions of the ML method and methods to reduce the bias of the ML estimator devised by Salama, Koch and Tolley (1978). The remarks on confidence intervals given in Section 5.5 also apply to the methods described in this Chapter.

The jackknife method and the bootstrap method provide estimetors of bias and variance for an extremely wide class of statistics. In this Chapter these methods are discussed and applied to dilution analysis. Although both application to the ML estimator and to the MC estinator could be performed, only application to the ML estimator will be elaborated on in this Chapter. The main reasons for this choice are the general, objections as discussed in Subsection 5.4.1, the fact that a more developed theory for the ML method is available, and the restriction of available computer time for the inherently time-consuming Monte Carlo comparisons. An important part of the development and testing of the simulation program has been performed on a VAX $11 / 780$ computer which is approximately 5 times slower than the VAX 8700 which has been used for the simulations described in Chapter 7. As an indication of the total CPU-time used it is noted that 62 hours of CPU-time were necessary for obtaining all the results of Chapter 7 .

In most applications, jackknife and bootstrap estimators can be constructed in different ways. When applied to dilution analysis, three versions of jackknifed ML estimators are worthwhile to study (Section 6.2), whereas four bootstrapped ML estimators are interesting (Section 6.3). Using Taylor expansions and implicit function theorems, Salame, Koch and Tolley (1978) showed the existence of blas-reducling methods thet are based on the ML method. These methods are described in Section 6.4 . 


\subsection{The Jackknife (three versions)}

\section{2 .1 Introduction}

The concept of the Jackknife method was originally proposed by Quenould Le (1949). The name "Jackknife" is due to Tukey. Quenouille (1949) introduced a technique for reducing the bias of a serial correlation estimator based on splitting the sample into two parts. Quenouille (1956) explored the general applicability of this concept when splitting the sample into parts of size h each. Miller (1974) gives an introduction and a historical survey. Here the "leaving-one-out" jackknife is considered where g. equals the sample size and $h=1$.

Let $x_{1}, \ldots, x_{N}$ be a sample of independent and identically distributed random variables. Suppose that one wishes to estimate a parameter $\theta$ based on the sample of size $N$. Consider an estimator $T_{N}=T_{N}\left(X_{1}, \ldots, X_{N}\right)$ of the parameter $\Theta$. Let $\mathbb{T}_{N-1}\left(x_{1}, \ldots, x_{k-1}, x_{k+1}, \ldots, x_{N}\right)$ be the corresponding estimator based on the sample of size (N-1) where observetion $k$ has been deleted. Then the $k$-th jackknifed pseudo-value is defined as

$$
T_{N k}^{J}=N_{N}-(N-1) T_{N-1}\left(x_{1}, \ldots, x_{k-1}, x_{k+1}, \ldots, x_{N}\right), k=1, \ldots,
$$

The jackknife estimator $\mathrm{T}_{\mathrm{N}}^{\mathrm{J}}$ defined by

$$
\mathrm{T}_{\mathrm{N}}^{\mathrm{J}}=\mathbb{N}^{-1} \Sigma_{k=1}^{N} \mathrm{~T}_{\mathrm{Nk}}^{\mathrm{J}}
$$

In many cases reduces the bias (see Efron (1982)). The reason behind this is: if

$$
E_{\Theta} T_{N}=\theta * E_{1} N^{-1}+a_{2} N^{-2}+\sigma\left(N^{-3}\right) \text {, as } N \rightarrow \infty \text {, }
$$

for some constants $a_{1}$ and $a_{2}$, then

$$
E_{\theta} T_{N}^{J}=\Theta+O\left(N^{-2}\right) \text {, as } N \rightarrow \infty \text {. }
$$

Thus the jackknife procedure reduces the bias by eliminating the first order bias term. Tukey (1958) suggested that the jackknife method could alsa be 
used to estimate the variance and obtain robust interval estimation. The jackknife estimator of variance is given by

$$
S_{\ominus}^{2}\left(T_{N}^{J}\right)=(N-1)\left[\Sigma_{k=1}^{N}\left(T_{N k}^{J}\right)^{2}-\left(\Sigma_{k=1}^{N} T_{N k}^{J}\right)^{2} / N\right] / N
$$

In the case of dilution series, the pseudo-values in $(6.1)$ can be obtained in three different ways. When $\mathrm{n}_{i}=\mathrm{n}, i=1, \ldots$, ra, the biometrical model (5.1) is a matrix with column that are independent, identically distributed (iid) random vectors. As jackknife estimators are in general determined from iid variables, the natural way to jackknife is to drop one column from (5.1) at a time (see Subsection 6.2.2). The two other versions are non-iid cases and are obtained by deleting either one row at a time or one element at a time (see Subsection 6.2.3).

\subsubsection{The ild case}

In general, jackknife estimators are determined from independent identically distributed (iid) random variables. In the case that the numbers of the replicates in all culture groups are equal, say $n$, we obtain such a jackknife method by leaving out the $j$-th replicate from each of the culture groups at a time. That is to say, in the biometrical model (5.1) the jackknife procedure is applied by leaving out one of the columns at a time. Thus, it is necessary that the individual elements of $\left\{Y_{1 j}\right\}_{i=1, \ldots, m ; j=1, \ldots, m}$ are known. The columns of this matrix provide the $\mathrm{X}_{1}, \ldots, \mathrm{X}_{\mathrm{N}}$ variables in this case. This procedure produces the Jackknife estimator $\hat{\varphi}_{\mathrm{J}}$. The bias-reducing effect of the jackknife in the lid case is a consequence of general theory of jackknife methods.

\subsubsection{Two non-11d cases}

Even if all $n_{i}=n$, the $R_{i}$ will not be Identically distributed, as the $x_{i}$ differ. The jackknife version which has been suggested in Subsection 6.2 .2 as the most natural one violates a certain symmetry inherent to the experiment, because one could permute the entries in any row in (5.1) as the $Y_{i j}$ are $i$ id within rows without altering the ML estimator of $p$. However, this would alter the estimator $\hat{\varphi}_{J c}$ obtained by jackknifing the columns of 
the natrix (5.1) which is a troubling lack of uniqueness. Another disadvantage of the procedure is that it can only be applied when there is an equal number of replicates in each culture group, $i . e ., n_{i}=$ for $i=1, \ldots, \mathrm{m}$.

Therefore two other jackknife versions are considered. One is based on jackknifing the rows of the matrix (5.1), i.e. "the jackknife procedure is based on $R_{1}, \ldots R_{\text {m }}$ which provide the $X_{1} \ldots \ldots X_{N}$ wariables in that case. Thus the jackknife estimator $\hat{p}_{J_{r}}$ is obtained. The other jackknife method is based on the elements of the matrix (5.1), 1.e. the procedure is besed on $Y_{11}, \ldots, Y_{\min }$ providing the $X_{1}, \ldots, X_{N}$ variables in that case. Thus the jackknife estimator $\hat{\varphi}_{\mathrm{Je}}$ is obtained. Resampling methods justifjable in the i.d case may not work in more complex situations. In Subsection 6.2 .4 it is Indicated why for both methods the first order bias term of the ML estimator disappears in these non-iid cases as well (cf. Quenouile (1956)). Note that all three jackknife methods are asymptotic methods. The one based on the columns demands $\mathrm{n} \rightarrow \infty$, the one based on the rows demands m $\rightarrow \infty$ and, finally, the one based on the elements in (5.1) demands that $\sum_{i=1}^{m} n_{1} \rightarrow \infty$.

For the determination of the 'element" jackknife estimator $\hat{\varphi}_{\mathrm{Je}}$ it is not necessary that the individual elements of $\left\{Y_{i j}\right\}_{i=1} \ldots, m_{i} j=1, \ldots, n_{i}$ be

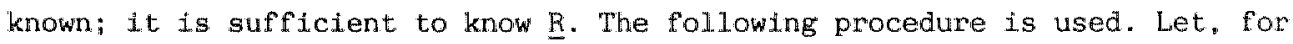
$i=1, \ldots, m, \hat{\varphi}_{M L}(i-)$ be defined by the ML estimator obtained from the data $\left\{\left(x_{1}, n_{1}, R_{1}\right), \ldots,\left(x_{i-1}, n_{i-1}, R_{i-1}\right),\left(x_{i}, n_{i}-1, R_{i}-1\right),\left(x_{i+1}, n_{i+1}, R_{i+1}\right), \ldots\right.$ $\left.\left\{x_{m}, n_{m}, R_{m}\right)\right\}$, and let $\hat{\varphi}_{M L}(i+)$ be the ML estimator obtained from the data $\left\{\left(x_{1}, n_{1}, R_{1}\right), \ldots,\left(x_{i-1}, n_{i-1}, R_{i-1}\right),\left(x_{i}, n_{i}-1, R_{i}\right),\left(x_{i+1}, n_{i+1}, R_{i+1}\right), \ldots\right.$ $\left.\left(x_{m}, m_{m}, R_{m}\right)\right\}$. When $R_{k}=0, k=1, \ldots, m$, let $\hat{\varphi}_{M L}(i-)$ heve an arbitrary value, and when $\mathrm{R}_{k}=\mathrm{n}_{\mathrm{k}}, \mathrm{k}=1, \ldots, \mathrm{m}$, let $\hat{\varphi}_{\mathrm{ML}}(\mathrm{i}+)$ have an arbitrary value. Then, $\hat{\varphi}_{\mathrm{Je}}$ and the variance estimator $S_{J e}^{2}$ are calculated according to

$$
\hat{\varphi}_{J e}=N \hat{\varphi}_{M L}-(N-1) S_{1} / N
$$

and

$$
s_{\mathrm{Je}}^{2}=(\mathrm{N}-1)\left(\mathrm{S}_{2}-\mathrm{s}_{1}^{2} / \mathrm{N}\right) / \mathrm{N}
$$

respectively, where $N=\sum_{i=1}^{m} n_{i}$, and 
$s_{k}=\Sigma_{i=1}^{m} R_{i}\left(\hat{p}_{M L}(i-)\right)^{k}+\sum_{i=1}^{m}\left(n_{i}-R_{i}\right)\left(\hat{\varphi}_{M L}(i+)\right)^{k}, k=1,2$.

6.2.4 Reducing the bias with jackknifing in the non-ild cases

Let $x_{1}, \ldots, x_{N}$ be independent random variables with smooth (in 0 ) density functions $f_{j}$ depending on the same parameter $\theta, j=1, \ldots, N$. Note that this is true in the situation of Subsection 6.2.3. Denote the first, second and third derivative of $\log f_{j}(\theta)$ with respect to $\Theta$ by $U_{j}$, $V_{j}$ and $W_{j}$, respectively. From the stachastic expansion of the ML estimator $\hat{\theta}_{\mathbb{N}}$ for $\theta$ it can be shown (see Brillinger (1964), Chibisov (1973)) that

$$
E_{\Theta}\left(\hat{\theta}_{N}-\Theta\right)=\frac{\sum_{j=1}^{N} a_{j}}{\left(\sum_{j=1}^{N} b_{j}\right)^{2}}+O\left(N^{-3 / 2}\right) \text {, as } N \rightarrow \infty \text {, }
$$

where

$$
a_{j}=E_{\Theta} U_{j} v_{j}+\frac{1}{2} E_{\Theta} W_{j} \text { and } b_{j}=E_{\Theta} U_{j}^{2}, j=\mathbb{1}_{n} \ldots, N \text {. }
$$

Note that $b_{j}>0$ for $j=1, \ldots, N$. Let $\hat{\Theta}_{N}(k)$ denotes the ML estimator for $\theta$ based on $\mathrm{X}_{1}, \ldots, \mathrm{X}_{\mathrm{k}-1}, \mathrm{X}_{\mathrm{k}+1}, \ldots, \mathrm{X}_{\mathrm{N}}$, then $\mathrm{its}$ expectation centered around $\theta$ satisfies

$$
E_{\theta}\left(\hat{\theta}_{N}^{(k)}-\theta\right) \doteq \frac{\Sigma_{j \neq k_{j}}}{\left(\Sigma_{j \neq k_{j}}\right)^{2}},
$$

where $=$ denotes that higher order terms have been neglected. If $b_{1} \ldots \ldots, b_{N}$ satisfy the condition

$$
\lim _{N \rightarrow \infty} \frac{\max _{1 \leq j \leq N} b_{j}}{\sum_{j=1}^{N} b_{j}}=0
$$

then (6.10) can be approximated by

$$
\frac{\sum_{j=1}^{N} a_{j}}{\left(\sum_{j=1}^{N} b_{j}\right)^{2}}\left(1+\frac{2 b_{k}}{\sum_{j=1}^{N} b_{j}}\right)-\frac{a_{k}}{\left(\sum_{j=1}^{N} b_{j}\right)^{2}} .
$$


By neglecting higher order teras 1 t follows from $(6.10),(6.11)$ and (6.12) that the $k$-th jackknifed pseudo-value (see (6.1)) satifies

$$
E_{Q} T_{N k}^{J} \pm \theta+\frac{\sum_{j=1}^{N} a_{j}}{\left(\sum_{j=1}^{N} b_{j}\right)^{2}}\left[1-N \frac{2 b_{k}}{\sum_{j=1}^{N} b_{j}}\right]+N \frac{a_{k}}{\left(\sum_{j=1}^{N} b_{j}\right)^{2}}
$$

and hence fit follows from (6.13) that the jackknife estimator $\mathrm{T}_{\mathbb{N}}^{\mathrm{J}}$ (see (6.2)) satisfies

$$
\mathbb{E}_{\Theta}{ }^{\top}{ }_{N}^{J}=E_{\Theta}\left(N^{-1} E_{k=1}^{N} T_{N k}^{J}\right) \doteq \Theta
$$

which shows that the first order bias term disappears.

\subsection{The bootstrap (four versions)}

\subsubsection{Introduction}

"The bootstrap method has been introduced by Efron $(1979)$. Let $\mathrm{X}_{1}, \ldots, \mathrm{X}_{\mathrm{N}}$ be a sample of independent and identically distributed random variables with common cumulative distribution function $\mathrm{F}$. Suppose again that $\mathrm{T}_{\mathrm{N}}=$ $\mathrm{T}_{\mathrm{N}}\left(\mathrm{X}_{1}, \ldots, \mathrm{X}_{\mathrm{N}}\right)$ is an estimator of the parameter $\Theta$. Furthermore, let $\mathrm{F}_{\mathrm{N}}$ be the empirical distribution function defined by $F_{N}(x)=\#\left\{i: x_{i} \leq x, 1 \leq i \leq N\right\} / N$ and write $\mathrm{E}_{\mathrm{G}}\left(\mathrm{T}_{\mathrm{N}}\right)$ for the expectation of the statistic $\mathrm{T}_{\mathrm{N}}$ computed based upon a random sample of size $N$ from $G$ and similarly for $\operatorname{Var}_{G}\left(T_{N}\right)$, then the bootstrap bias and variance estimators for $\mathrm{T}_{\mathrm{N}}$ are given as $\left[\mathrm{E}_{\mathrm{F}_{\mathrm{N}}}\left(\mathrm{T}_{\mathrm{N}}\right)-\mathrm{T}_{\mathrm{N}}\right]$ and $\operatorname{Var}_{\mathrm{F}_{\mathrm{N}}}\left(\mathrm{T}_{\mathrm{N}}\right)$, respectively. These estimators must be evaluated by drawing a Large number of random samples ("bootstrap samples") from $\mathbb{F}_{N}$. The ordinary bootstrap approach consistis of drawing $M$ bootstrap samples $\left(x_{1}^{k} \ldots \ldots, x_{N}^{k}\right)_{k=1} \ldots, \ldots$ of size $N$ from $F_{N}$ (see Efron (1982)). Such a sample is obtained by computer generated random sampling with replacement. Although there exist more elaborate bootstrap methods (see Davison. Hinkley and Schechtman (1986)) the simple bootstrap method will be used. Repeated resampling from $F_{N}$ results in an approximation $\bar{T}_{N}^{B}$ for $E_{F_{N}}\left(\mathbb{T}_{N}\right)$ :

$$
\overline{\mathrm{T}}_{\mathrm{N}}^{\mathrm{B}}=\mathrm{M}^{-1} \sum_{k=1}^{\mathrm{M}} \mathrm{T}_{\mathrm{Nk}}^{\mathrm{B}}
$$


where $T_{N k}^{B}=T_{N}\left(x_{1}^{k} \ldots, x_{N}^{k}\right), k=1, \ldots, N$. This estimator has a bias in estimating $\mathrm{T}_{\mathrm{N}}$ which approximates the bias of $\mathrm{T}_{\mathrm{N}}$ in estimating $\theta$. Thus, $\mathrm{B}_{\mathrm{N}}(\Theta)$ is used as an approximation of the bootstrap estimator of bias $\left[E_{F_{N}}\left(T_{N}\right)=T_{N}\right]$ and defined by

$$
B_{N}(\theta)=\bar{T}_{N}^{B}-T_{N}
$$

This leads to the bias-corrected "bootstrap estimator" $\mathrm{T}_{\mathrm{N}}^{\mathrm{B}}$ for $\theta$

$$
T_{N}^{B}=T_{N}-B_{N}(\theta)=2 T T_{N}-T_{N}^{B}
$$

The bootstrap estimator of variance $\operatorname{Var}_{\mathrm{F}_{\mathrm{N}}}(\mathrm{T})$ is approximated by

$$
S_{\Theta}^{2}\left(T_{N}^{B}\right)=\left[\Sigma_{k=1}^{M}\left(T_{N k}^{B}\right)^{2}-\left(\Sigma_{k=1}^{M} T_{N k}^{B}\right)^{2} / M\right] /(M-1)
$$

As discussed in Section 6.2, there are three different ways to define a set $\left(x_{1}, \ldots, X_{N}\right)$ from the biometrical model (5.1), thus resulting in the bootstrap estimators $\hat{\varphi}_{\mathrm{Ec}}$ " $\hat{\varphi}_{\mathrm{Br}}$ and $\hat{\varphi}_{\mathrm{Be}}$. As before, the c-variant represents the $i$ id-case and is only applicable when all $n_{1}=n, i=1, \ldots, m$. A fourth bootstrap version denoted by $\hat{\varphi}_{\mathrm{Bx}}$ will be discussed in Subsection 6.3 .3 .

\subsubsection{The ild case}

Most of the theoretical work regarding resampling methods like the jackkife and the bootstrap thus far has been for the ild case. There seems to be no general rule to choose between the two methods for bias reduction and variance estimation. However, since examples are known for which the application of the bootstrap in more complex situations leads to inapproprlate estimators (see Wu (1986)), it is interesting to conpare bootstrap methods with jackknifie methods. In the iid case the bootstrap samples are taken from the columns of the matrix $\left\{Y_{i j}\right\}$ which provide the $x_{1}, \ldots, x_{N}$ variables in this case. In other words, if we let $\left\{j_{t}\right\}_{t=1} \ldots, \ldots$ be a random sample with replacement from $\{1, \ldots, n\}$, then $\left\{\left(x_{1}, n, \Sigma_{t=1}^{n}\{1-\right.\right.$ $\left.\left.\left.Y_{i j}\right)\right\rangle\right\}_{1=1, \ldots, m}$ contains the data for the estimator corresponding with an individual bootstrap semple. Thus the bootstrap estimator $\hat{\varphi}_{\mathrm{Bc}}$ results. 


\subsubsection{Three non-1id cases}

The bootstrap counterpart of the "row' jackknife version is obtained by letting $x_{1}, \ldots, x_{N}$ be the rows of $\left\{Y_{i j}\right\}$ producing the estimator $\hat{\varphi}_{B r}$. Let $\left\{1_{t}\right\}_{t=1} \ldots$, be a candom sample with replacement from $\{1, \ldots$, in $\}$. Then $\left\{\left(x_{i}, n_{t}, x_{t}\right)_{t}\right\}_{t=1} \ldots$. contains the data for the estimator corresponding with an individual bootstrap sample. Note thet, as a result of the resampling procedure, it is possible that one or more dilutions are not included. whereas some dilutions are included more than once in the individual bootstrap samples for this bootstrap version.

The 'element' bootstrap estimator is obtained by letting $x_{1}, \ldots . x_{N}$ be the elements of $\left(Y_{1, j}\right)$ producing the estimator $\hat{\varphi}_{\text {Be }}$. Let $\left.\left(1_{t} \cdot j_{t}\right)\right\}_{t=1}, \ldots, T$ (where $T=\sum_{i=1}^{\text {tin }} n_{i}$ ) be a rendom semple with replacement from $\{(1, j)\}_{d=1} \ldots, \ldots ; j=1, \ldots, n_{1}$ and let $f_{1 j}$ be the frequency of the combination $(1, j)$ In that sample. Then $\left\{\left(x_{i}, \Sigma_{j=1}^{n_{i}} f_{1 j}, \Sigma_{j=1}^{n_{i}} f_{1 j}\left(1-Y_{1 j}\right)\right)\right\}_{1=1, \ldots, m}$ contains the data for the estimator corresponding with an individual bootstrap sample. When $\Sigma_{y=1}^{n_{1}} f_{1 j}=0$ for some 1 , the corresponding data $\left(x_{i}, 0,0\right)$ are excluded from the computations.

A fourth bootstrap version is constructed to avoid some of the undesirable properties of the previous two versions. When each bootstrap sample is produced by joining individual samples from each row of $\left\{\mathrm{Y}_{i j}\right\}$, a bootstrep estimator results which will be denoted by $\hat{\varphi}_{\mathrm{Bx}}$. Let $\left\{j_{t}(1)\right\} t=1, \ldots, n_{i}$ be a random sample with replacement from $\left\{1, \ldots, n_{i}\right\}$, $1=1, \ldots, m$. Then $\left\{\left(x_{i}, n_{i}, \Sigma_{t=1}^{n_{i}}\left(1-Y_{i j}(i)\right)\right)\right\}_{i=1} \ldots$, contains the data for the estimator corresponding with an individual bootstrap sample. If the resampling procedure for $\hat{\varphi}_{B e}$ would be performed under the condition that the semples must contain exactly $n_{1}$ elements from row $1, i=1, \ldots, m$, then $\hat{p}_{B e}$ and $\hat{P}_{\mathrm{Bx}}$ colncide. A major disadvantage of the $x$-version is that, when $\left(R_{i}=0\right.$ $R_{i}=n_{i}, 1=1, \ldots, m$, all bootstrap samples are equal, so that an estimator of the variance camnot be evaluated. 


\subsection{Other bias-reducing methods}

As the distribution of the random variable $\mathbb{R}$ is specified, it is possible to investigate the stochastic expansion of $\hat{\varphi}_{\mathrm{ML}}$ and base a corrected ML estimator on the corresponding properties. Using Taylor expansions and implicit function theorems, Salama, Kach and Tolley (1978) showed the existence of functions $\mathrm{H}\left(\underline{Q}, \hat{\varphi}_{\mathrm{ML}}\right)$ such that the estimator $\hat{p}_{\mathrm{S}}$ defined by

(6.19) $\quad \hat{\varphi}_{S}=\hat{s}_{M L}-H\left(Q, \hat{\varphi}_{M L}\right)$

satisfies

(6.20) $\quad E\left(\hat{\varphi}_{S}\right)=\varphi+\sum_{i=1}^{m} \theta\left(n_{i}^{-2}\right)$.

thus removing the first order bias term. The following two alternatives for the function $\mathrm{H}$ are given (producing the estimators $\hat{\varphi}_{\mathrm{S} 1}$ and $\hat{\varphi}_{\mathrm{S} 2}$ ):

$$
G_{1}\left(\underline{Q}, \hat{\varphi}_{M L}\right)=\frac{1}{2} \Sigma_{i=1}^{m}\left(\frac{\partial^{2} \hat{\varphi}_{M L}}{\partial Q_{i}^{2}}\right) n_{i} e^{-\hat{\varphi}_{M L} x_{i}}\left(1-e^{-\hat{\varphi}_{M L} x_{i}}\right)
$$

and

(6.22) $G_{2}\left(Q, \hat{\varphi}_{M L}\right)=\frac{1}{2} \sum_{i=1}^{m}\left(\frac{\partial^{2} \hat{\varphi}_{M L}}{\partial Q_{1}^{2}}\right)_{\underline{u}} n_{i} e^{-\hat{\varphi}_{M L} x_{i}}\left(1-e^{-\hat{\varphi}_{M L} x_{i}}\right)$.

The second order derivatives in the right-hand side of (6.22) are evaluated at $\underline{u}$ defined by $\underline{u}=E(Q)$. Unfortunately, the formula given by Salama, Koch and Tolley (1978) for $\frac{\partial^{2} \hat{\varphi}_{M L}}{\partial Q_{\mathrm{k}}^{2}}$ shows typing errors. The correct formula $\mathrm{j}_{\mathrm{s}}$ :

$$
\begin{aligned}
& \frac{\partial^{2} \hat{\varphi}_{M L}}{\partial Q_{K}^{2}}=\frac{F_{k}^{2}}{D^{3}}\left[\Sigma_{i=1}^{\mathbb{M}} Q_{i} e^{-\hat{x p}_{M L} x_{i}} F_{i}^{2}\left(x_{i}+2 F_{i} e^{-\hat{\varphi}_{M L} x_{i}}\right)\right] \\
& -2 \frac{F_{k}^{3}}{D^{2}} e^{-\hat{\varphi}_{M L} x_{k}}
\end{aligned}
$$


where $F_{1}$ find $D$ are defined by, respectively.

(6.24) $\quad F_{i}=F_{i}\left(\hat{\phi}_{M L}\right)=x_{1} /\left(1-e^{-\hat{\rho}_{M L} x_{i}}\right)$

and

(6.25) $\quad D=D\left(0 . \hat{\varphi}_{M L}\right)=\Sigma_{j=1}^{m} Q_{j} e^{-\hat{\rho}_{M L} x_{j}} F_{j}^{2}$.

(It is noted that $\partial \hat{\varphi}_{\mathrm{ML}} / \partial Q_{i}=F_{1} / D$, as can be established from the equation a $\operatorname{logL}(\varphi) / \partial \varphi=0$, see $(5.5)$.) Salama, Koch and Tolley (1978) used a special modification of the $M L$ estimator in case all $Q_{i}$ equal $n_{i}, i=1, \ldots$, : $\hat{\varphi}_{S}$ is taken as the maximum over all realizations of the experiment for which at least one of the $Q_{i}$ is less than $n_{i}$. This modification is essentially the same as the modification of the ML estimator described earlier in Subsection $5 \cdot 3 \cdot 2$.

The paper of Salama, Koch and Tolley (1978) does not provide an estimator for the standard deviation of $\hat{\varphi}_{S}$ based on the same principles. This, of course, is a serious drawback of the proposed method, since corresponding confidence interval estimates cannot be determined. 


\section{A MONTE CARLO STUDY FOR THE COMPARISON OF THE ESTIMATORS}

\subsection{Introduction}

Research on estimators in dilution analysis requires a design method that can be used as a frame of reference. The design method proposed in Subsection 2.3 .2 seems to be an acceptable candidate for use in general dilution assays and in Monte Carlo comparisons. The advantages of this design method are : it incorporates the researcher"s criteria, it has suitable properties, and it can easily be used in Monte carlo experiments aimed at a meaningful comparison of estimation methods. As a design according to this method is based on an a priori interval estimate of the unknown parameter, a means of examining an estimator's performance over a range of parameter values is automatically provided.

In onder to perform a simulation study the following design parameters have to be chosen : a lower $\left(\varphi_{1}\right)$ and an upper $\left(\varphi_{2}\right)$ bound for the unknown parameter $\varphi\left(0<\varphi_{1}<\varphi_{2}\right)$, a lower $\left(\mathrm{P}_{1}\right)$ and an upper $\left(\mathrm{P}_{2}\right)$ bound for a fraction of negative responders in a culture group to be considered sufficientlyt informative $\left(0<\mathrm{P}_{1}<\mathrm{P}_{2}<1\right)$, an integer number d of groups of replicate cultures which will produce sufficiently informative data as specified by $\mathbb{P}_{1}$ and $P_{2}$. (d $\geq 1)$, and finally, the number of replicates $n_{i}$ in group $i$. On the basis of the parameters chosen, the number $m$ of replicate culture groups and the number $x_{i}$ of cells/organisms per replicate in group $1=1, \ldots, m$, can be calculated according to the formulae (2.1) - (2.4). Thowgh very many different combinations of these design parameters are possible and meaningful, some acceptable limitations for a Monte Carlo study can be made. All simulations are performed with an equal number of replicates $n_{i}=n, i=1, \ldots$, with different $n_{i}, i=1, \ldots, m$, the 'column' versions of the jackknifie and bootstrap method could not be executed. Moreover, when the other design parameters are chosen carefully, there is no reason to depart from this choice. As noted by Fazekas de St. Groth (1982), biological experiments (LDA's) indicate that values of the order of 20 suffice in practice. of 
course, such a statement cannot be made without specifying the other design parameters. In particuliar, $n=20$ appears to suffice when $P_{1}$ is not too close to zero $(\mathrm{e} . \mathrm{g} .0 .15)$ and $\mathrm{P}_{2}$ is not too close to one $(\mathrm{e} . \mathrm{g} .0 .70)$ and when $\mathrm{d}=2$ or $d=3$. However, restriction to relatively small values of $n$ seems to be sensible for three reasons. In the first place, it turns out that differences between estimation methods are especialy interesting for these values. Secondly. the Monte Carlo experiments use a great deal of cPu-time. And, thirdly, in SDA swaller values of $n$ are commonly used (e.g. $n=3$, or $n=6)$. As for the choice of $\varphi_{1}$ and $\varphi_{2}$, it should first be noted that only the quotient $\varphi_{2} / \varphi_{1}$ is relevant and not the individual values of $\varphi_{1}$ and $\varphi_{2}$. This is both a consequence of the experimental design (according to formulae $(2.1)-(2.4))$ and the biological model used in dilution analysis. After consultation of researchers in the field of LDA, a reasonable choice for this quotient appears to be 10 . Thus, the following experimental designs are used in the simulations : $p_{1}=0.001, \varphi_{2}=0.01, P_{1}=0.15, P_{2}=0.70, d=2$ (leading to $m=4$ ) and $d=3$ (leading to $m=7$ ). For the case $d=2$, the simulation program has been executed with $n=6,12$ and 18 , and, for the case $d=3$, with $n=6$ and 12. Simulation results have been obtained for 19 equidistant values of $\varphi$ within the interval $\left[\rho_{1}{ }^{*} \varphi_{2}\right]$ starting with $\varphi=\varphi_{1}$ and ending with $\varphi=\varphi_{2}$. The number of generated samples for each combination of $\varphi_{1}, p_{2}, P_{1}, P_{2}, d, n$ and $\varphi$ was 1.000. As Efron and Tibshirani (1986) indicated that a number of bootstrap replications in the range 50 to 200 is quite adequate in most situations and taking into consideration the liwitations on computer time, the number $M$ of bootstrap sanples was chosen to be 100 .

Many criterla could be used to compare the estination methods. However. restriction has been made to three criteria concerning the bias, the mean square error and the realized conftdence levell. According to Taswell (1987). "to demonstrate convincingly in a Monte Carlo experiment that an estimator is superior for a given set of assumed parameter values and assay-design constants, it would be necessary to prove that it has a lower coefficient of variation corresponding not only to its point estimates but also to its interval estimates", the last type of coefficient of variation being defined "by taking the mean of the individual ratios of each estimate's standard error to the estimate"s value". However, the last type of coefficient of variation is not at all a valid criterium, since not the magnitude of the estimate of the standard deviation is relevant but, instead, its ability to 
produce correct interval estimates. The three criteria used to compare the performance of the estimation methods are the mean relative bias (MRB) determined as the mean bias relative to the true value of $p$, the coefficient of variation (CV) determined as the square root of the mean square error relative to the true value of $\varphi$, and the realized confidence level (RCL) determined as the proportion of times that the calculated $95 \%$ confidence interval includes the true value of $p$. "Thus, the criteria are calculated as follows :

$$
\begin{aligned}
& \text { MRB }=\operatorname{MB} / \varphi, \text { where MB }=\sum_{t=1}^{T}\left(\hat{\varphi}_{t}-\varphi\right) / T, \\
& C V=(M S E)^{1 / 2} / \varphi \text {, where MSE }=\sum_{t=1}^{T}\left(\hat{\varphi}_{t}-\varphi\right)^{2} / T, \\
& \text { RCL } \left.=\# t: \varphi \in\left[\hat{\varphi}_{t}-1.960 \mathrm{~s}_{t}, \hat{\varphi}_{t}+1.960 \mathrm{~s}_{t}\right], 1 \leq t \leq T\right) / T .
\end{aligned}
$$

For Monte Caxlo replicate $t(1 \leq t \leq 1,000), \hat{\varphi}_{t}$ and $s_{t}$ denote the point estimate and the estimate of the standard deviation, respectively. The number $T$ " of non-missing estimates is usually 1,000. However, and in particular for the smallest designs, it can occur that a jackknifed or bootstrapped MLestimator does not produce a meaningful value (e.g. less than zero). "The lowest observed value for $T$ has been 996 for the jackknife "row' version used with the $(d=2, n=6)$-design.

\subsection{The simulation program}

A PASCAL-program has been witten to perform the Monte Canlo experiments for the comparison of the statistical methods described in Chapters 5 and 6 . The program uses the NAG (FORTRAN) subroutines CO5DZF and GO5DYF for the generation of the Bernoulli variables $\left\{Y_{i j}\right\}$ and the bootstrap samples, respectively. The structure of the program will be described for the case $d=2$. For each of the 19 values of $\varphi$, matrix $\left\{y_{i, j}, 1=1, \ldots, 4\right.$; $\mathrm{j}=1, \ldots .18$ is generated 1,000 times. These numbers are used twice : one time for $n=18$ and one time for either $n=6$ or $n=12$. This concession has been made in order to curteil the required CPU-time. Depending on the value of $n$, the numbers $r_{i}$ are determined by $r_{i}=n-\Sigma_{j} y_{i j}$ where $\Sigma_{j}=\Sigma_{j=1}$, for $n=6$. $\Sigma_{j}=\Sigma_{j=7}^{18}$, for $n=12$ and $\Sigma_{j}=\Sigma_{j=1}^{18}$, for $n=18$. Thus, 1,000 datasets $\left(x_{i}, I_{i}, n\right)$, 
$1=1, \ldots, 4$, result for each combination of $s$ and $n$. For each dataset the program calculates, $1 f$ possible, the weighted-mean estimate $p_{0}$ (cf. Taswell (1981)). When all $r_{1}=0$ or $n$, this estimate cannot be determined. In that case $\varphi_{0}=\left(\varphi_{1}+\varphi_{2}\right) / 2$ has been taken. $\varphi_{0}$ served as an initial estimate for the iterative determination of $\hat{\varphi}_{M L}$. $\hat{\varphi}_{M L}$ served as an initial estimate for the determination of $\hat{\varphi}_{M C}$, the Jackknifed pseudo-values and the individual bootstrap estimates.

Much care has been taken to test the program. For example, the results of Salalme, Koch and Tolley (1978) which have been based on the exact distributions of $\hat{\varphi}_{\mathrm{S} 1}$ and $\hat{p}_{\mathrm{S} 2}$ could be reproduced quite satisfactory in the sturilations.

The complete program is presented in the Appendix. However, only the statistlcal methods, mentioned in Subsection 7.3 .5 are included. Future simulation research on dilution analysis could take advantage of this program.

\section{$7 \cdot 3$ Resull ts}

\subsubsection{Introduction}

In order to obtain a clear impression of the properties of all estimation methods in the designs used, the results of the simulation study will be presented as follows. In Subsection 7.3 .2 the three jackknife versions of the ML estimator will be compared with the ML estimator which leads to a particular version as the most favourable alternative. Analogously, in Subsections 7.3 .3 and 7.3 .4 one bootstrap version and one wethod of Salane, Koch and Tolley (1978) will be chosen, respectively. Only criterda (7.1) and (7.2) are used for these comparisons. Furthermore, only the simulation results of the smallest design $(m=4, n=6)$ will be presented. For this design differences are most explicit, whereas the properties of the compared estimators for liarger designs can be described very well without presenting the numerical results obtained. Finally, in Subsection 7.3 .5 the MLi estimator, the MC estimator, the chosen jackknife and bootstrap alternatives and the chosen method of Salama, Koch and Tolley (1978) will be compared. All obtained numerical results are then presented including the results on realized confidence levels (see formula (7.3)). 


\section{3 .2 Comparison of the ML estimator with the jackknife versions}

The uncorrected ML estimator exhibits a positive bias. Theoretically this is due to the fact that there is a positive probability that all. dilutions will produce growth so that the ML estimate becomes infinite. In practice, when $m$ and $\mathrm{n}_{1}, i=1, \ldots, \mathrm{m}$, are sufficiently large and the experimental design is chosen carefully, this situation will not occur and Monte Carlo simulations reveal the positive bias in that case. Resampling plans such as the jackknife are designed to reduce the bias. The values of the MRB and the CV obtained by the simulation program for the ML estimator and the three jackknife versions of it ( $\mathrm{Jc}_{\mathrm{c}}, \mathrm{J}_{\mathrm{x}}$, and $\mathrm{J}$ ) when using the smallest design are presented graphically in the Figures $7.1 \mathrm{a}$ and $7.1 \mathrm{~b}$. The MRB of the ML estimator varies rom 3 to about $12 \%$ in this design. Both the Jc and the Je estimator reduce the bias significantly to values around zero, whereas the Jr estimator shows a different behaviour. This can be explained as follows. In the first place, it is intuitively clear that Je and Je are capable of reducing the bias more than $\mathrm{In}$, since the higher order bias terms

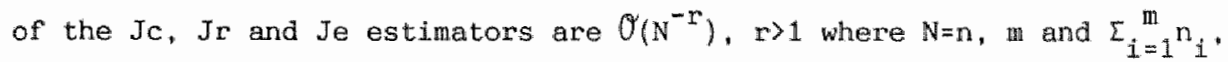
respectively. It is gratifying to find that the Monte Carlo experiments confirm this statement. Secondly, the strong ascending behavioum of both the MRB and the $\mathrm{CV}$ for the Ir estimator at the end of the $\varphi$-range can be clarified in the following way. For all three jackknife estimators several ML estimators (the jackknifed pseudo-values) heve to evaluated. The probability of having at least one pseudo-value for which the data contains all positive responses, and hence needs to be modified according to the method described in Subsection 5.3.2, is generally larger for the $\mathrm{Jr}_{\mathrm{r}}$ estimator than for the other two jackknife estimators. Furthermore, the influence of such a modification on the jackknife estimator is generally greater for the Jr version than for the other jackknife verstons. For example, when using the design of Fig. 7.1, the (maximum) probabilities of the event that all responses are positive when calculating a jackknifed pseudo-value are $0.270,0.013$ and 0.011 for the $J r$, Jc and Je estinators, respectively (these figures are $0.073,0.00007$ and 0.00006 , respectively. for the design of Fig. 7.5). The results obtained with the other four designs used in the simulation study can be summarized as follows. As m and $\mathrm{n}$ increase, the three jackknife estimators coincide increasingly, until they 


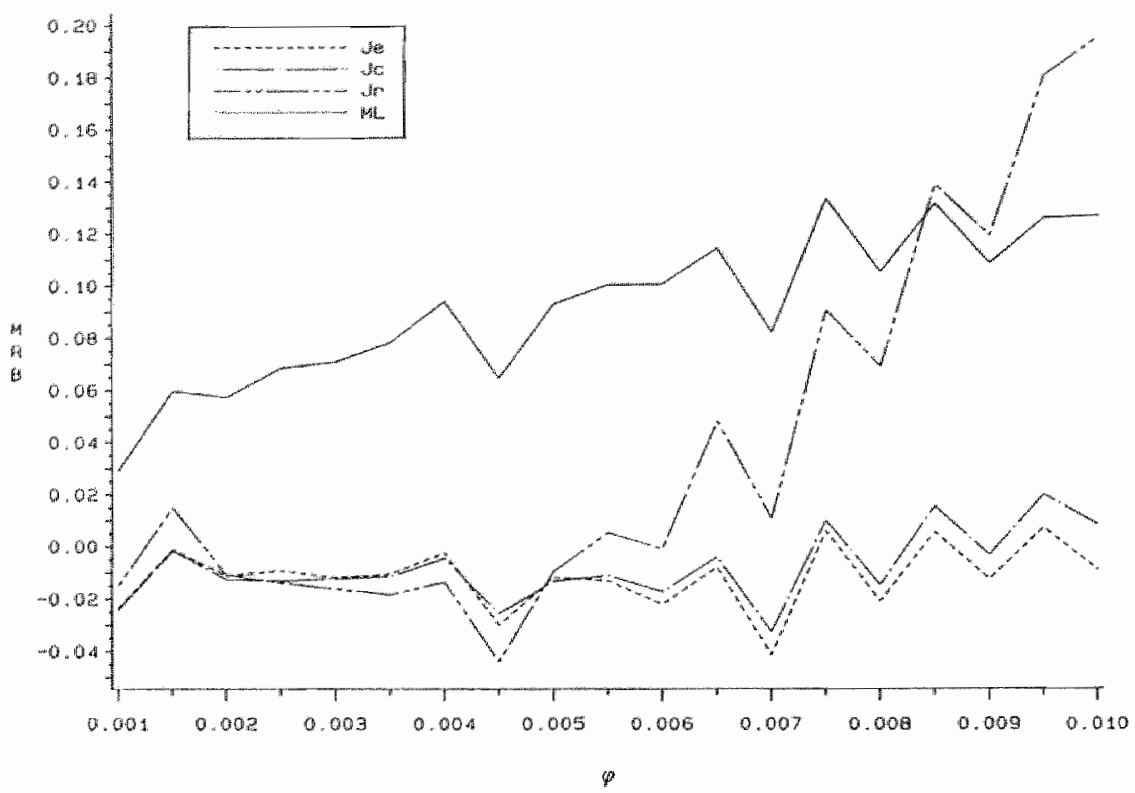

Fig. 7.1a. Mean Retative Bias of the ML, Je, In and Je estimators. The destgn parameters are $\varphi_{1}=0.001, \varphi_{2}=0.01, p_{1}=0.15, p_{2}=0.70, d=2$ (leading to $m=4)$ and $n=6$.

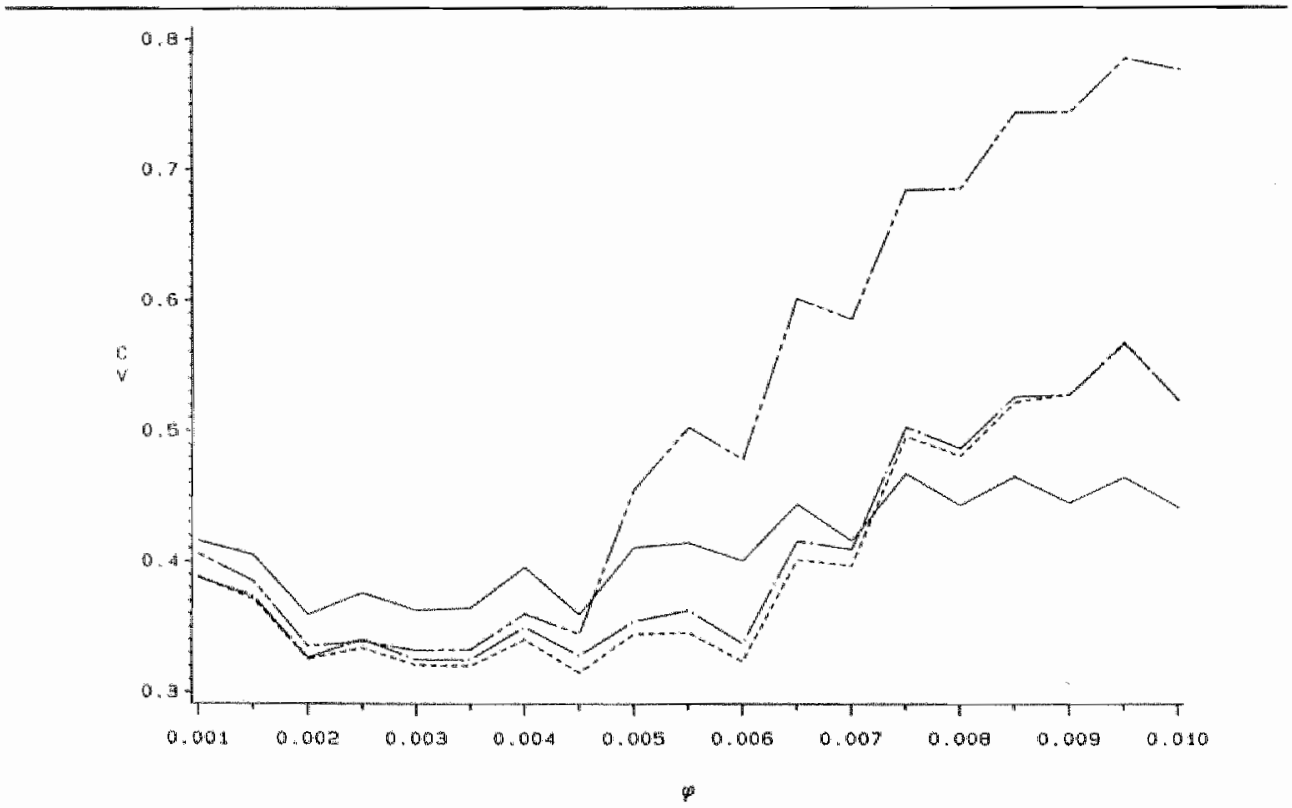

Fig. 7.1b. Coefficlent of Variation of the $M L, J_{C}, J r$ and Je estimators. Design as in Fig. 7.1a. 


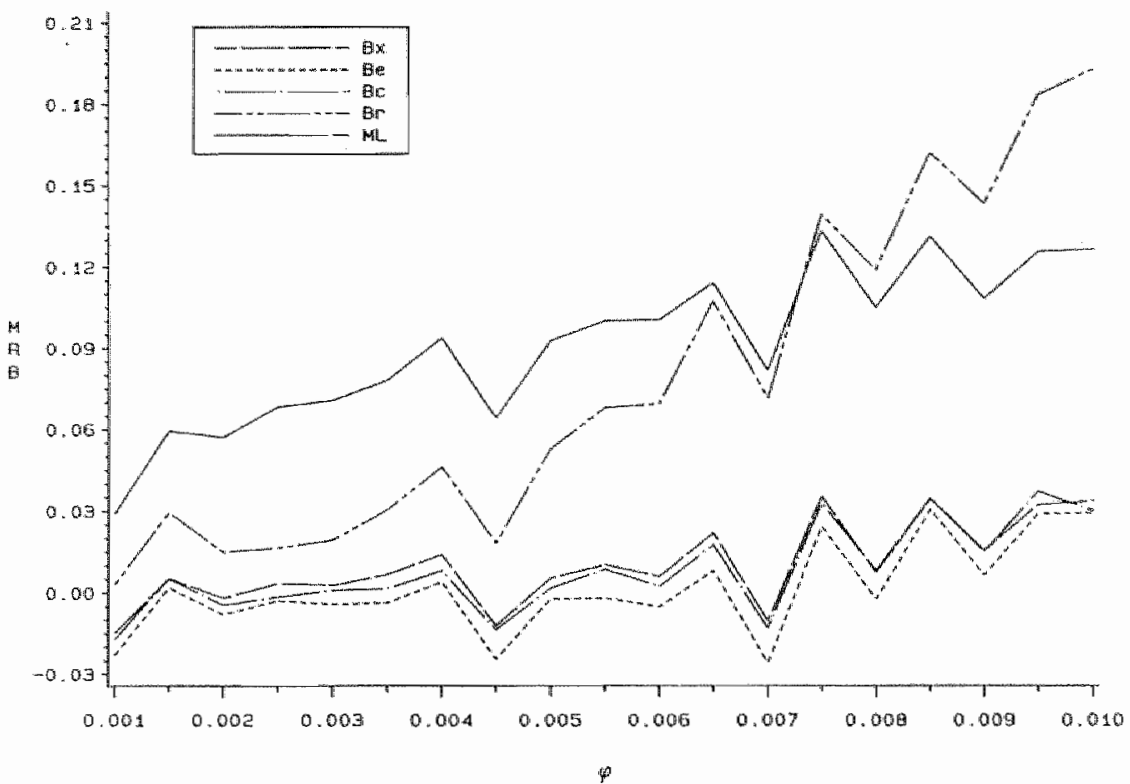

Fig. 7.2a. Mean Relative Bias of the ML, Bc, Br, Be and Bx estimators. The design parameters are $\varphi_{1}=0.001, \varphi_{2}=0.01, P_{1}=0.15, P_{2}=0.70, d=2$ (leading to $m=4$ ) and $n=6$.

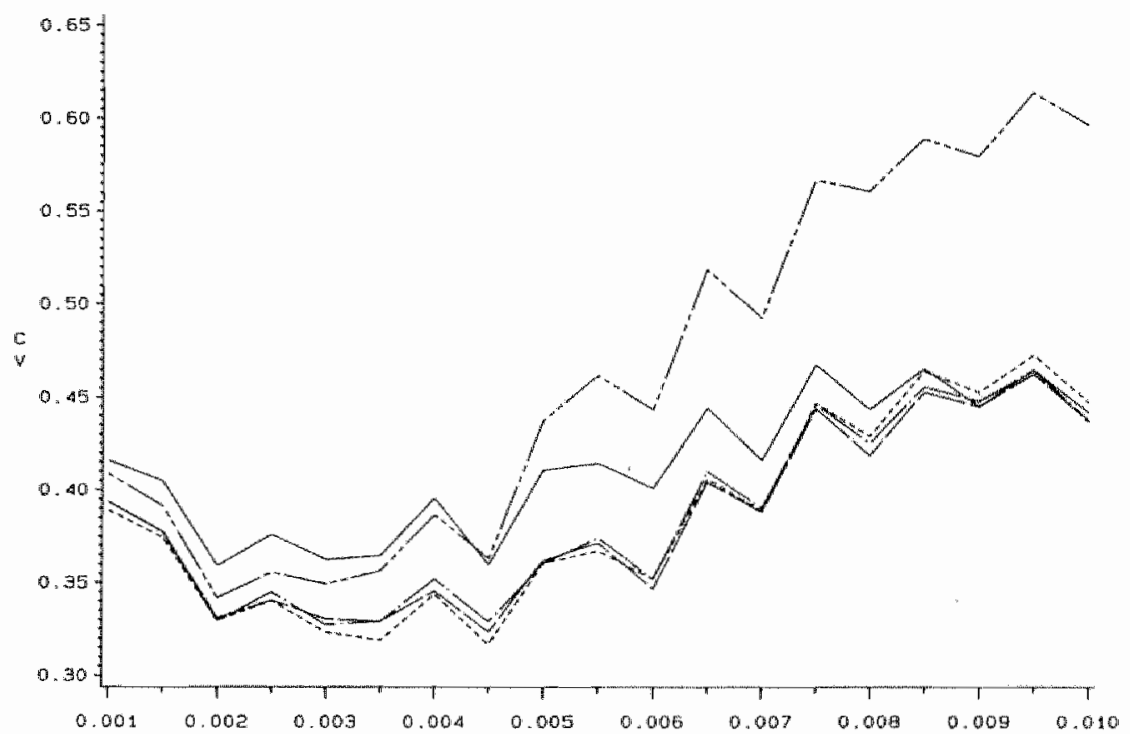

Fig. 7.2b. Coefficient of Variation of the ML, BC, Br, Be and Bx estimators. Design as in Fig. 7.2a. 
are practically undlscernible in the largest design while still reducing the MRB ower the fu11 $p$-range. Moreover, the reduction of the CV becomes Mgniflcant over the full $\varphi$-range as soon as the (maximum) probability of the event that all responses are positive when calculating the jackknifed pseudo-values vanishes.

As for the jackknife versions of the ML estimator, it can be concluded from theoretical considerations, the finite sample computations and the wider applicablilty of the Je estimator as compared to the Jc estimator. that the Je estimator obtained by deleting one element of the matrix $\left\{Y_{i j}\right\}$ at a time is the statistical method of chaice. The next best method is the Jc estimator based on deleting one colum of $\left\langle Y_{i j}\right\rangle$ at a time.

\subsubsection{Comparison of the ML estimator with the bootstrap versions}

Figures $7.2 \mathrm{a}$ and $7.2 \mathrm{~b}$ present the simulation results for the four bootstrap versions ( $\mathrm{BC}, \mathrm{Br}, \mathrm{Be}$ and $\mathrm{Bx}$ ) of the ML estimator obtained with the smallest design. As can be expected from the theory, the $c-, r-$ and $e-$ alternatives of the Jackknife and the bootstrap are very strongly related and the $\mathrm{Bx}$ estimator is comparable to the Bc and Be estimators. The same conclusions pertain to the larger designs. On the basis of these results, the Bc. Be and Bx estimators are to be preferred. However, the Bc estimator is disregarded because of its less wide applicability. As the Be and Bx estimators are very much alike, the first is preferred because of its correspondence to the Je estimator. It is worthwhlle to note here the importance of the modification of the ML estimator as suggested in Subsection 5.3.2 for the bootstrap method in dilution analysis. The probability of obtaining one or more bootstrap samples with $R_{i}=0, i=1, \ldots, m$, Increases atrongly as the design becomes smaller. Formulae (7.4)-(7.6) grive these probabilities for the $3 \mathbf{r}$, $B c$ and Be estimators, respectively.

$$
P_{r}=1-\left[1-\left[\frac{1}{m} \Sigma_{i=1}^{m}\left(1-\exp \left(-\varphi_{x_{1}}\right)\right)^{n}\right]^{m}\right]^{M}
$$

$$
P_{c}=1-\left[1-\pi_{i=1}^{m}\left(\mathbb{1}-\exp \left(-\varphi_{x_{1}}\right)\right)^{n}\right]^{M}
$$




$$
P_{e}=1-\left[1-\left[\frac{1}{m} E_{i=1}^{m}\left(1-\exp \left(-p_{x_{1}}\right)\right)\right]^{n m}\right]^{M} .
$$

Table 7.1 shows these probabilities for the five different designs when $\varphi=\varphi_{2}$. Without the modification a bootstrap estimate would not be calculable in many more cases than when the corresponding jackknife estimate is not calculable.

\begin{tabular}{|c|c|c|c|c|c|}
\hline \multirow[b]{2}{*}{$\mathrm{n}=$} & \multicolumn{3}{|c|}{$d=2$} & \multicolumn{2}{|c|}{$d=3$} \\
\hline & 6 & 12 & 18 & 6 & 12 \\
\hline $\mathrm{Br}$ & 0.99995 & 0.994 & 0.97 & 0.77 & 0.42 \\
\hline $\mathrm{BC}$ & 0.43 & 0.003 & 0.00002 & 0.002 & 0.0000000 \\
\hline $\mathrm{Be}$ & 0.69 & 0.014 & 0.0002 & 0.012 & 0.0000000 \\
\hline
\end{tabular}

Table 7.1. The tabulated values represent the probabilities af obtaining one or more bootstrap samples with all positive responses $\left(R_{i}=0, i=1, \ldots, m\right)$ when evaluating the $B x, B C$ and Be estimators. The designs used are the destigns of Fig. 7.4-7.8, characterized by the corresponding values of the design parameters $d$ and $n$. The probabilities are evaluated $f^{*} \circ x^{*} \varphi=\varphi_{2}$.

Figures $7.2 \mathrm{a}$ and $7.2 \mathrm{~b}$ bring to the attention that several curves are not distinguishable, as will be the case in subsequent Figures. This, obviously, does not complicate the interpretation of the properties of the corresponding estimators.

\subsubsection{Comparison of the ML estimator with other bias-reducing estimators}

Figures $7.3 a$ and $7.3 b$ idlustrate the MRB and $C V$, respectively, for the bias-corrected estimators of Salama, Koch and Tolley (1978) in the smallest, design. As can be expected from the formulae given in Section 6.4, there is practically no difference between the two methods. A slight preference for the 52 estimator exists, however, on the basis of the MRB. 


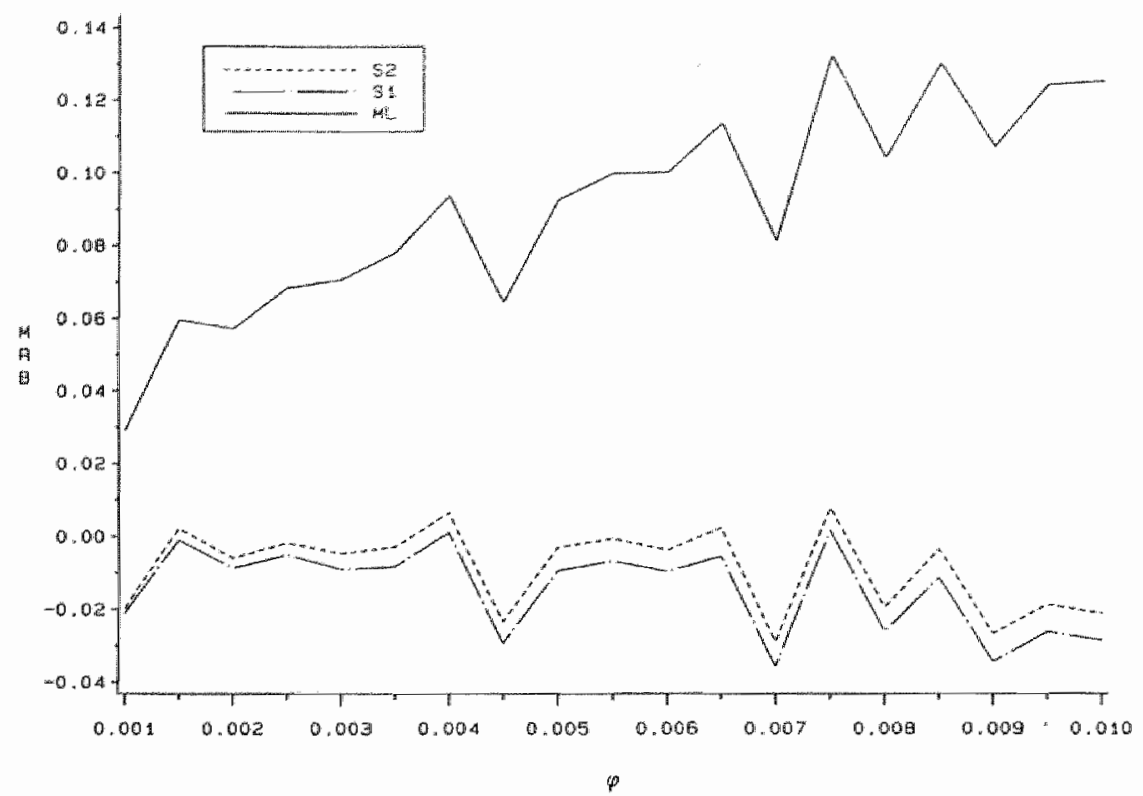

Fig. 7.3a. Mean Retative Btas of the ML, SI and S2 estimators. The design parameters are $\varphi_{1}=0.001, \varphi_{2}=0.01, P_{1}=0.15, P_{2}=0.70, d=2$ (leading to $m=4$ ) and $n=6$.

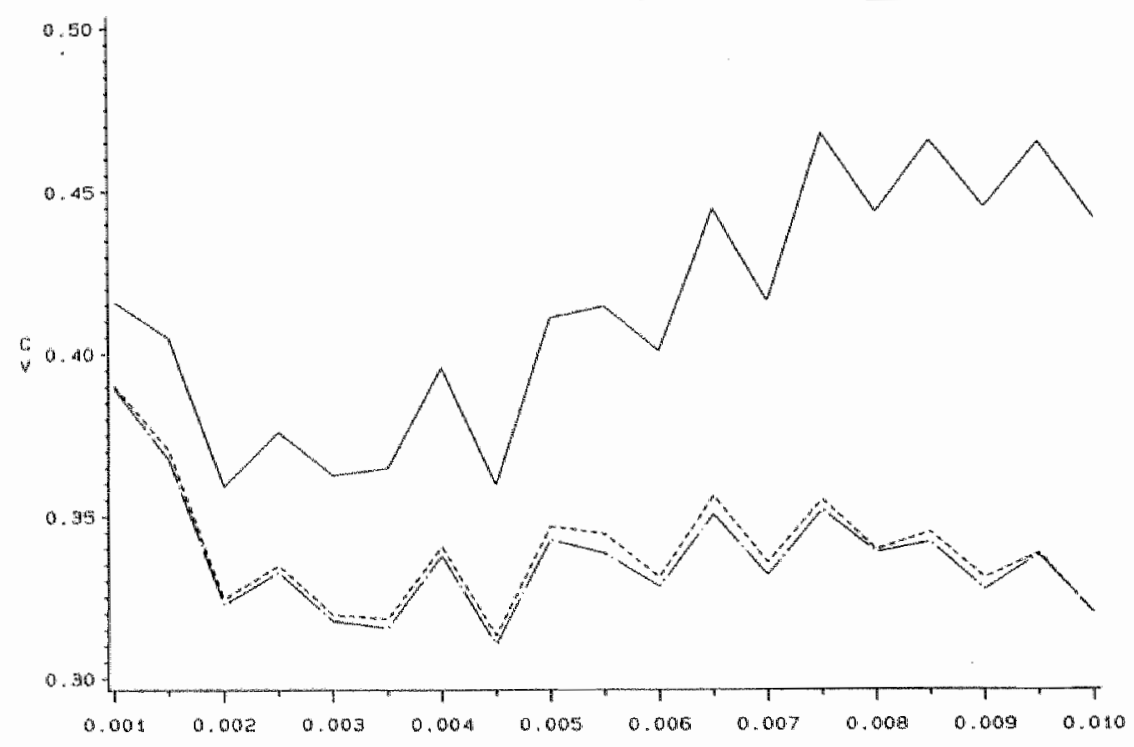

Fig. 7.3b. Coeffictent of Vartation of the ML, S1 and S2 estimators. Destgn as in Fig. 7.3a. 


\subsubsection{Final comparison}

In this Subsection the estimation methods which are chosen to be preferable in each category (see Subsections $7.3 .2-7.3 .4$ ) are compared with the ML and the MC estimators for the five experimental designs mentioned in the Intraduction (7.1). The MRB and the $\mathrm{CV}$ are presented in the Figures $7.4 \mathrm{a}-7.8 \mathrm{~b}$, and (except for the S2 estimator) the RCL (formula 7.3 ) resulting from a separate simulation run is compared in the Figures 7.9-7.13. Note that the vertical axes in the Figures are not fixed. When comparing the five estimators on the basis of the MRB and $C V$, it becomes clear that in general the Je, Be and $\mathrm{S} 2$ estimators should be preferred. An attractive property of the jackknife and the bootstrap is that they also produce the variance estimate used to determine proper confidence bounds for $\varphi$. A major disadvantage of the $S 2$ estimation method is the lack of an estimator for the variance. Consequently, the $S 2$ estimator is not suitable for general use. The difference between the jackknife and the bootstrap estimators which Is mainly apparent for small designs can be explained as follows. The jackknifed pseudo-values for the Jc, Jr and Je estimators are based on $\mathrm{n}(\mathrm{m}$ 1), $n(m-1)$ and $n m-1$ observations, respectively, whereas the corresponding ML estimators for the individual bootstrap samples are based on $\mathrm{nm}$ observations. On the other hand, occurence of the situation that the modification of the ML estimation procedure has to be applied is more likely for the bootstrap than for the jackknife. It is probable that the interaction between these two phenomena chiefly determines the observed differences between the jackknife and the bootstrap estimators in dilution analysis for small designs. From a computational point of view, it is obvious that the jackknife is more attractive than the bootstrap, certainly for the Iarger designs. However, in very small designs, the Be estimator should be preferred over the Je estimator, since the last estimator is characterized by the undesired property of a strongly increasing ov for values of $\varphi$ near $\varphi_{2}$. The designs which are commonly used for LDA are sufficiently large to justify the general advocacy of the Je and Be estimators for these assays. 


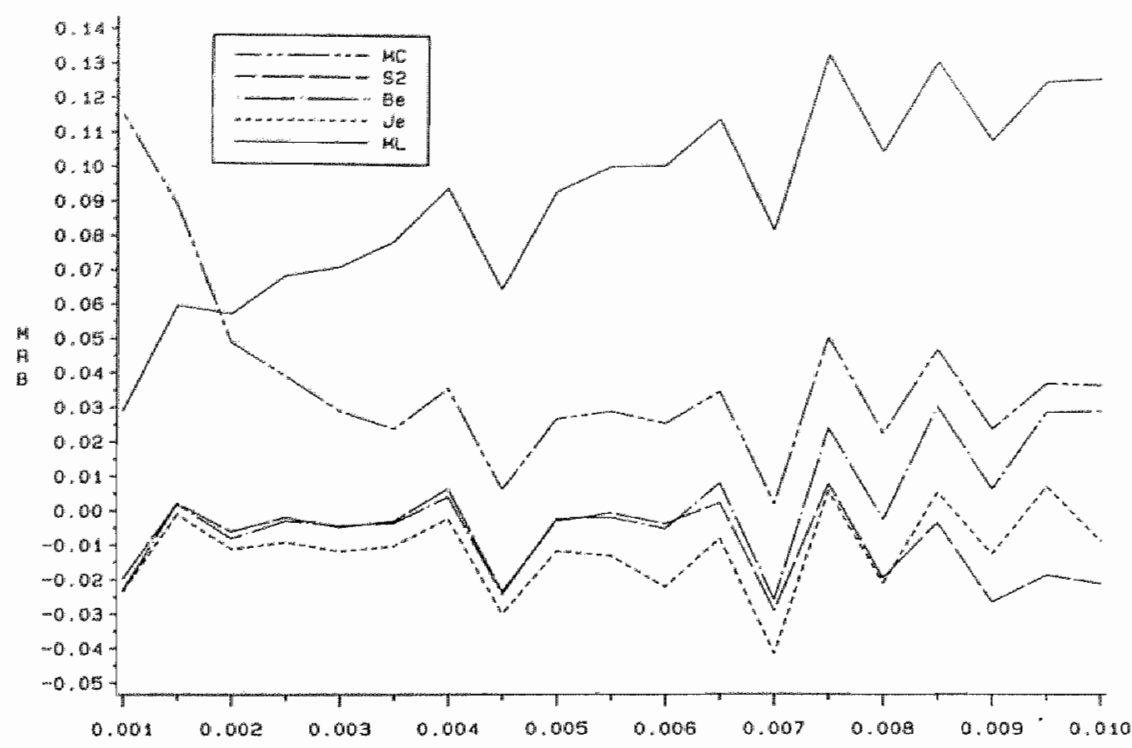

Fig. 7.4a. Mean Relative Btas of the ML, Je, Be, S2 and MC estimators. The design parameters are $\varphi_{1}=0.001, \varphi_{2}=0.01, p_{1}=0.15, p_{2}=0.70, d=2$ (leading to
$m=4$ ) and $n=6$.

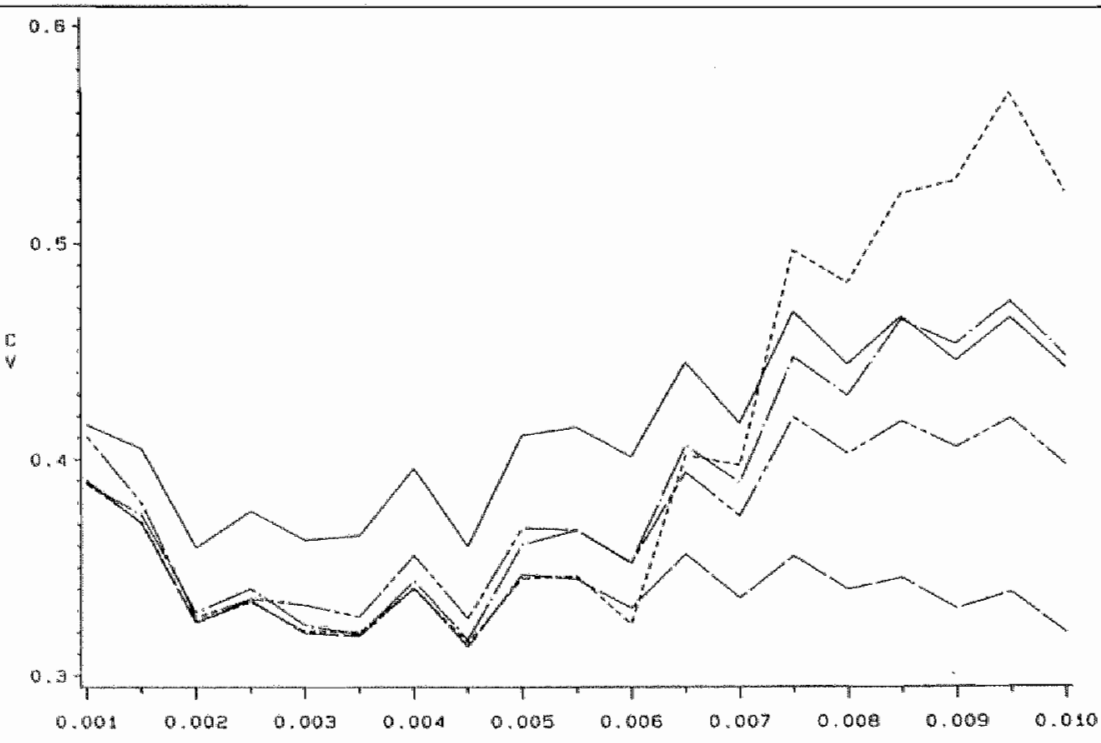

Fig. 7.4b. Coeffictent of Vartation of the ML, Je, Be, S2 and MC estimators. Design as in Fig. 7,4a. 


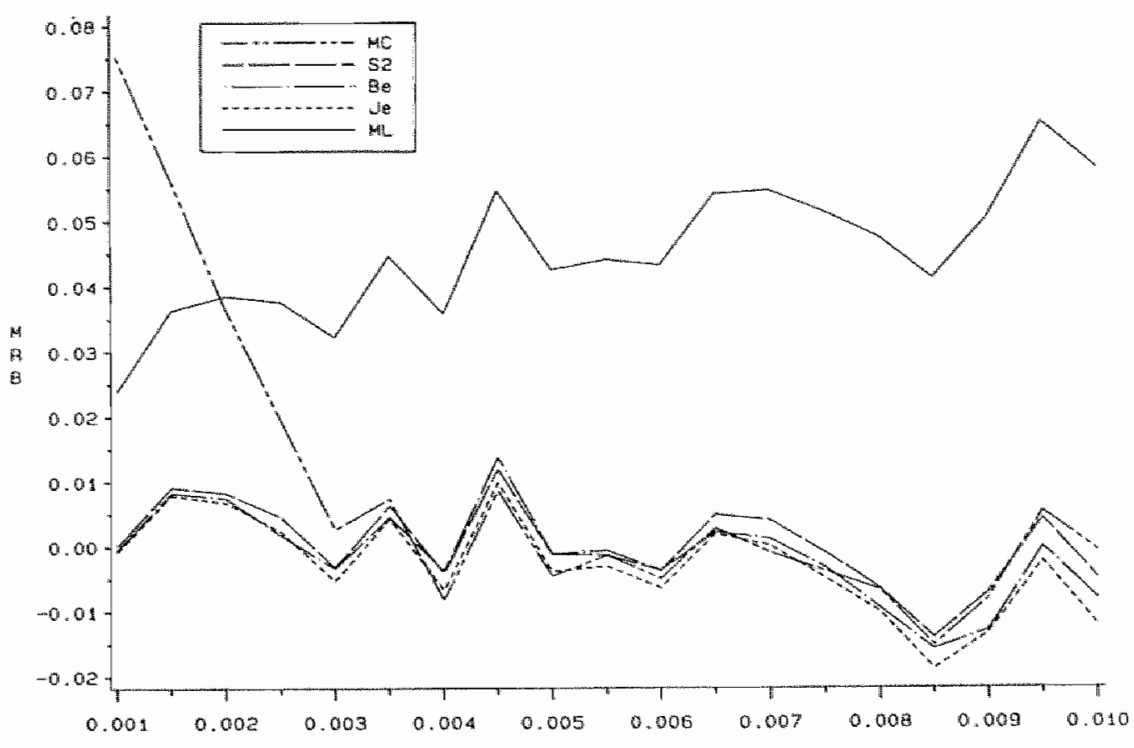

Fig. 7.5a. Mean Relative Bias of the ML, Je, Be, S.2 and MC estimators. The design parameters are $\varphi_{1}=0.001, \varphi_{2}=0.01, P_{1}=0.15, P_{2}=0.70, d=2$ (Leading to $m=4$ ) and $n=12$.

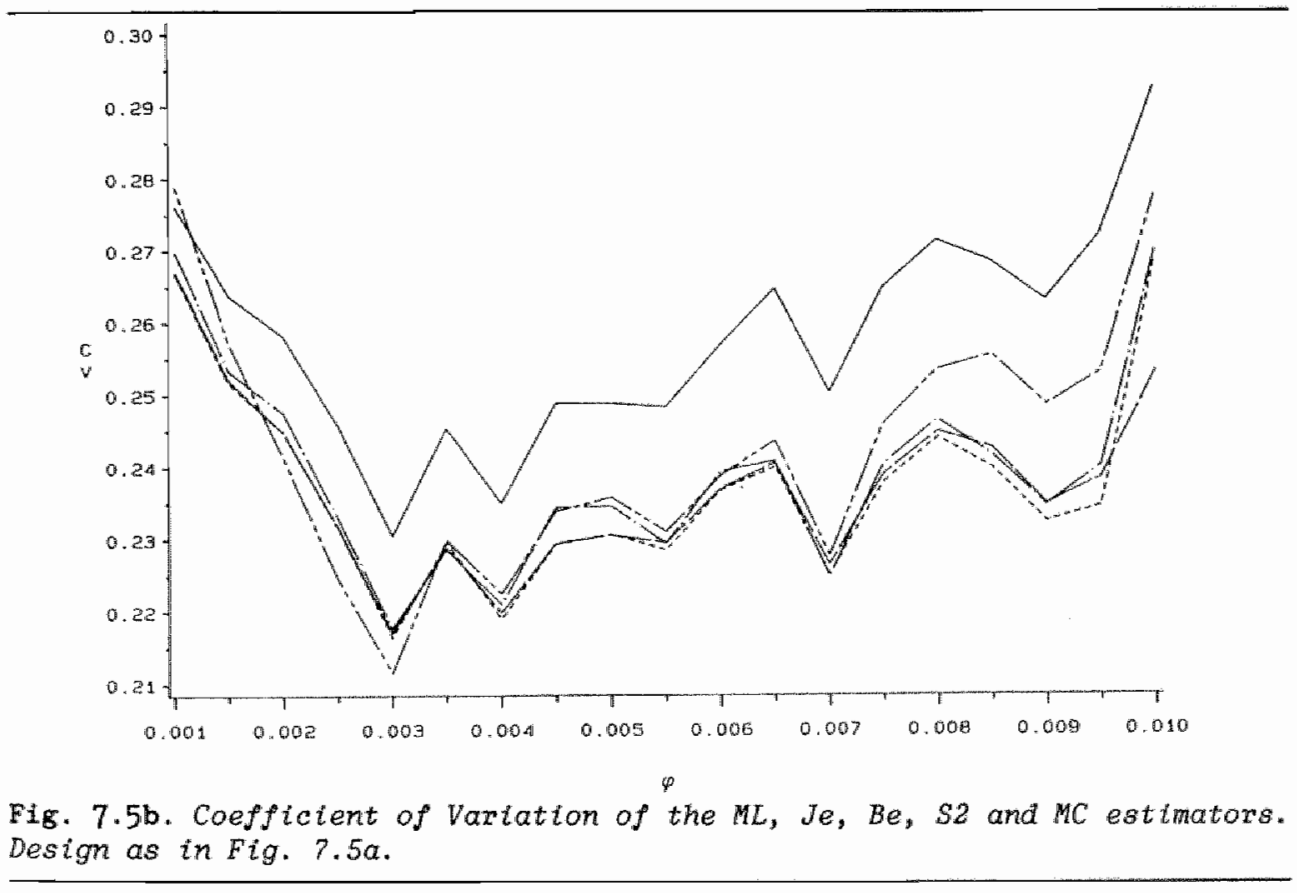




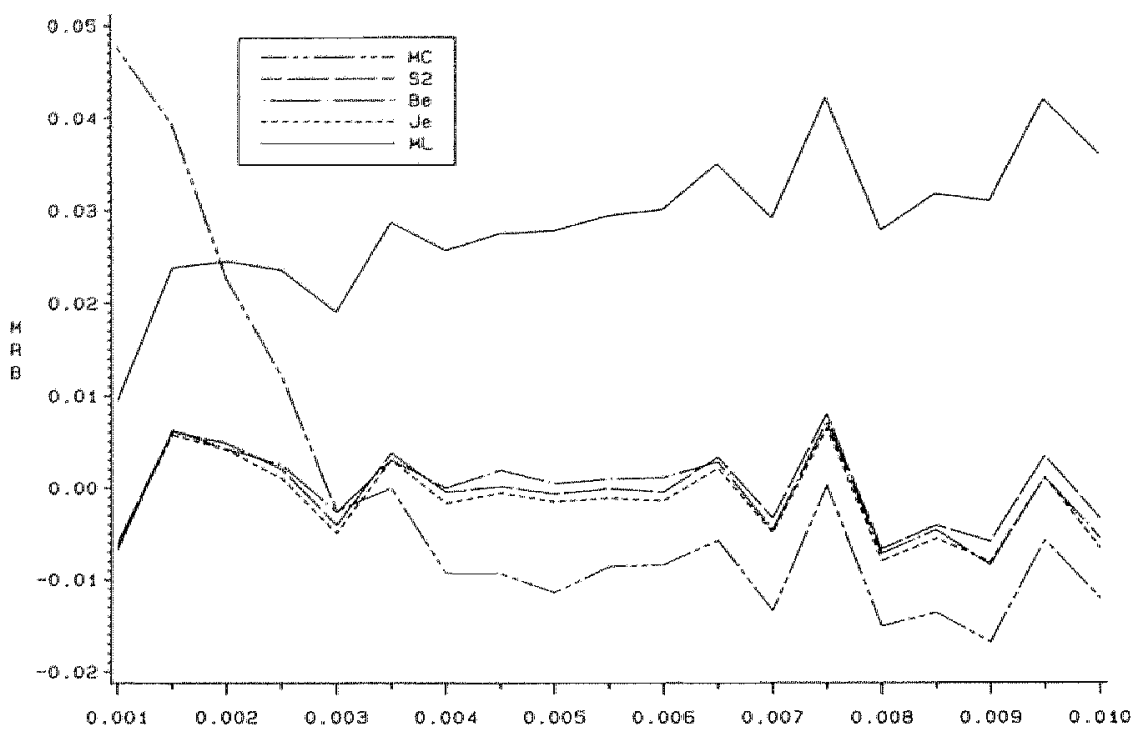

Fig. 7.6a. Mean Retative Blas of the ML, Je, Be, S2 and MC estimators. The destgn parameters are $\varphi_{1}=0.001, \varphi_{2}=0.01, P_{1}=0.15, P_{2}=0.70, d=2$ (leading to $m=4$ ) and $n=18$.

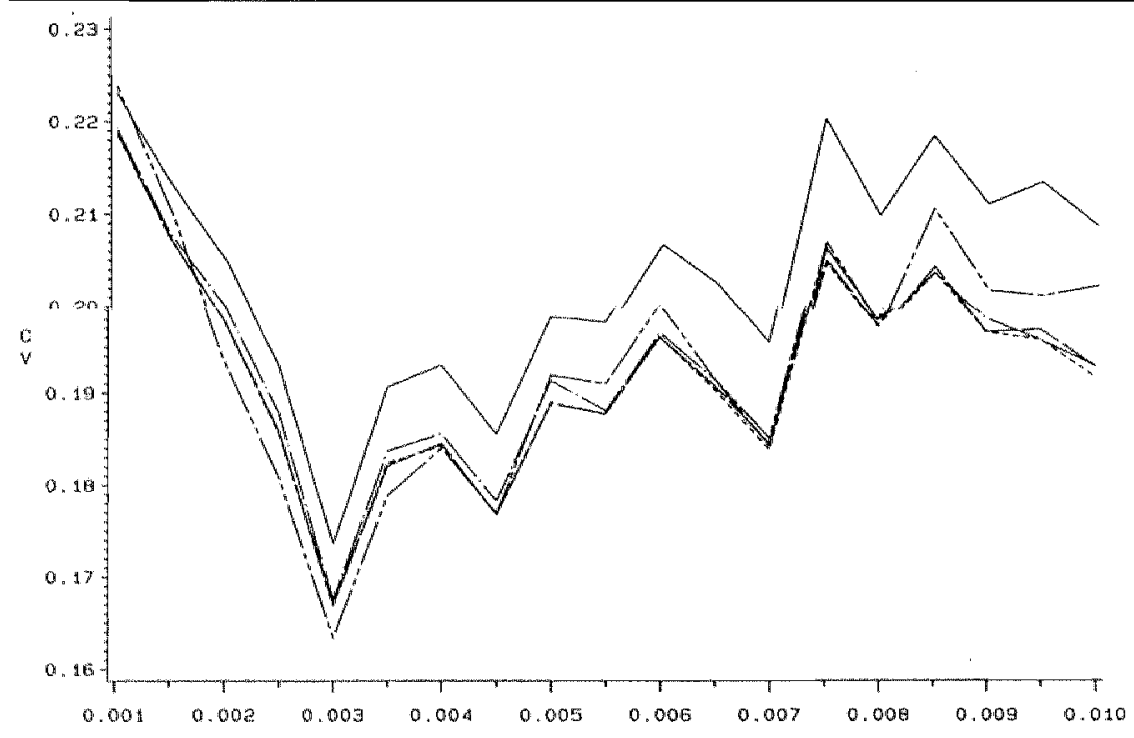

Fig. 7.6b. Coeffictent of Variation of the ML, Je, Be, S2 and MC estimators. Design as in Flg. 7.6a. 


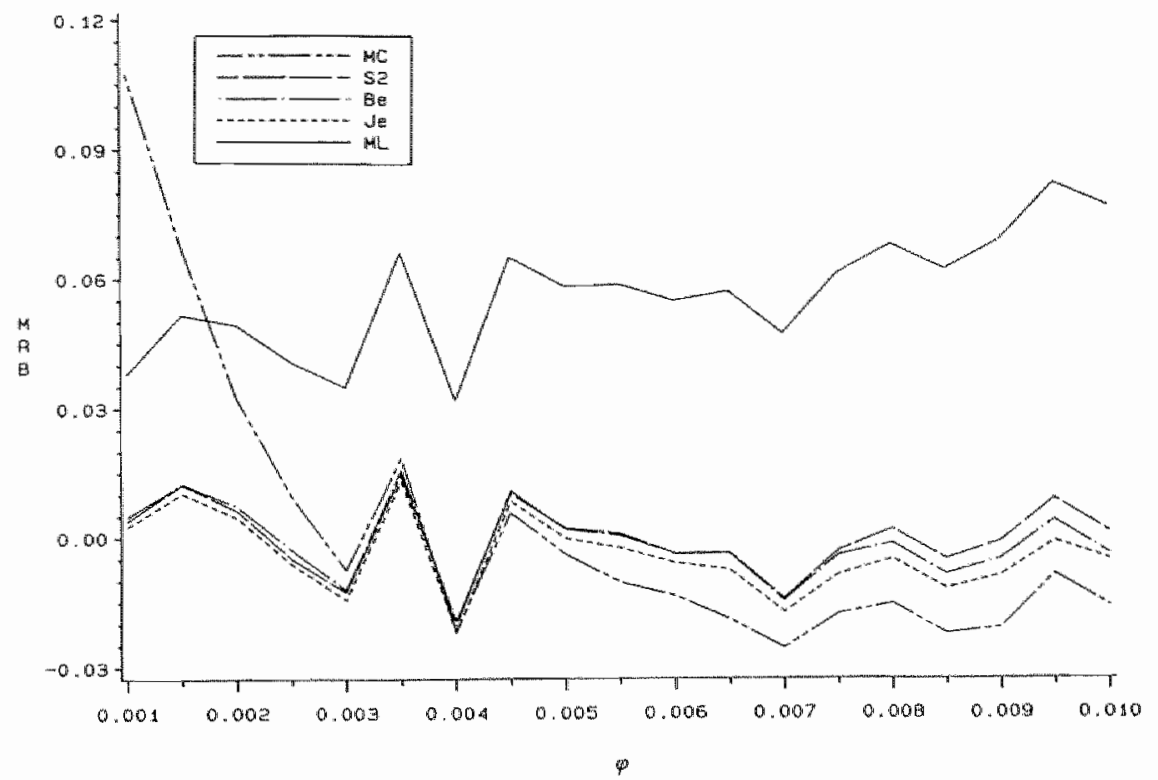

Fig. 7.7a. Mean Relative Bias of the ML, Je, Be, S2 and MC estimators. The design parameters are $p_{1}=0.001, \varphi_{2}=0.01, p_{1}=0.15, P_{2}=0.70, d=3$ (leading to $m=7)$ and $n=6$.

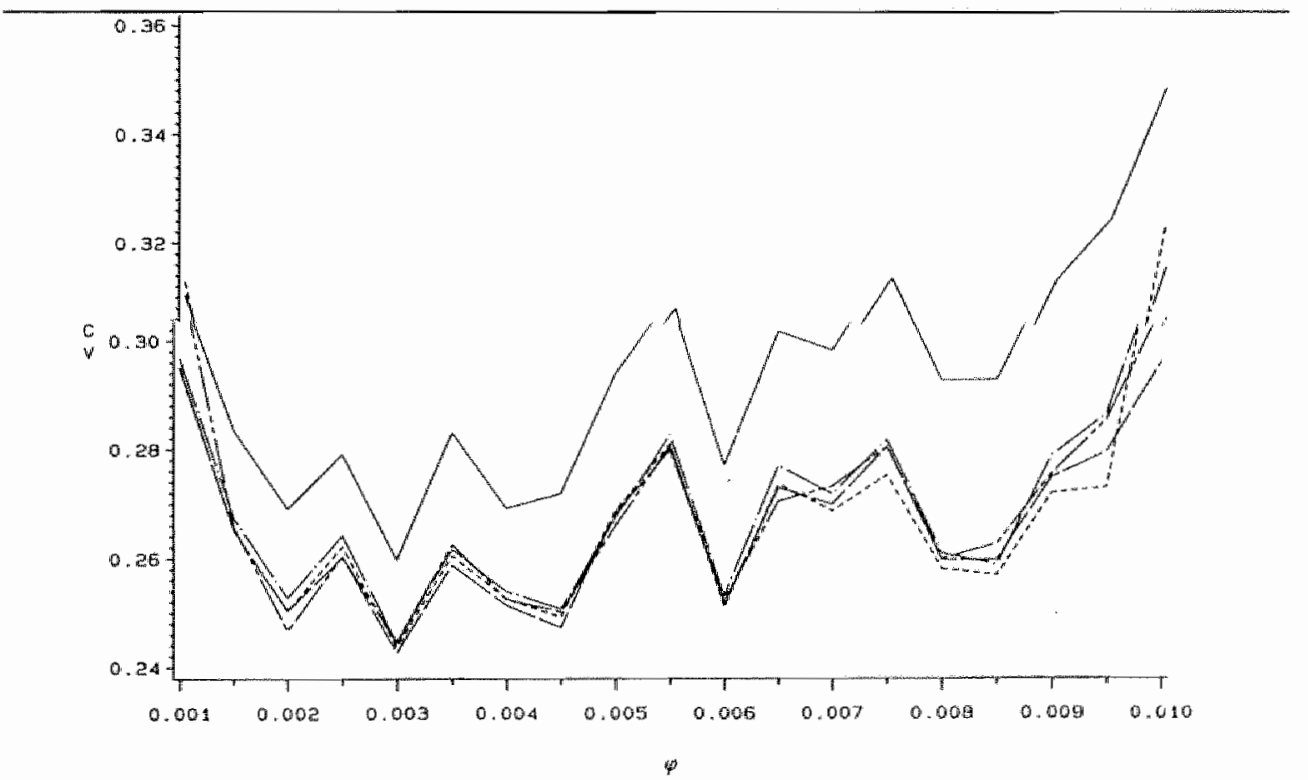

F1g. 7.7b. Coeffictent of Variation of the ML, Je, Be, S2 and MC estimators. Design as in Fig. 7.7a. 


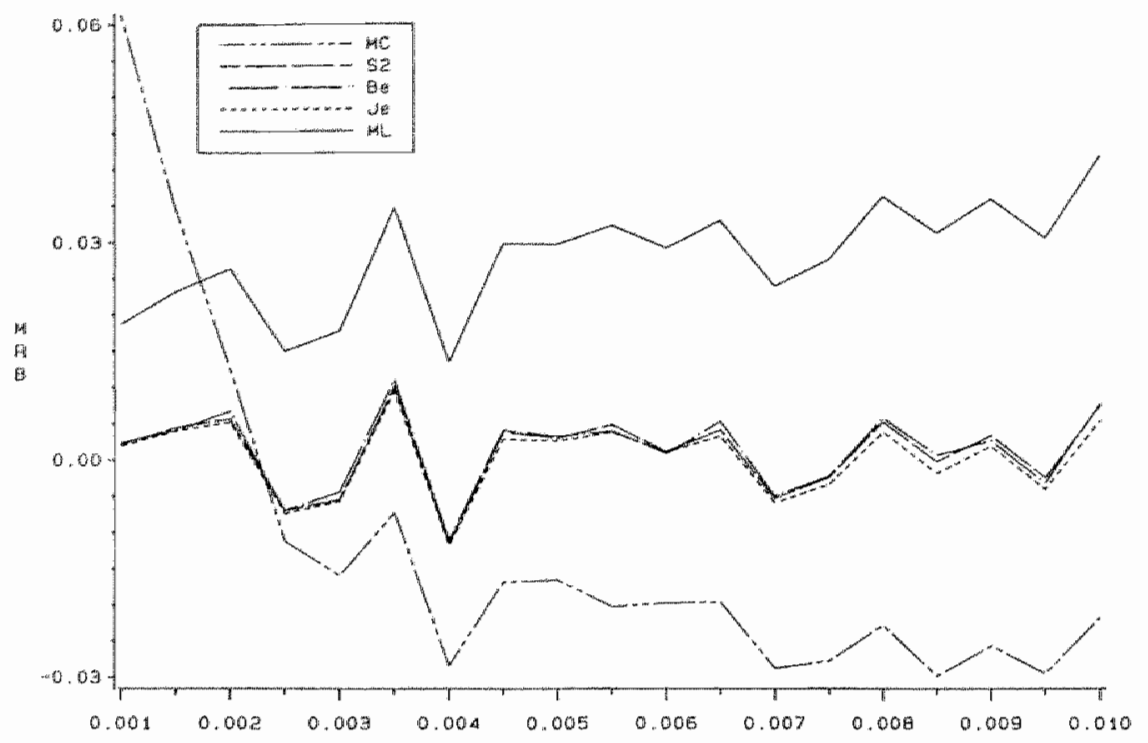

FIG. 7.8a. Mean Relative Blas of the ML, Je, Be, S2 and MC estimators. The destgn parameters axe $\varphi_{1}=0.001, \phi_{2}=0.01, p_{1}=0.15, P_{2}=0.70, d=3$ (Leading to $m=7)$ and $n=12$.

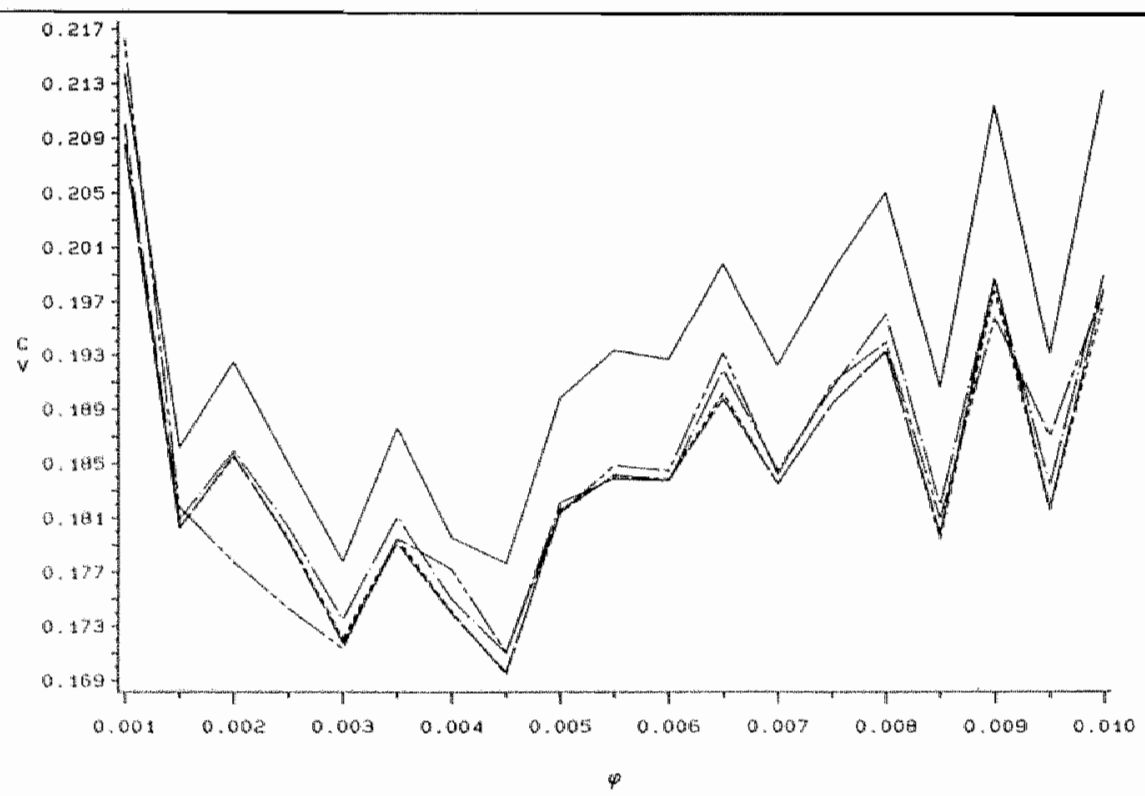

Fig. 7.8b. Coeffletent of Variation of the ML, Je, Be, S2 and MC estimators. Design as in Fig. 7.8a. 
The simulation study of Taswell

With regard to the MC estimator, the results of Taswell (1981) wil be discussed. He performed a study on the ML and MC estimators with (quoting) "Monte Carlo experiments for a wide range of values $\varphi\left(\varphi=1\right.$ to $\left.\varphi=10^{-6}\right)$ and a wide varlety of symmetric and asymmetric assay designs with $m=2$ to $m=5$ and $\Sigma_{i=1}^{m} n_{i}=48$ to 192 (symmetric and asymmetric assay designs are designs in which the doses $x_{i}$ are spaced evenly or unevenly, respectively, about a dose $x_{i}$ corresponding to $\mathbb{P}_{i}=0.5$ )". Furthermore he stated : "The efficiency of each estimator was observed to be independent of the value of $\varphi$ but dependent upon the values $n_{i}$ and $x_{i}$ of the assay design. $x^{2}$ minimization was clearly found to be the minimum-bias minimum-variance estimator of $\varphi$ as measured by the mean square error of the estimates". The fact that the value of $\varphi$ used did not influence the simulation results of Taswell (1981) is not. surprising and can be understood easily from the properties of the biological model (cf. Section 7.1). On the basis of the simulation results in this Chapter it is less obvious that MC should be preferred over ML. What is clear, however, is that the properties of the MC estinator with respect to the ML estimator strongly cepend on which design is used and for which values of $\varphi$ the simulations are performed. Since Taswel1 (1981) studied only designs for which the $x_{i}{ }^{\prime} s, i=1, \ldots, m$, are spaced evenly or unevenly about $-(\log 0.5) / \varphi$ there is an obvious explanation for his finding that depending upon the assay design ML has 3 to $15 \%$ greater bias and MSE than MC. Referring to Figures $7.4 \mathrm{a}-7.8 \mathrm{~b}$ it is noted that MC is always better than ML for some interval in the middle of the range $\left[\varphi_{1}, \varphi_{2}\right]$. this interval narrowing when $n$ increases. In the paper by Mantel. (1985) it is argued that the MC estimation procedure minimizes the retio of 15.9$)$ in two ways: reducing the numerator and increasing the denominator leading to a bias toward 50\% with respect to the binomial parameters involved. Thus, fitting by MC will tend to averestimate binomial parameters under $50 \%$, but underestimate those over 50\%. In LDA, this leads to overestimating p for values smalier and underestimating $\varphi$ for values larger than a certain value $\varphi_{i}$. The described phenomemon suggests that simulating the way Taswell (1981) did favours MC. A small Monte Carlo experiment has been performed to confirm the phenomenon. Attempting to construct a design which could be like one of the designs Taswell (1981) used, the following design parameters have been 
chosen for this experiment: $\varphi_{1}=0.001, \varphi_{2}=0.01, p_{1}=0.30, p_{2}=0.70$ and $d=2$. resulting in mo5. Note that the midale of the informative range is 0.5 .

Three walues of the true parameter value has been used: $\varphi_{1}, \varphi_{2}$ and $\sqrt{\varphi_{1} \varphi_{2}}=0.0032$ which corresponds to the value Taswell would have used in this situation. The number of replicates are 24, 48 and 96. respectively. Table 7.2 gives the resulting Mean Pelative Blas and Coefficient of Variation according to $(4.1)-(4.2)$.

\begin{tabular}{|c|c|c|c|c|c|c|c|c|c|}
\hline \multicolumn{6}{|c|}{$-\infty-$ STMULATION - - -PARAMETERS - - } & \multicolumn{2}{|c|}{$\cdots--M R B-\cdots$} & \multicolumn{2}{|c|}{ 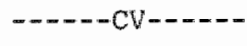 } \\
\hline$P_{1}$ & $P_{2}$ & $d$ & 的 & $n$ & $\varphi$ & ML & $\mathrm{MC}$ & ML & $\mathrm{MC}$ \\
\hline 0.30 & 0.70 & 2 & 5 & 6 & $\begin{array}{l}0.0010 \\
0.0032 \\
0.0100\end{array}$ & $\begin{array}{l}0.026 \\
0.047 \\
0.080\end{array}$ & $\begin{array}{r}0.156 \\
0.018 \\
-0.014\end{array}$ & $\begin{array}{l}0.391 \\
0.300 \\
0.340\end{array}$ & $\begin{array}{l}0.409 \\
0.264 \\
0.297\end{array}$ \\
\hline 0.30 & 0.70 & 2 & 5 & 12 & $\begin{array}{l}0.0010 \\
0.0032 \\
0.0100\end{array}$ & $\begin{array}{l}0.025 \\
0.019 \\
0.036\end{array}$ & $\begin{array}{r}0.105 \\
0.003 \\
-0.029\end{array}$ & $\begin{array}{l}0.274 \\
0.206 \\
0.231\end{array}$ & $\begin{array}{l}0.291 \\
0.190 \\
0.218\end{array}$ \\
\hline 0.30 & 0.70 & 2 & 5 & 24 & $\begin{array}{l}0.0010 \\
0.0032 \\
0.0100\end{array}$ & $\begin{array}{l}0.012 \\
0.019 \\
0.022\end{array}$ & $\begin{array}{r}0.054 \\
0.011 \\
-0.020\end{array}$ & $\begin{array}{l}0.197 \\
0.143 \\
0.154\end{array}$ & $\begin{array}{l}0.204 \\
0.137 \\
0.151\end{array}$ \\
\hline 0.30 & 0.70 & 2 & 5 & 48 & $\begin{array}{l}0.0010 \\
0.0032 \\
0.0100\end{array}$ & $\begin{array}{l}0.007 \\
0.007 \\
0.008\end{array}$ & $\begin{array}{r}0.029 \\
0.003 \\
-0.019\end{array}$ & $\begin{array}{l}0.133 \\
0.101 \\
0.101\end{array}$ & $\begin{array}{l}0.136 \\
0.099 \\
0.104\end{array}$ \\
\hline
\end{tabular}

Table 7.2. Illustration of the phenomenon that the MC estimation procedure

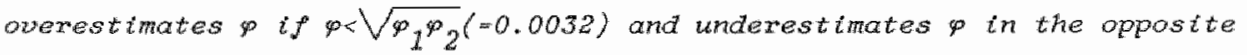
case when usting a destgn in which the values $x_{t}, t=1, \ldots, m$, are spaced eventy on a logarithric scale about $x=-(\log 0.5) / \sqrt{\varphi_{1} \varphi_{2}}$ where $\varphi_{1}=0.001$ and $\varphi_{2}=0.01$.

Finally, as concerns criterium (7.3), Figures $7 \cdot 9-7.13$ and Table $7 \cdot 3$ make clear that for almost all experimental situations the MC estimator of variance produces too small. $95 \%$ confidence intervals. Moreover, these data clearly demonstrate that the coefficient of variation defined on the basis of the standard deviation (see Section 7.1) when used as a criterium for comparing estimation methods would wrongly favour the MC estimator. 


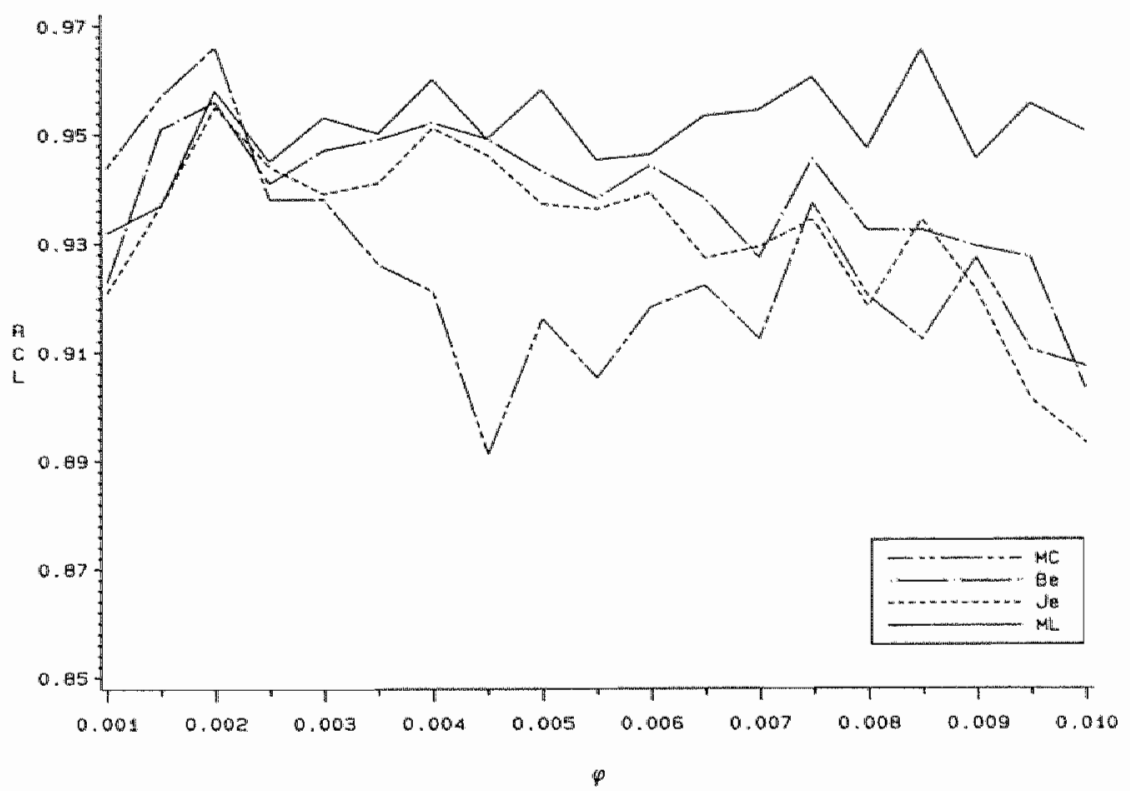

Fig. 7.9. Realized Confidence Levels for the ML, Je, Be and MC methods. The design parameters are $p_{1}=0.001, \varphi_{2}=0.01, p_{1}=0.15, p_{2}=0.70, d=2$ (leading to $m=4)$ and $m=6$.

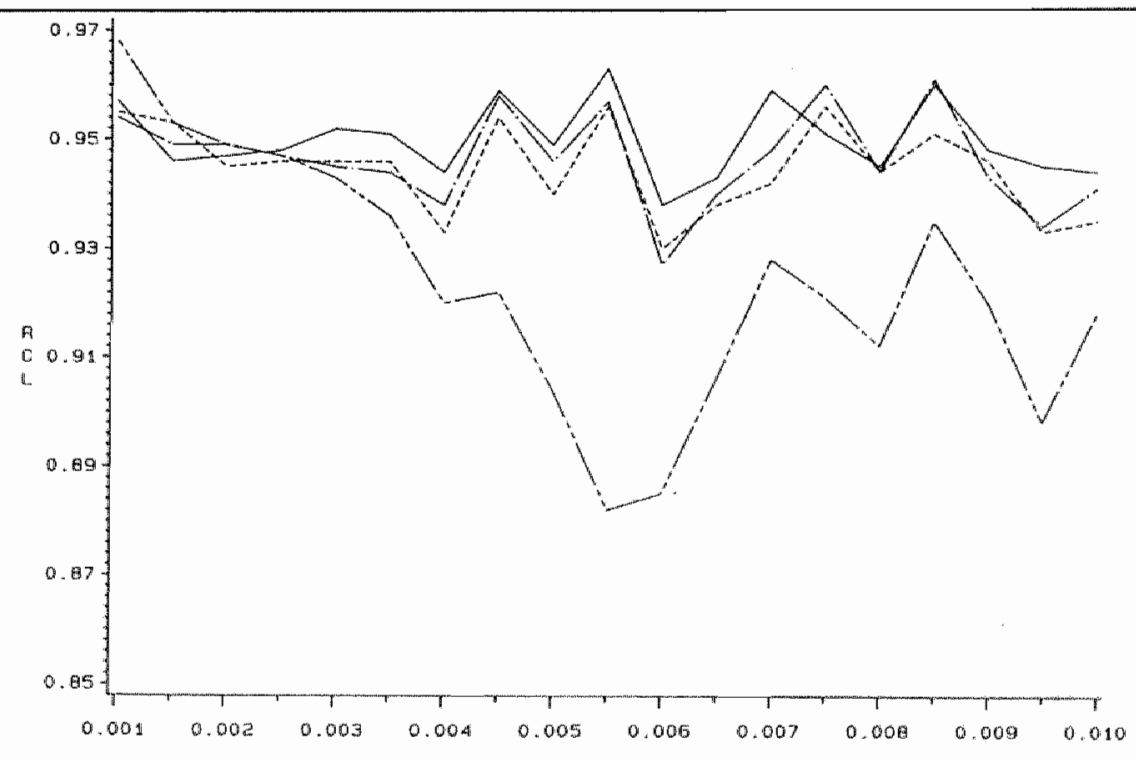

Fig. 7.10. Realized Confidence Levels for the ML, Je, Be and MC methods. The design parameters are $\varphi_{1}=0.001, \varphi_{2}=0.01, p_{1}=0.15, p_{2}=0.70, d=2$ (Leading to $m=4$ ) and $n=12$. 


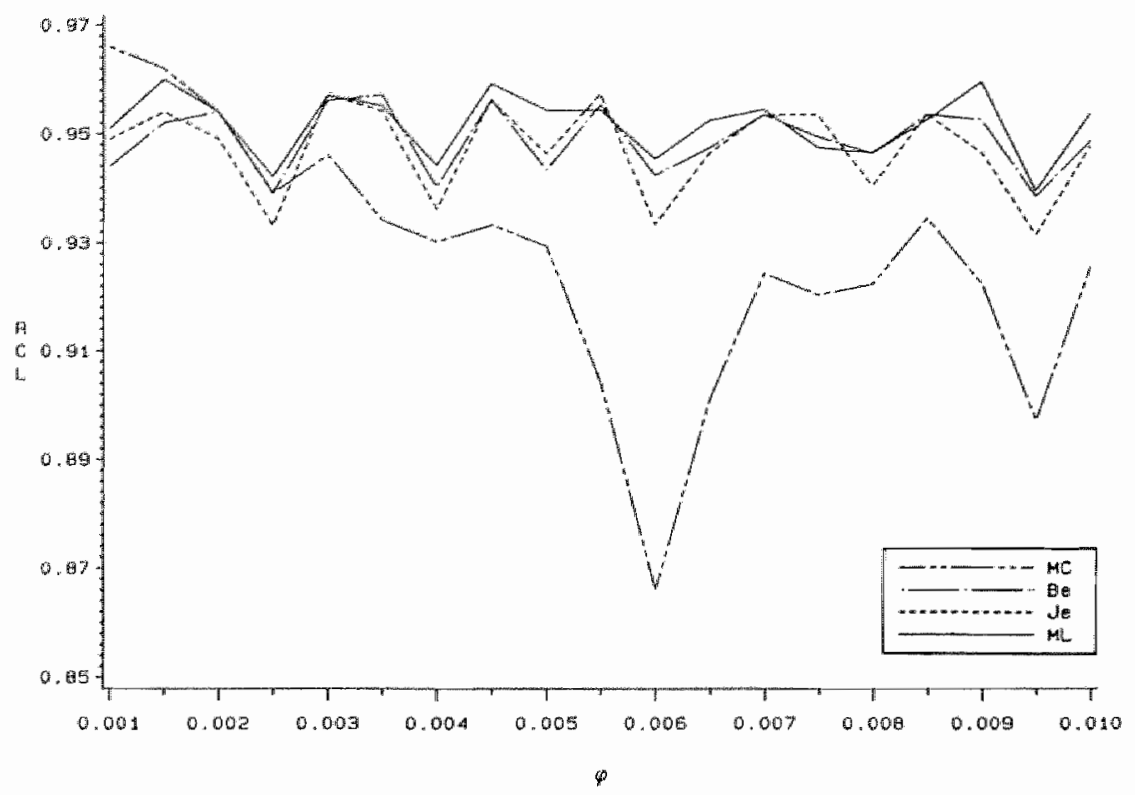

Fig. 7.11. Realtzed Conftdence Levels for the ML, Je, Be and MC methods. The destgn parameters are $\varphi_{1}=0.001, \varphi_{2}=0.01, P_{1}=0.15, P_{2}=0.70, d=2$ (Leading to
$m=4$ ) and $n=18$.

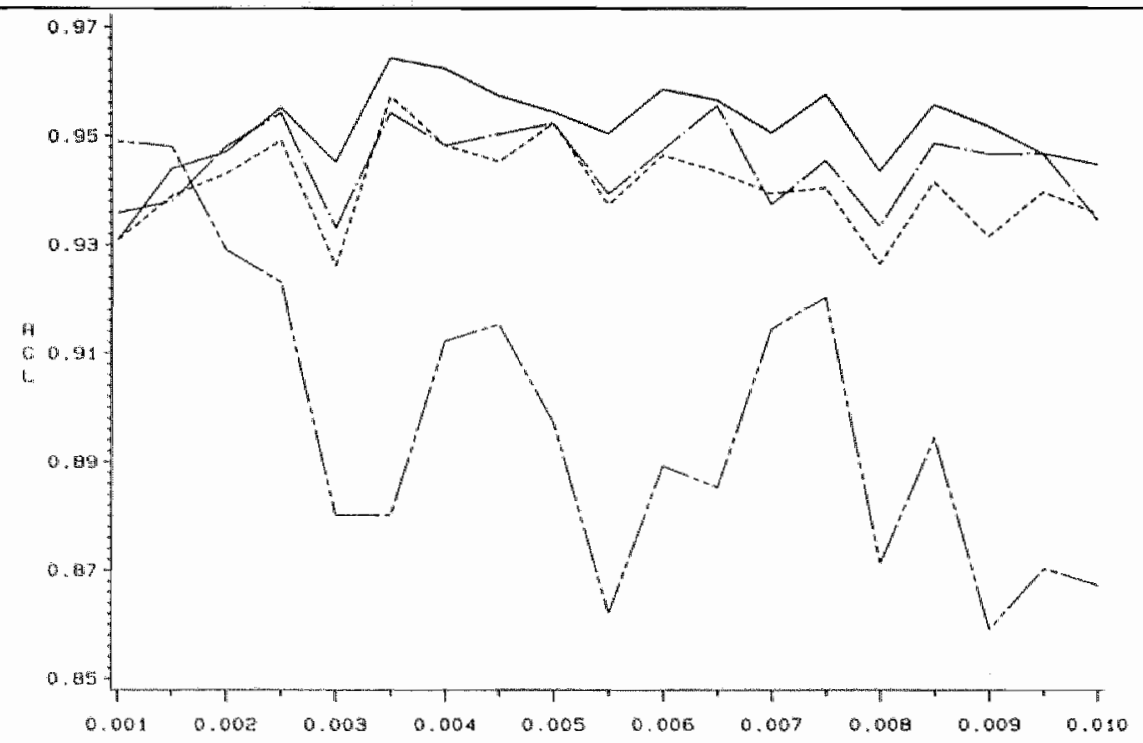

Fig. 7.12. Realtzed Conidence Levels for the ML, Je, Be and MC methods. The design parameters are $\varphi_{1}=0.001, \varphi_{2}=0.01, p_{1}=0.15, P_{2}=0.70, d=3$ (Leading to $m=7$ ) and $n=6$. 


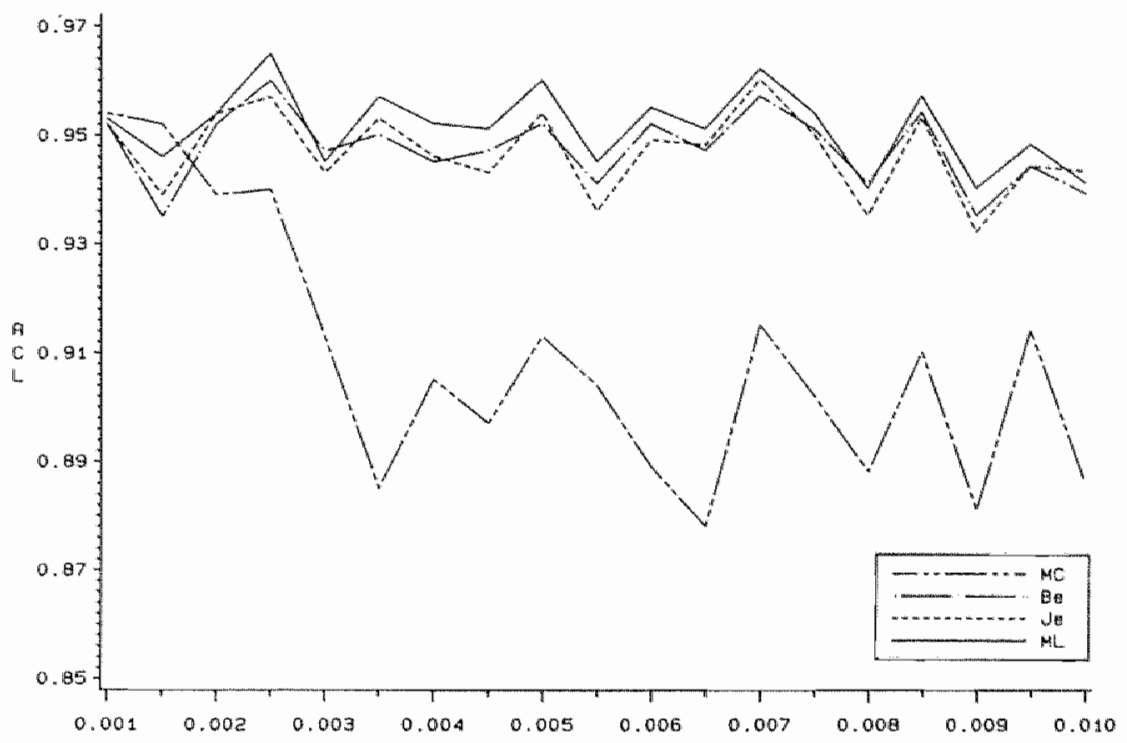

Fig. 7.13. Realtzed Confidence Levels for the $M L$, Je, Be and MC methods. The design parameters are $\varphi_{1}=0.001, \varphi_{2}=0.01, P_{1}=0.15, P_{2}=0.70, d=3$ (Leading to
$m=7$ ) and $n=12$.

The ML estimator of variance produces the best confidence intervals. The Je and Be estimators of variance produce on the average $95 \%$ confidence intervals which are slightly too small. However, using percentile points of the corresponding student distribution instead of the standard nomal distribution when calculating the $95 \%$ confidence bounds could correct the $\mathrm{Je}$ and Be confidence intervals satisfactorily.

\begin{tabular}{|c|c|c|c|c|c|}
\hline \multirow[b]{2}{*}{$\mathrm{n}=$} & \multicolumn{3}{|c|}{$d=2$} & \multicolumn{2}{|c|}{$d=3$} \\
\hline & 6 & 12 & 18 & 6 & 12 \\
\hline ML & 0.9506 & 0.9500 & 0.9514 & 0.9510 & 0.9514 \\
\hline $\mathrm{Je}$ & 0.9317 & 0.9447 & 0.9470 & 0.9404 & 0.9469 \\
\hline $\mathrm{Be}$ & 0.9382 & 0.9466 & 0.9486 & 0.9444 & 0.9474 \\
\hline MC & 0.9246 & 0.9235 & 0.9267 & 0.8981 & 0.9087 \\
\hline
\end{tabular}

Table 7.3. The tabutated figrures represent the mean values of RCL for the estimation methods and designs compared. 



\section{APPENDIX}

A PASCAL program for the simulation of limiting dilution experiments and the comparison of estimation methods.






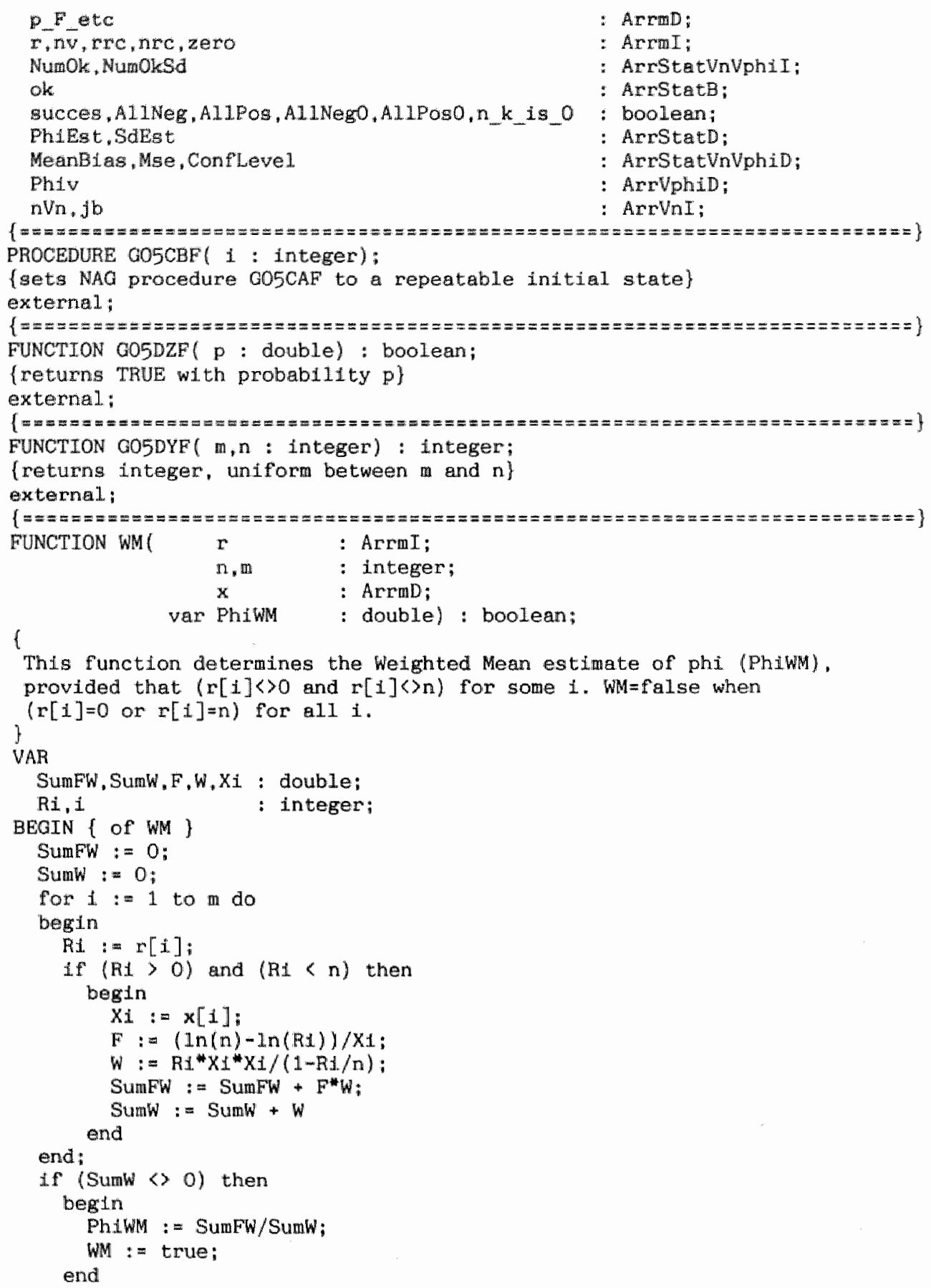


else WM: = false

END; \{ of WM \}

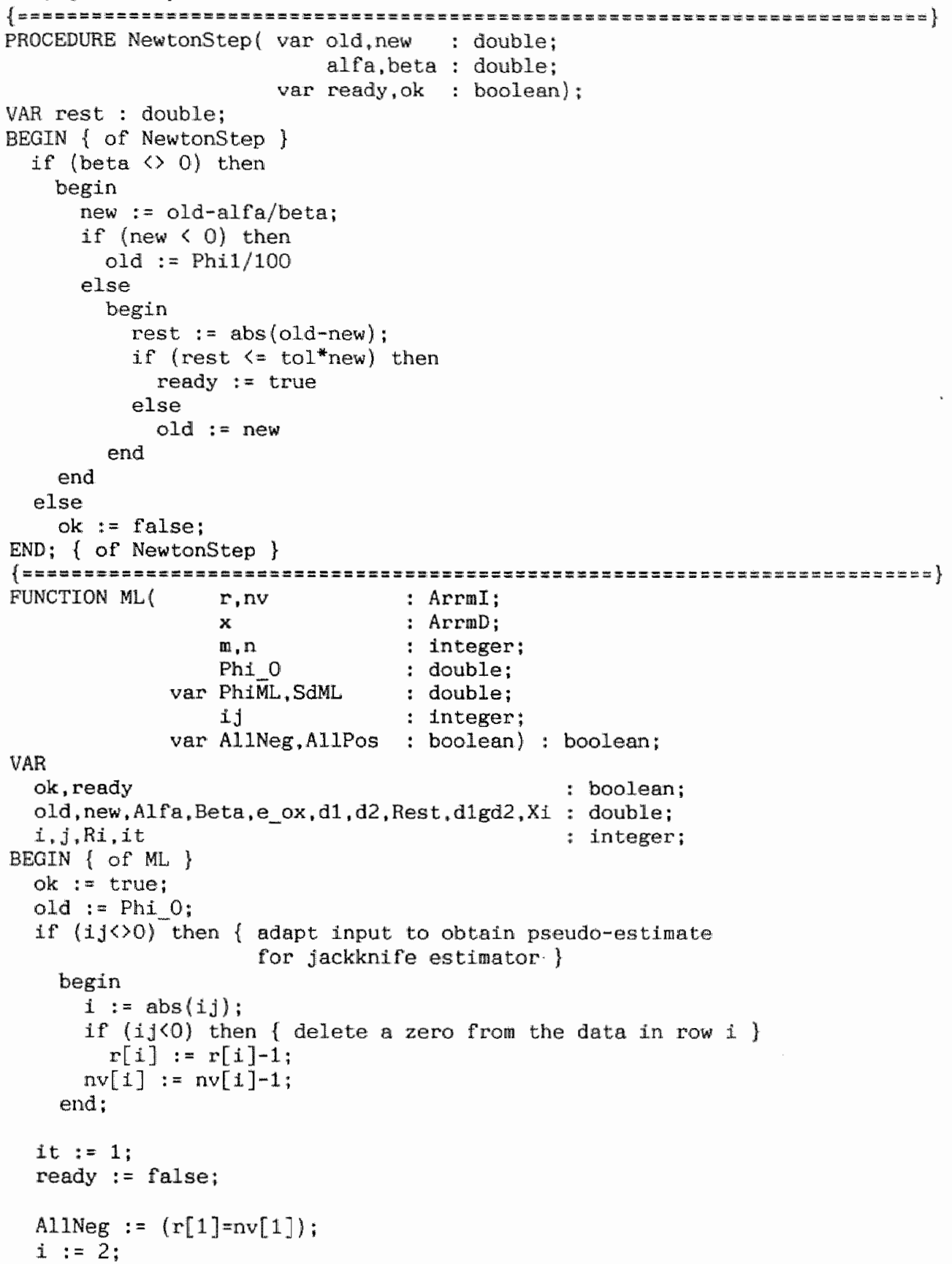




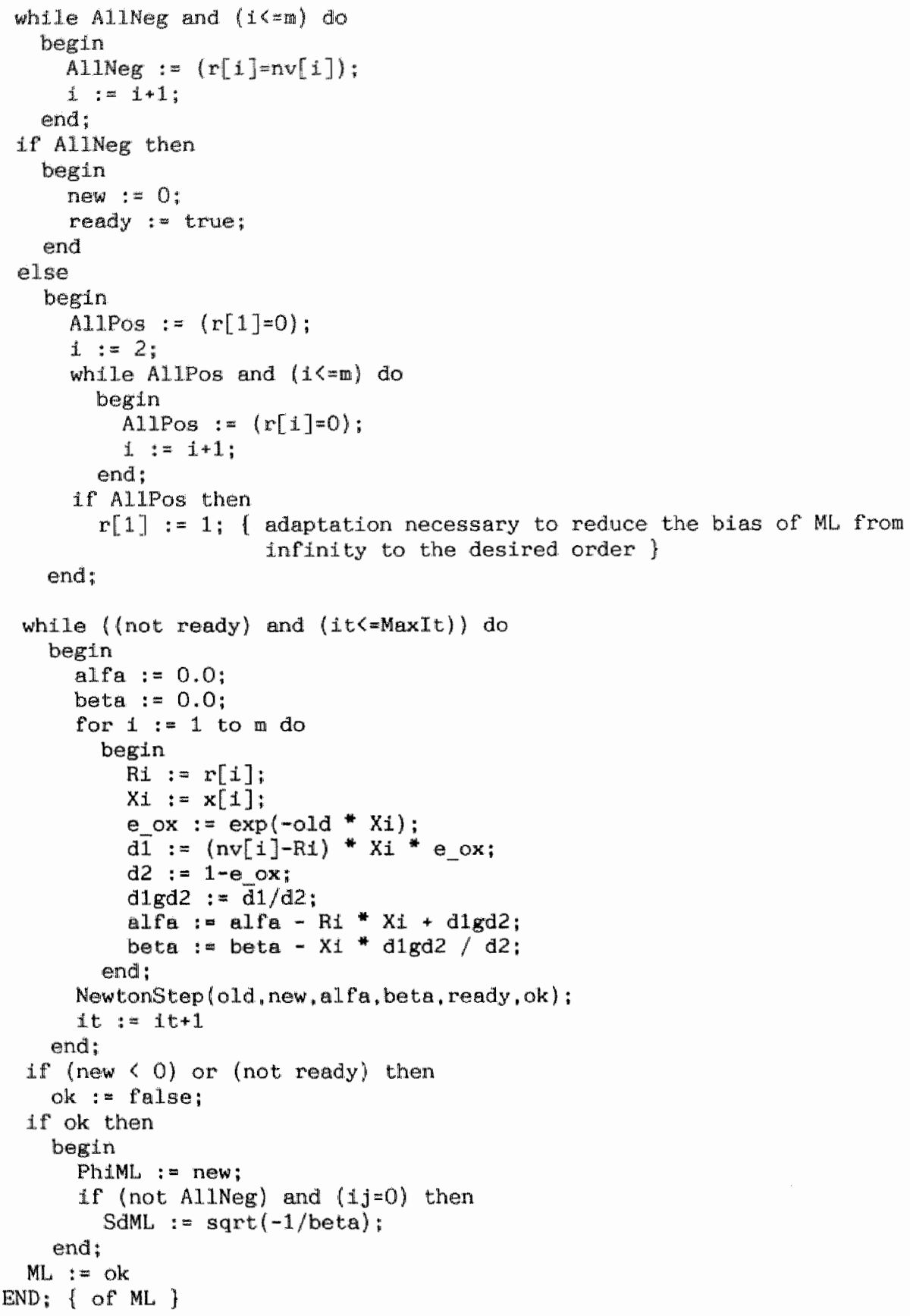




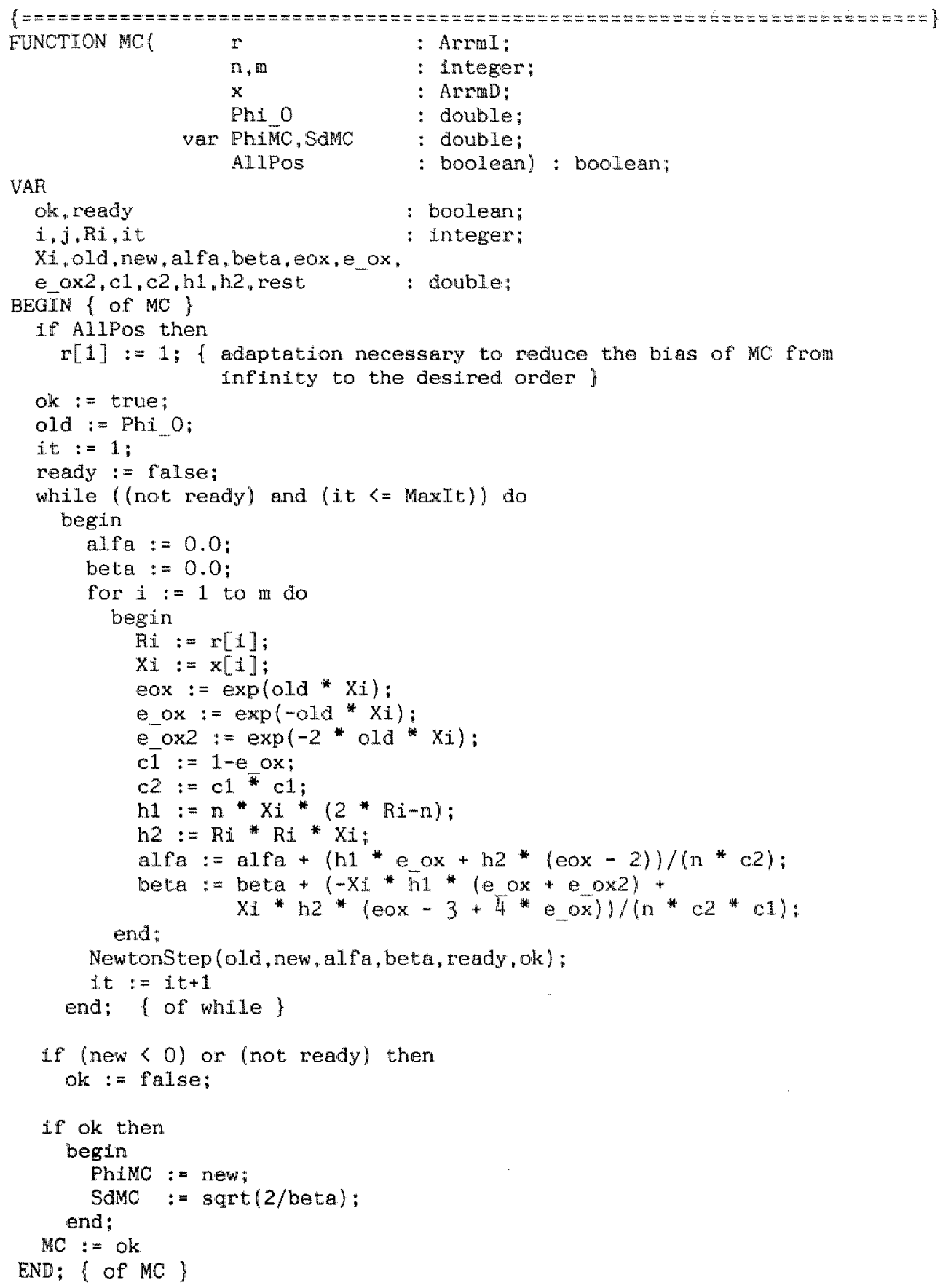




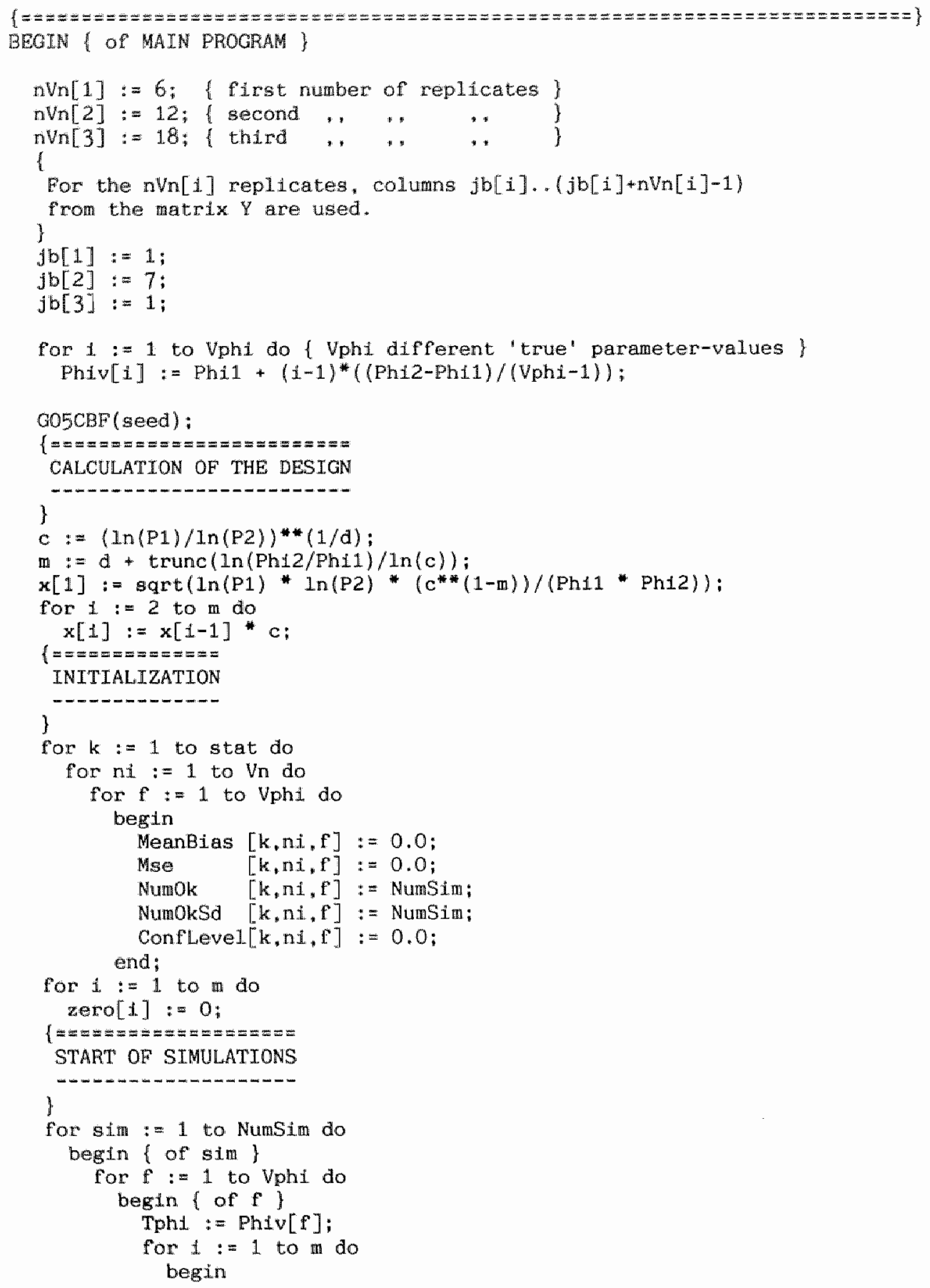




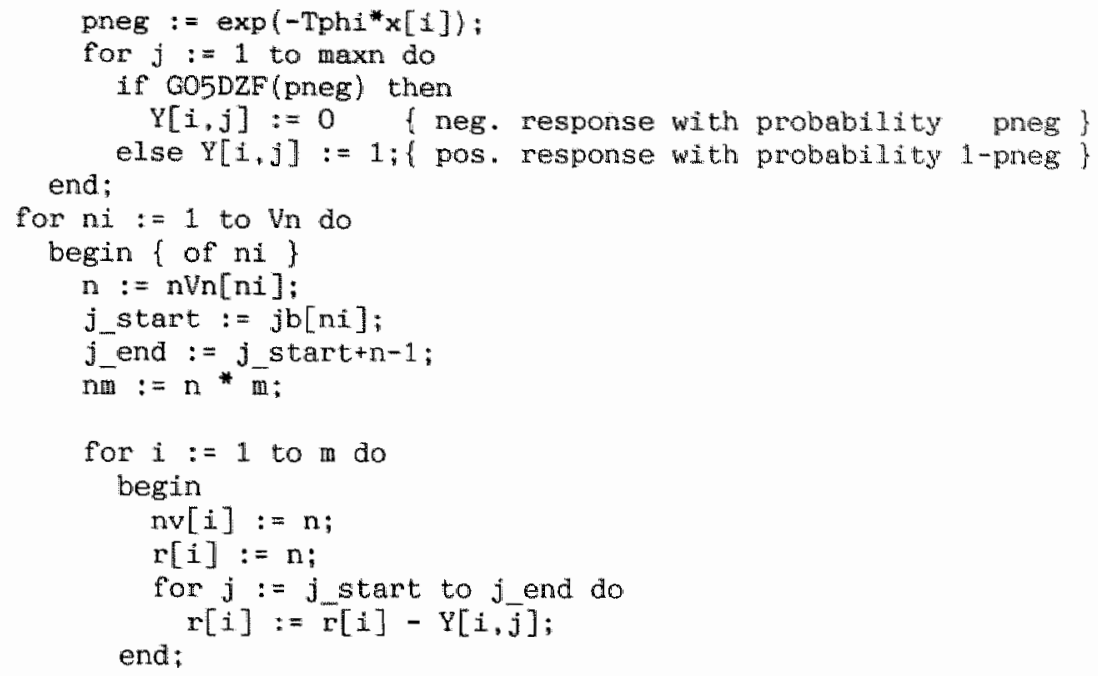




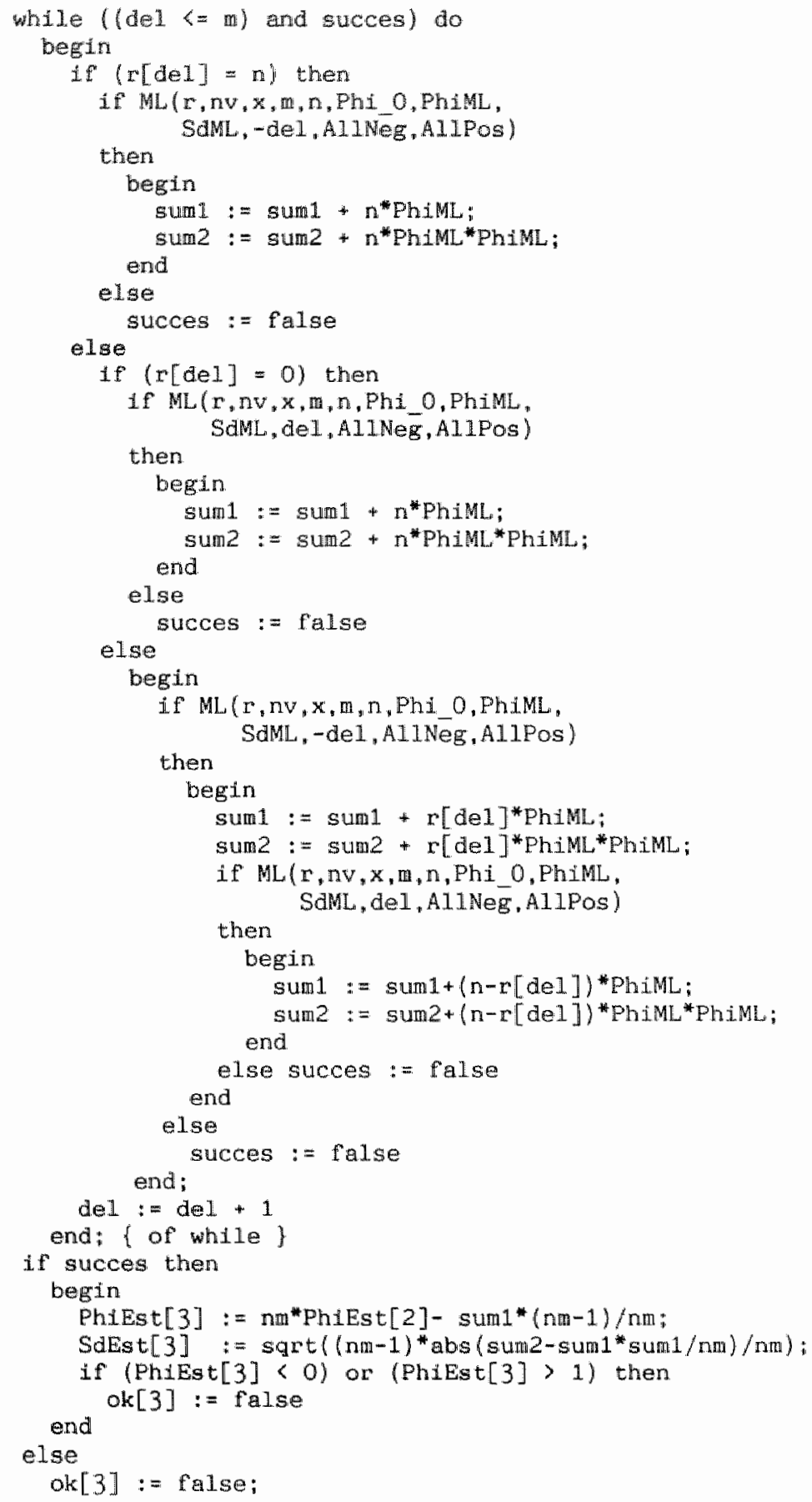




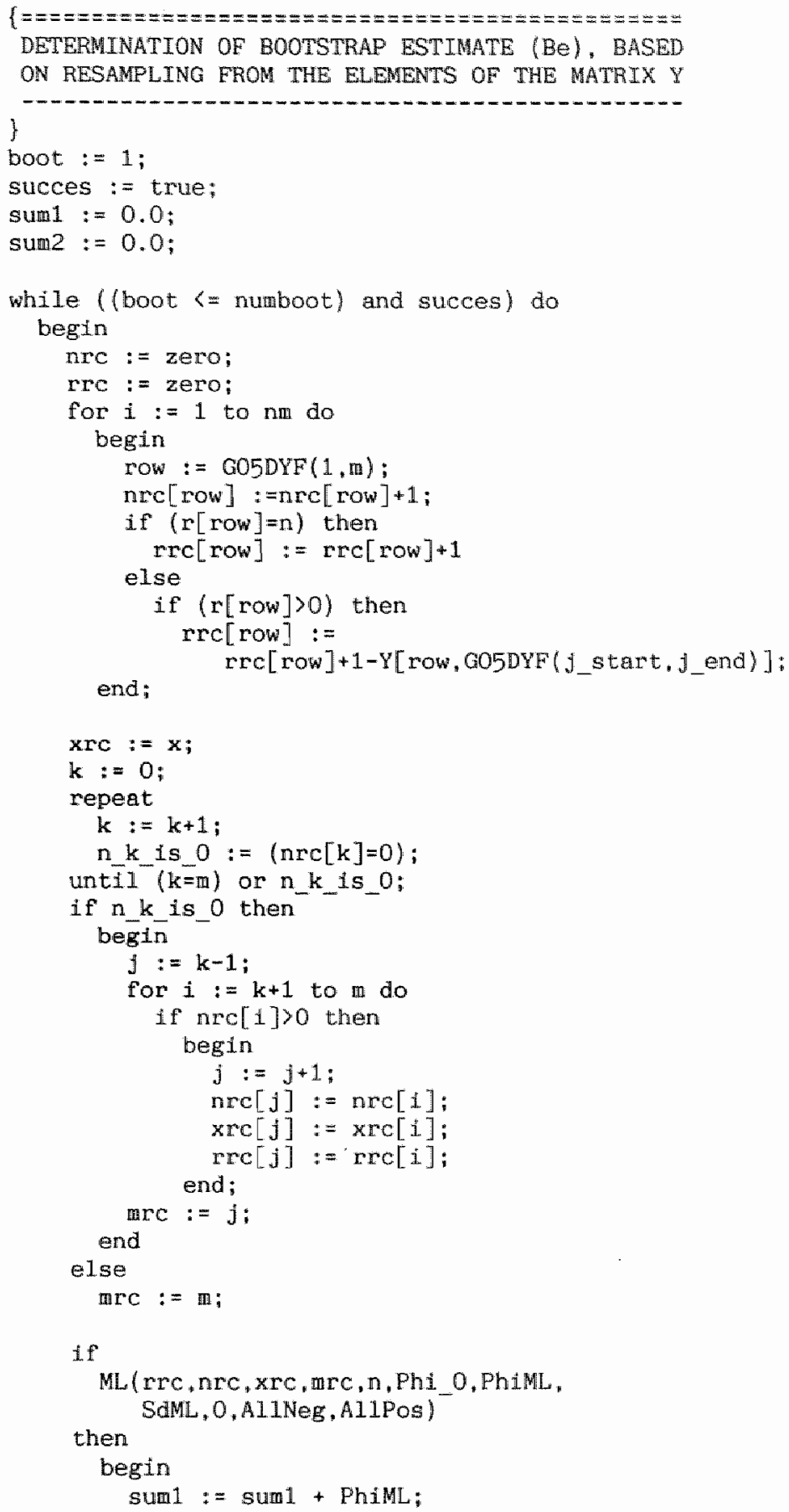


end:

PhiEst $[5]:=$ Phi_o - Sun2 $/ 2$;

if (PhiEst [5] (0) or (PhiEst[5]>1) then ok $[5]:=$ false

end

else \{(J,B,S)ML-estimates cannot be determined \}

for $i:=2$ to stat-1 do

ok $[i]:=$ false:

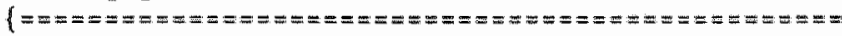

DETERMINATION OF MINIMUM CHI-SQUARE (MC) ESTIMATE

)

if (not AllNeg0) then

begin

if MC ( $r, n, m, x$, Phil_o,PhiEst [6],SaEst[6], AlIPos0) then ok $[6]:=$ true

else

ok [6] := false;

end;

$\{===z=z==x===$

UPDATE TABLES

\}

for $k:=2$ to stat do

if $(\mathrm{ok}[\mathrm{k}])$ then

begin

PhiEstk : = PhiEst $[k]$;

MeanBias $[k, n i, f]:=$ MeanBias $[k, n i, f]+$ PhiEstk;

Mse $[k, n i, f]:=$ Mse[k,ni,f] + PhiEstk * PhiEstk;

if $(k<>5)$ then \{an estimate for SdS2 is not avajleble\} begin

SdEstk : $=$ SdEst $[k]$;

if AllNego or (SaEstk=0) then

NumOkSa $[k, n i, f]:=\operatorname{NumOkSd}[k, n i, f]-1$

else

If (PhIEstk+1.960*SaEstk $>=$ Tphi) and

(PhiEstk-1.960* SdEstk $<=$ Tphi) then

end

end

else

begin

NunOk $[k, n d, f]:=$ NumOk $\left[k, n \mathbb{1}, f^{c}\right]-1$;

NumOkSd[k,n1,f] $:=$ NumOkSd[k, n1, f $]-1 ;$ end:

end $\{$ of $n i\}$

end $\{$ of $f\}$

end; $\{$ of $\operatorname{sim}\}$

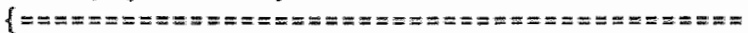

WRITING THE RESULTS TO STANDARD OUTPUT FILE

) 


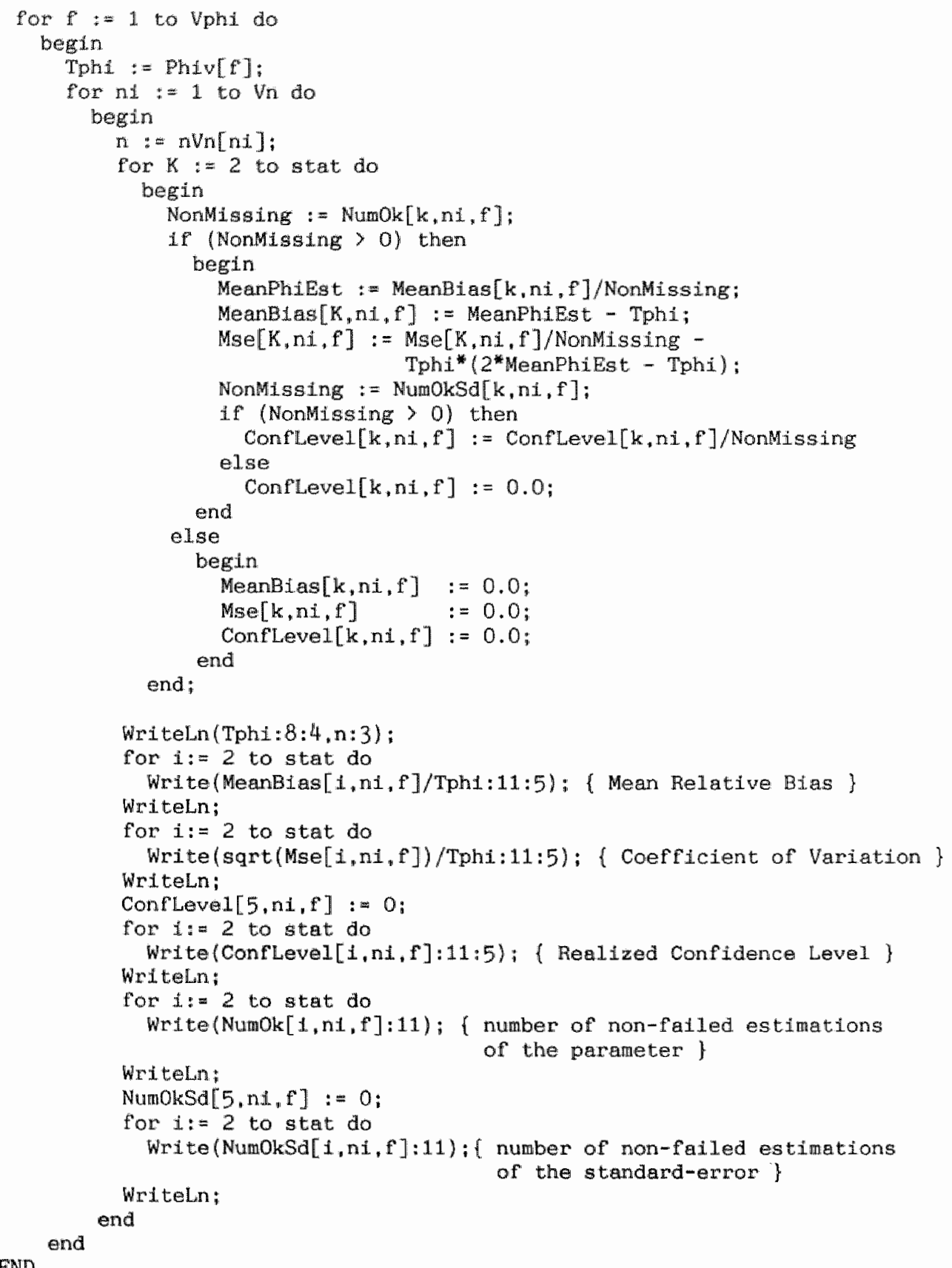

END. 


\section{REFERENCES}

Amemiya, T. (1981). Qualitative response models: a survey", Jowmat of Economic Literature, 19. 1483-1536.

Ashton, W.D. (1972), The Logit Transformation, London : Oriffin.

Berkson. J. (1944). Application of the logistic function to bio-assay, Journal of the American Statistical Assoctation, 39, 357-365.

Berkson, J. (1980), Minimum chi-square, not maximum likelihood!, Annals of Statistics, $8,457-487$.

Bickel, P.J. and Doksum, K.A. (1977), Mathematicat Statistics : Basic Ideas and Selected Topics, San Francisco : Holden-Day.

Bishop, Y.M.M., Fienberg, S.E., and Holland, P.W. (1975), Discrete Muitivariate Analysis, Theory and Practice, Cambridge, Mass.: MTT Press.

Brillinger, D.R. (1964). The asymptotic behaviour of Tukey's genereI method of setting approximate confidence limits (the jackknife) when applided to maximum 1 ikelihood estimates, Revtew of the Internationat Statistcal Institute, 32, 202-206.

Brown, B.Wm., Jr. (1966), Planning a quantal assay of potency, Blometrtes, 22, $322-329$.

Buurman, W.A., Daemern, A.J.J.M., Groenewegen, Q., Does, R.J.M.M., Wan der Linden, C.J. and Vegt, P.A. (1983), Limiting dilution analysis of canine alloantigen-reactive T 1ymphocytes. Transplantation, 32. 363367 . 
Chibisow, D.M. (1973), An asymptotic expansion for a class of estimators containing maximum likelihood estimators. Theory of probabllity and Its Apptications, $18,295-303$.

Cochran. W.G. (1950). Estimation of bacterial densities by means of the 'Most probable number', Blometrtics, 6. 105-116.

Cox, D.R. (1970), The Analysls of Binary Data, London : Methuen.

Daellenbach, H.G., George, J.A. and McNickle, D.C. (1983), Introduction to Operations Research Techniques, Boston : Allyn and Bacon.

Daganzo, C. (1979). Multtnomlal Probtt, New York : Acadenic Press.

Devison, A.C., Hinkley, D.V, and Schechtman, E. (1986), Efficient bootstrap simulation, Btometrika, 73, 555-566.

Does, R.J.M.M., Strifbosch, L.W.G. and Albers, W. (1988), Using jackknife methods for estimating the parameter in dilution series. Btometrics, 44. 1093-1102.

Does, R.J.M.M., Strijbosch, L.W.G. and Buurman, W.A. (1988), Dilution series : experimental design and statistical analysis. The Proceedings of the 1-st World Congress on Mathematical Statistics and Probability, Nauka Publishing House, Moscow.

Doveren, R.F.C., Bururman, W.A., van der Linden, C.J., Strijbosch, L.W.G., Sproncken, E.E.M. and Kootstra, G. (1986), Analysis of cytotoxic T lymphocyte response in rejecting allografted canine kidneys, Transplantation, 41, 33-38.

Efron, B. (1979), Bootstrap methods : another look at the jackknife, Annals of statistics, 7. 1-26.

Efron, B. (1982), The Jackknife, the Bootstrap and other Resampling plans, Philadelphia : SIAM. 
Efron, B. and Tibshirani, $\mathbb{R}$. (1986), Bootstrap methods for standard errors, confidence intervals, and other measures of statistical accuracy. Statisteat setence, 1. 54-77.

Eisenhart, C. and hilson. P.W. (1943), Statistical methods and control in microbiology, Bacteriologtcal Reviews, I. 57-137.

Fazekas de St. Groth, S. (1982). The evaluation of limiting dilution assays, Joumat of Immunologtcal Methods, 49. R11-R23.

Finney, D.J. (1947). The principles of biological assay, Journat of the Royal Statistical Society, Series B Suppt., 2, 46-91.

Finney, D.J. (1951), The estimation of bacterial densities from dilution series, Journal of Hygiene, 49, 26-35.

Finney, D.J. (1971), Problt Anatysis, 3nd Edition, Cambridge : University Press.

Einney. D.J. (1978), Statistical Method in Biological Assay, 3rd Edition, New York : Academic Press.

Fisher, R.A. (1922), On the mathematical foundations of theoretical statistics. Royal Society of the London phi Losophical Transactions (Series A), 222, 309-368.

Fisher, R.A. and Yates, F. (1963). Statisttcat Tables for Btological, Agricultural and Medlcal Research, 6th Edition, EdInburgh : Oliver \& Boyd.

Haberman, S.J. (1974), The Analysis of Frequency Data, Chicago: University of Chicago Press.

Haberman, S.J. (1978), Analysts of Qualttative Data, Vol. I. Introductory Topics, New York : Academic Press. 
Habertan, S.J. (1979). Anatysts of Qualtative Data, Vot. II. New Developments, New York : Acadenic Press.

Halworson, H.O. and Zlegler, N.R. (1933). Application of statistics to problems in bacteriology. II. A consideration of the accuracy of dilution data obtalned by using a single dilution, Jownal of Bacteriology, 26. 331-339.

Hamilton, M.A. (1979). Robust estimates of the ED50, Journal of the Amertcan Statisticat Assoctation, $74.344-354$.

Hamilton, M.A. (1980). Inference about the ED50 using the trimmed SpearmanKarber procedure - A Monte Carllo investigation "Communications in Statistics - Stmulation and Computation, Bg(3), $235-254$.

Hs1. B.P. (1969). The multiple sample up-and-down method in bioassay. Joumal of the American Statisticat Association, 64, 147-162.

Johnson, E.A. and Brown, B.Wm. "Jr. (1961). The Spearnan estimator for serial dilution assays, Biometrics, 17, 79-88.

Kendall, M.G. and Stuart, A. (1973). The Advanced Theory of Statisties, 3rd Edition, London : Griffin.

Karber, a. (1931). Beltrag zur kollektiven Behandlung pharmakologischer Rethenversuche, Arch. Exp. Path. Pharmak., 162, 480-487.

Lefkovits, I, and Waldmann. H. (1984), Limiting dilution analysis of the cells of immune system. I. The clonal. basis of the immune response, Immunology Today, 5, 265-268.

Loyer, M.W. (1981). Using a serial dilution experiment to estimate the denstty of organlsms, Unpubltshed Ph.D. Thesis: Montana State untuensity. 
Loyer, M.W. and Hamilton, M.A. (1984). Interval estimation of the density of organisms using a serial-dilution experiment, Blometwics, 40, 907-916.

Mantel. M. (1985). Maximum likelihood vs, minimum chi-square. Biometrics, $41,777-783$.

Maryanski, J.L., Cerottini, J.-C. and Brunner, K.T. (1980), Susceptibility of proliferating cytolytic T lymphocytes to 33258 Hoechst-modified BUdR and light treatment : quantitation of the residual precursor cells by limiting dilution analysis, Journat of Immunotogy, 124, 839-845.

Maryanski, J.L., MacDonald, H.R. and Cerottinl, J.-C. (1980), Limiting dilution analysis of alloantigen-reactive $T$ lymphocytes. IV. High frequency of cytolytic $T$ lymphocyte precursor cells in MLC blasts separated by velocity sedimentation, Jaumal of Immunology, 124. 42-47.

Mather, K. (1949), The analysis of extinction time data in bloassay, Btometxics, $5,127-143$.

McCarthy, J.A., Thomas, H.A., Jr. and Delaney, J.E. (1958), Evaluation of the reliability of coliform density counts. American Journal of Pubitc Health, 48, 1628-1635.

McCrady, M.H. (1915), The numerical interpretation of fermentation-tube results, Joumal of Infectious Diseases, 17. 183-212.

Miller, R.G. (1974). The jackknife - a review, Btometrtka, 61, 1-15.

Milier, R.G. (1982), Clonal analysis by limiting dilution. An overview. In Isolation, Charactertzation, and Vtltzation of $T$ Lymphocyte Clanes. (C.G. Fathman and F.W. Fitch, eds,). Chap. 1.8, pp. 219-231. New York : Academic Press.

Okamoto, M. (1958). Some inequalities relating to the partial sum of binomial probabilities, Annals of the Institute of Statistical Mathematics, 10, 29-35. 
Peto, S. (1953). A dose-response equation for the invasion of microorganisms, Btonetritcs, 2, 320-335.

Plackett, R.L. (1974), The Analysts of Categarical Data, London: Griffin.

Quenouille, M.H. (1949), Approximate tests of correlation in time series, Jourrat of the Royal Statistical Society, Sertes B, 11, 18-84.

Quenouille, M.H. (1956), Notes on bias in estimation, Btometrika, 43. 353360.

Rao, C.R. (1957). Theory of the method of estimation by minimum chi-square, Bulletin de l'Inst tut International de Statistique, 35. 25-32.

Salama, I.A., Koch, G.G. and Tolley, H.D. (1978), On the estimation of the most probable number in a serial dilution experiment, Communteations in Statistics - Theoxy and Methods, A7(13), 1267-1281.

Spearman, c. (1901). The method of the 'right and wrong cases' ('constant stimuli') without Gauss's formulae, Brittsh Journal of Psychology, 2 . $227-242$.

Strijbosch, L.W.G. Buurman, W.A., Does, R.J.M.M., Zinken, P.H. and Groenewegen, G. (1987), Limiting dilution assays : experimental design and statistical analysis, Joumal of Immunological Methods, 27. 133140.

Strijbosck, L.W.G, and Does, R.J.M.M. (1988), Comparison of bias-reducing methods for estinating the parameter in dilution series, Communtcations in Statistics - Stmulation and Computation, B17(4). $1173-1190$.

Strijbosch, L.W.G., Does, R.J.M.M. and Albers, W. (1988), Design methods for some dose-response models, Medical Informatics and Statistics Report, 21, University of Limburg, Maastricht, Submitted for publication. 
Strijbosch, L.W.G., Does. R.J.M.M. and Burman, W.A. (1987), Experinentele proefopzet en statistische analyse wan verdunigsreeksen (in Dutch). Kwantitatieve Methoden, 24, 149-160.

Strijbosch, L.W.G., Does, R.J.M.M. and Buurnen, W.A. (1988), Computer dided design and evaluation of limiting and serial dilution experiments. International Joumal of Bio-Medical Computing. 23, 279-290.

Taswel1, C. (1981), Limiting dilution assays for the determination of immunocompetent cell frequencies. I. Data analysis, Joumal of Immonotogy, 126, 1614-1619.

Taswe11, C. (1984), Limiting dilution assays for the determination of immunocompetent cell frequencies III : Validity tests for the singlehit Poisson model. Joumal of Immunological Methods, $72,29-40$.

Taswel1. C. (1987), Limiting dilution assays for the separation. characterization, and quantitation of biologically active particles and their clonal progeny. In Cell Separation: Methods and Selected Applications, 4, Pretlow, T.G. and Pretlow, T.P. (eds), 109-145. New York : Academic Press.

Thomas, H.A., Jr. $(1942)$, Bacterial densities from fermentation tube results, Journal of the Amertcan Water Works Association, 34. 572-576.

Thomas, H.A., Ir. (1955). Statistical analysis of collform data, Sewage and Industrtal Wastes, 27. 212-22.2.

Thomes, H.A., Jr. and Woodward, R.L. (1955). Estimation of collform density by the membrane filter and the fermentation tube methods, Amertcan Journal of Publtc Health, 45. 1431-1437.

Tsutakawa, R.K. (1972), Design of experiment for bloassay. Journal of the Amertcan Statistical Assoctation, 67. 584-590. 
Tsutakawa, R.K. (1980). Selection of dose levels for estimating a percentage point of a logistic quantal response curve. Applied Stattstics, 29, 2533.

Tukey $J . W .(1958)$, Blas anc confidence in not quite large samples. abstract, Arricls of Mathematical Statistics, 29, 614.

Tukey. J.W. (1977), Exploratary Data Analysts, Reading, Mass.: AddisonWesley.

Vose, B.M. and Bonnard, C.D. (1983), Limiting dilution analysis of the frequency of human $\mathrm{T}$ cells and large granular lymphocytes proliferating In response to interleukin 2. I. The effect of lectin an the proliferative frequency and cytotoxic activety of cultured lymphoid cells, Journat of Immunolagu, 130, 687-693.

Wetheril1, G.B. (1963), Sequential estimation of quantal response curves, Journat of the Royal Statstical Soctety. Sertes B., 25. 1-48.

Woodward, R.L. (1957). How probable is the most probable number" Journat of the Amertcan Water Works Assoctation, 49, 1060-1068.

Wu, C.F.J. (1986), Jackknife, bootstrap and other resampling methods in regression analysis, Annals of Statistics, 14, 1261-1295. 


\section{SUMMARY}

This thesis is a contribution to the theory of Limiting and Serial. Dilution Assays (LDA's. SDA's) which are used in many areas of bioresearch. In general, the air of such an assay is the estimation of the frequency of a particular cell type among other but similar cells (LDA), or the estimetion of the density of particular cells or microorganisms per unit volume of solution (SDA). In bath LDA and SDA the unknown parameter is commonly estimated by using the "single-hit Poisson model" with binary" (positive or negative) data produced by samples taken from different dilutions. In this study research has been performed on two important statistical issues of bioassays. These are the construction of an experimental design and the choice of the estimation techniques to be used.

For the setup of a design for a LDA or SDA one has to choose the number of dilutions, the number of replicates in each dilution and the (mean) number of cells/organisms per replicate. A design which has been constructed properly should take advantage of existing a priori information of the researcher and incorporate simple design paraneters chosen by the researcher" in such a way that the production of useless data is limted and the precision of the estimator is controlled. In Chapter 2 a useful and simple method for setting up a design on the basis of the researcher's criteria and a priori information about the unknown parameter is presented. Refinements for this design method and a program to perform these techniques are presented in chapter 3 . The methads of Chapter 2 and 3 regard the experimental design for LDA"s and SDA"s. The basic design method of chapter 2 can be generalized to some other rellated and widelly used biological models, such es the "logistic regression model" which is most common in bloassay. As the advance information on two unknown parameters have to be incorporated here, the experimentall design is more complicated. The corresponding generalizations for three different cases of advance information are presented in Chapter 4.

The second main issue contained in this dissertation is the study of the commonly used estimation methods and some bias-reducing methods when applied to dilution analysis. In Chapter 5 two conventional statistical procedures (the Maximum Likelihood (ML) method and the Minimum Chi-square 
(MC) method) are described. For an experiment with all positive responses the corresponding estinates are infinite. Thus, modified ML and MC estimators are proposed in order to reduce the bias of these estimators from infinity to the desired order. However, the resulting estimators are still blased. Little is known about bias and efficiency of the modified ML and MC estimators when applied to data from dilution experiments with small or moderate size. Resampling methods like the jackknife and the bootstrap provide estimators of bias and variance for an extremely wide class of statistics. In general, these methods are applied to independent identically distributed (iid) random variables. There are also several reasons to consider some jackknife and bootstrap wersions based on non-ild variables. In Chapter 6 three jackknife and four bootstrap versions of the ML method are discussed and applited to dilution analysis.

Results on Monte Carlo comparison of estimators have been published by several authors. However, there is a difficulty in comparing these results because of the absence of generally accepted design methods. Some controversies emerged partly as a consequence of this kind of difficulty. Research on estimators in dilution analysis requires a design method that can be used as a frame of reference. Thus, the design method proposed in Chepter 2 is used for the simulation study conducted in this dissertation. A PASCAL-program has been written to perform the Monte Carlo experiments for the comparison of the statistical methods described in chapters 5 and 6 . The simulation results are presented and discussed in Chapter 7 . The criteria used to compare the estimation methods concern the bias, the coefficient of variation (based upon the mean square error) and the realized confidence level (1.e. the proportion of times that the realized $95 \%$ confidence interval contains the true value of the parameter). The main results can be sumarized as follows. The corresponding jackknife and bootstrap versions of the ML estimator are very strongly related. Generally, all resanpling methads reduce the blas of the ML estimator significantly to values around zero. Provided that the desigr used is not too small, the most preferable method is a particular jackknife version (obtained by deleting one individual replicate culture at a time). The MC estimator is shown to be inferior to the ML estimator. 


\title{
SAMENVATTING
}

\author{
EXPERIMENTEEL ONTWERP EN STATISTISCHE ANALYSE
}

VAN BIOLOGISCHE VERDUNNINGSREEKSEN

In dit proefschrift wordt een bijdrage geleverd aan de theorie over biologische verdunningsreeksen. In de literatuur worden twee typen verdunningsreeksen onderscheiden, te weten de "Limiting Dilution Assay" (LDA) en de "Serial Dilution Assay" (SDA). Bij LDA gat het er veelal on te schatten welke proportie van een verzameling gelijksoortige cellen een bepaalde eigenschap bezit, terwijl bij SDA de dichtheid van een beprald type cel per volume eenheid wordt geschat. Zowel bij een LDA als een SDA wordt bij het schatten van de onbekende parameter meestal gebruik gemakt van de veronderstelling dat het aantal relevante cellen per volume eenheid een Poisson verdeling heeft, en dat de aanwezigheid van eén relevante cel in een volume eenheid al met zekerheid kan worden vastgesteld. Aangezien de te schatten parameter onbekend is en het tellen van cellen doorgaans ommogelijk is, dient met verschillende verdunningen gewerkt te worden ten einde onafhankel1 jk van de waarde van de parameter in een bepaald gebied een schatting te kunnen bepalen. In het hier beschreven onderizoek worden zowel de experimentele proefopzet als de analyse van verdunningsreeksen bestudeerd.

Voor een LDA of een SDA dient bij het ontwerp van een experiment het aantal verduningen gekozen te worden, alsmede het asntal te herhalen bepalingen per verdunning en het (gemiddeld) aantal cellen per herhaling. Een goed ontwerp houdt rekening met de voorkennis van de onderzoeker en bevat ontwerp parameters die de statistische eigenschappen van het ontwerp. zoals de te bereiken nauwkeurigheid, bepalen. In hoofdstuk 2 wordt een dergelijk ontwerp gepresenteerd, terwijl in hoofdstuk 3 diverse verfijningen worden ultgewerkt en een computer-programma wordt beschreven dat deze technieken uitvoert. De basisprincipes uft hoofdstuk 2 kunnen worden gegeneraliseerd voor toepassing op andere biologische modellen (met twee onbekende parameters) die sterk aan LDA's en SDA's gerelateerd zijn, zoals het "logistische regressie made1". Aangezien hier de voorkennis met betrekking tot twee onbekende parameters in het experimenteel ontwerp verwerkt moet worden, is een dergelijk ontwerp ingewikkelder. In hoofdstuk 4 
worden voor drle vergchllenda gevallen van aarwezlge voorkennis ontwerp voorstellen gedaan.

Het tweede hoofd onderwerp in dit proefschrift betreft de bestudering wan de gebrulkel1jke schattingsmethoden en enige onzulverheid-reducerende schattingsmethoder voor toepassing bij verdunningsreeksen. In hoofdstuk 5 worden twee conventionele schatters besproken, namelijk de "Maximum Likel hood" (ML) schatter en de "Minimum Chi-square" (MC) schatter. Bij een experiment met alleen positieve uitslagen zijn de corresponderende schattingen oneindig. Ten einde de onzuiverheid van deze schatters terug te brengen tot de gewenste orde, worden gemijzigde ML en MC schatters voorgesteld. Deze schatters vertonen echter nog steeds een onzuiverheid, die bij expermenten van kleine of bescheiden onvang bezwaarlijk kan zijn. Wanwege de brede toepasbarheld van zgn. Jackknife en bootstrap methoden kan worden geprobeerd de onzuiverheid te schatten om daarmee een schatter te construeren die minder orzuiver is. Jackknife en bootstrap methoden verschaffen ook automatisch een schatter voor de variantie. In het algemeen worden deze methoden toegepast op onafhankelifke en identiek verdeelde stochastische vartabelen. De speciale toepassing op verdunningsreeksen echter suggereert ook varianten die zijn gebaseerd op onafhankelijke maex" niet identiek verdeelde variabelen. In hoofdstuk 6 worden drie jackknife en vier bootstrap varianten van de ML methode besproken en toegepast op verdunningsreeksen.

Het ontbreken van algemeen geaccepteerde ontwerpmethoden voor verdunningsreeksen makt het moefiljk om de Monte Carlo resultaten van verschtllende onderzoekers te vergelijken. Sommige tegenstrijdigheden in de 1.teratuur kunnen hieraen worden toegeschreven. Onderzoek naar de eigenschappen van schatters voor de onbekende parameter in verduningsreeksen vragkt on een ontwerpmethode, die kan worden gebruikt als een referentiekader. De in hoofdstuk 2 beschreven methode is hiervoor geschikt en wordt gebruikt in het simulatie onderzoek, dat in hoofdstuk 7 beschreven is. Dit onderzoek vergelijkt m.b.v. een speciaal voor dit doel in PASCAL geschreven programa de volgende drie elgenschappen van de in hoofdstukken 5 en 6 beschreven schatters: de gemiddelde relatieve onzuiverheld, de varlatiecoefficient (afgeleid van de gemiddelde kwadratische fout) de proportie van het antal keren dat het gerealiseerde $95 \%$ betrouwbaarheidsinterval de werkelijke waarde van de 
parameter bevat. De belangrijkste resultaten kunnen alsvolgt worden samengevat. De met elkaar corresponderende jackknife en bootstrap varianten hebben sterk op elkaar gelijkende eigenschappen. In het algemeen reduceren ze de onzuiverheid van de ML schatter significant tot waarden rond nul. Mits het ontwerp een voldoend aantal elementaire bepalingen bevat kan worden gesteld dat de jackknife variant die wordt verkregen door het beurtelings weglaten van één elementaire bepaling de voorkeur geniet. Van de MC schatter wordt aangetoond, dat deze niet te verkiezen $\mathcal{L}$ s boven de ML schatter. 



\section{DANKBETUTGING}

Een aantal mensen wil ik op deze plaats grang bedanken voor de nol die $z i j$ hebben gespeeld bij de voorbereidingen en de totstandkoming van het proefschrift. Dr. Win Bunman heeft van uit zijn dagelijkse onderzoekspraktijk (een deel van) de problematiek voorgelegd aan dr. Ronald Does, die op zijn beurt mij bij het projekt betrok. De samenwerking met Wim Bumrman is mede door zijn enthousiasme van doorsilaggevende betekenis geweest. Bij de voorbereiding en uitvoering van de eerste computersimulaties is de inzet wan Piet Zinken van groot belang geweest. Na acceptatie van het eerste artikel. suggereerde Ronald Does mij om op dit onderwerp te promoveren. Vit intensieve samenwerking met hem werd een onderzoeksplan opgesteld en uitgevoend. Deze samenwerking is door mij als zeer plezierig ervaren. Met name zijn adviezen en zijn optimistische benadering hebben de vooxtgang van het onderzoek gunstig ber̃nvloed. Met veel genoegen denk ik ook terug aan de vele telefoongesprekken die wij samen hebben gevoerd. Van grote betekenis voor mij is geweest een gesprek met prof. D.J. Finney (destijds direkteur van het "Research Centre" van het "International Statistical Institute" te Voorburg), die zeer geinteresseerd was in het onderwerp van mijn onderzoek en miy aanmoedigde de resultaten te publiceren. Mijn promotor prof d $\mathrm{n}$. Wim Albers dank ik voor zijn nauwgezette bestudering van (eerdere versies van) het proefschrift die heeft geleid tot een aantal verbeteringen en veel waardevolle aanvullingen. Mijn ouders hebben de basis gelegd voor mijn wetenschappelijke belangsteling en studie, waervoor ik hen veel dank verschuldigd ben. Liesbeth, zonder jouw aanmoedigingen en Jouw bereidheld on gedurende lange tijd mijn aandeel in het gezin voor een groot deel over te nemen, was dit proefschrift nooit geschreven. Jij en de kinderen hebben er alles aan godean om alles zo optimagl mogelijk te laten verlopen, lets dat mij in het vuir van de strijd wel eens ontging. Bif het gereedmaken van het manuscript voor de drukker heb $1 k$ dankbaar gebrulk gemaakt van de diensten van Jan PIjnenburg. o.a. voor het ontwerpen van de omslag, van ing. Henk Op den Brouw voor diverse adviezen op het gebied van de tekstverwerking en van Mw. Micky Sichim van der Loef $f$ voor de correctie van het Engels. De onduidelijkheden die na haar zorgvuldig en uitgebreid commentaar nog resteren komen uiteraard geheel voor mijn rekening. Tat slot bedank ik prof.dr. Frank van der Duyn Schouten en ir. Ed van den Bosch voor het in mij gestelde vertrouwen, en mijn kamergenoot ir. Anton Markink voor zijn interesse en medeleven. 


\section{CURAICULUM VITAE}

Leo Strijbosch werd op 7 juni 1947 geboren te Helmond (NB). In die plaats volgde hij ook het lager onderwijs (St. Canisiusschool, 1953-1959) en het middelbaar onderwijs (St. Carolus Borromeus College, Gymnasium B, 19591966). In september 1966 begon hij met de studie Werktuigbouwkunde aan de Technlsche Hogeschool te Elndhoven, maar zette na een half jaar de studie voort an de Onderafdeling der Wiskunde. Na het behalen van het kandidaatsdiploma in funi 1971 heeft hij zich vooral verdiept in de Informatica en de Operations Research. Het afstudeerwerk had betrekking op een onderwerp ult de Operations Research (gesloten netwerksystemen van wachtrijen). De afstudeerhoogleraar hierbij was prof.dr. J. Wessels. Het diploma wiskundig ingenieur werd behaald in februari 1975.

Van april tot oktober 1975 wes $h i j$ als wetenschappelij jk ambtenaar varbonden aan de vakgroep Statistiek van de Onderafdeling der Wiskunde voor de ontwikkeling van statistische programmatuur. In oktober 1975 aanvaardde hij een baan bij de Rijksuniversiteit Limbung en was daar aanvankelijk bij de capaciteitsgroep Medische Sociologie (tot augustus 1976) werkzaam, daarna bij de Dienst Informatieverwerking (tot december 1982) en tensilotte bij de capaciteitsgroep Medische Informatica en Statistiek (tot augustus 1985). In deze periode was hij met name betrokken bij diverse onderzoeksprojecten als adviserend statisticus. In de latere jaren van het dienstverband bij de Rijksuniversiteit Limburg vond een verschuiving plaats naar meer (statistiek) onderwijs en eigen onderzoek. In de jaren 1983-1985 werd in samenwerking met $\mathrm{dr}$. Ronald Does en dr. Wim Buurmen de basis gelegd voor het ondierzoek dat heeft geled tot de totstandkoning wan dit proefschrift.

Vanaf september 1985 tot heden is hij verbonden aan de Katholieke Universiteit Brabant en als speclalist wetenschappelijke toepassingen werkzam byj de Automatiserings Unt van de Faculteit der Economische Wetenschappen. In deze perlode werd het proefschrift afgerand. 